Aus der ehem. Arbeitsgruppe „Molekulare Mechanismen der Signalübertragung" (Leiter: PD Dr. rer. nat. C. Rosenmund) in der Abteilung Membranbiophysik (Prof. Dr. rer. nat. E. Neher) des Max-Planck-Institutes für biophysikalische Chemie in Göttingen

\title{
Funktionelle Charakterisierung der synaptischen Transmission in APP/APLP1/APLP2-defizienten Mäusen
}

\author{
INAUGURAL - DISSERTATION \\ zur Erlangung des Doktorgrades \\ der Medizinischen Fakultät der \\ Georg-August-Universität zu Göttingen
}

vorgelegt von

Susann Kaufmann

aus Parchim

Göttingen, 2006 
Dekan: Prof. Dr. med. C. Frömmel

I. Berichterstatter: PD Dr. rer. nat. C. Rosenmund

II. Berichterstatter/in:

III. Berichterstatter/in:

Tag der mündlichen Prüfung: 


\section{Inhalt}

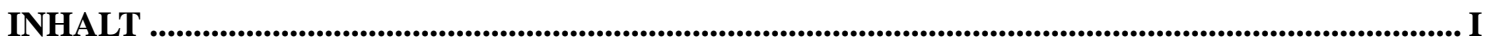

ABBILDUNGSVERZEICHNIS.................................................................................................. II

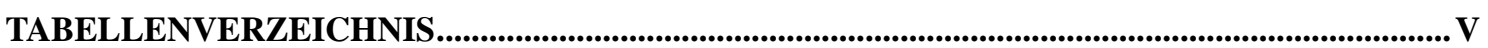

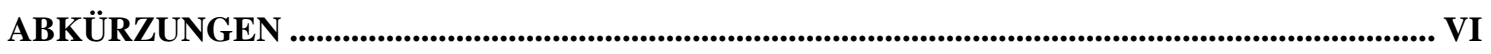

1 EINLEITUNG .........................................................................................................................

1.1 ARTEN DER INFORMATIONSÜBERTRAGUNG IM NERVENSYSTEM ..............................................

1.2 PRINZIPIEN SYNAPTISCHER TRANSMISSION ........................................................................

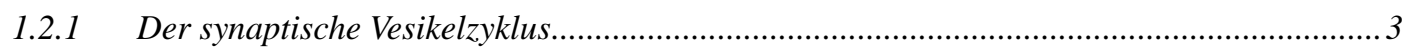

1.2.2 Proteine des synaptischen Vesikelzyklus.......................................................................

1.3 DiE AMYLOID-PRECURSOR- UND AMYLOID-PRECURSOR-LIKE-PROTEINFAMILIE ............................

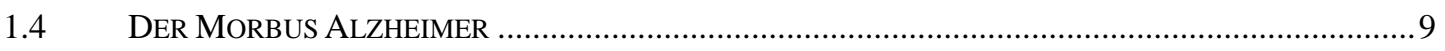

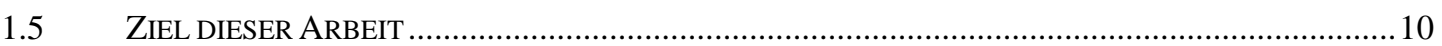

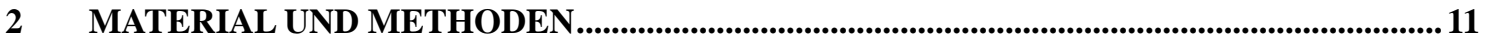

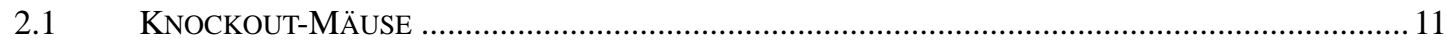

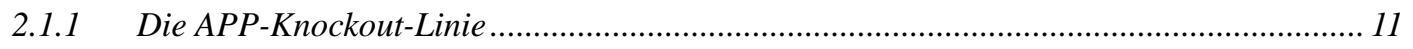

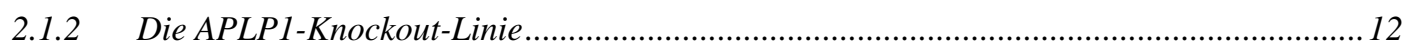

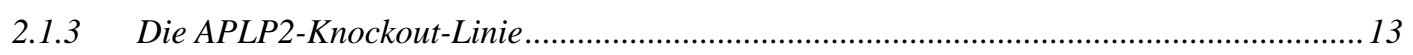

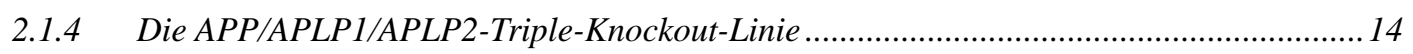

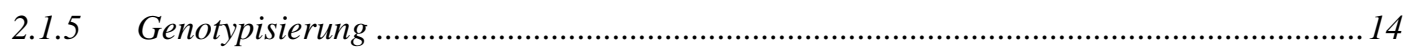

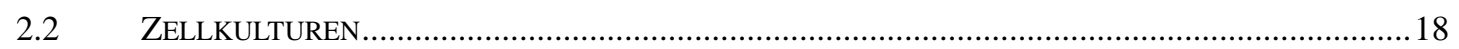

2.2.1 Präparation der Astrozyten und Microdots .................................................................18

2.2.2 Präparation und Kultur exzitatorischer Neurone .........................................................19

2.2.3 Besonderheiten der autaptischen Kultur ............................................................................20

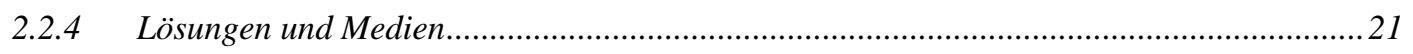

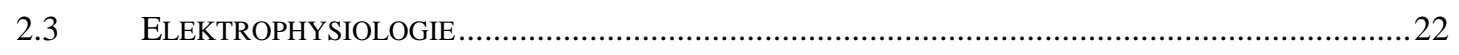

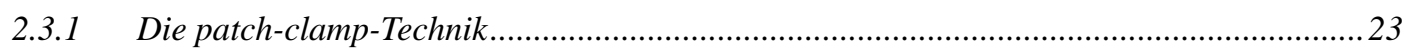

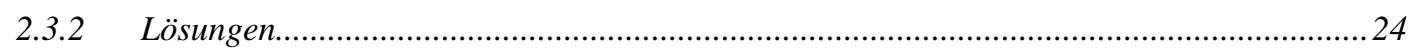

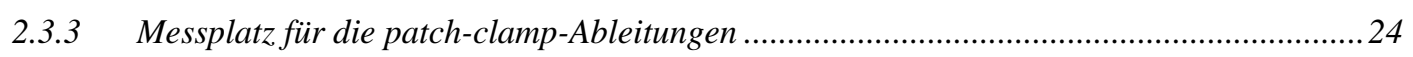

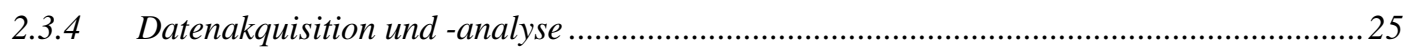

2.3.5 Autaptisch kultivierte Neuronen und deren Ableitung in whole-cell-Konfiguration.............26

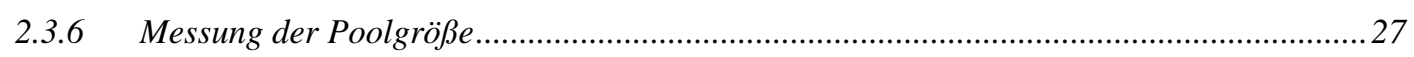

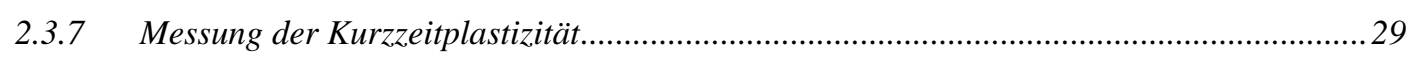

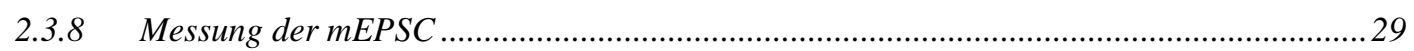

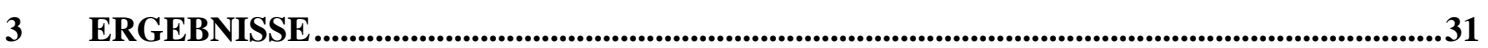

3.1 MAKROSKOPISCHER PHÄNOTYP DER APP- UND APLP-KNOCKOUT-LINIEN.................................31 
Inhalt

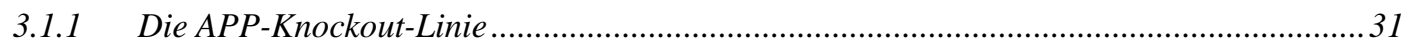

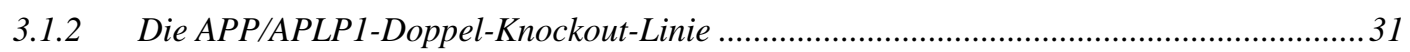

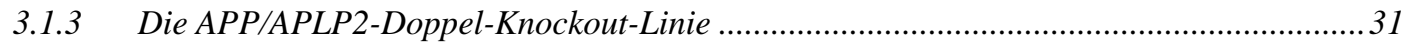

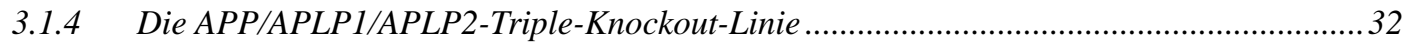

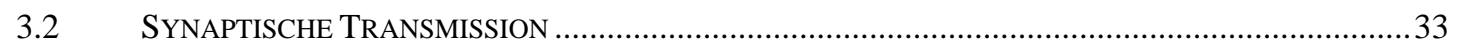

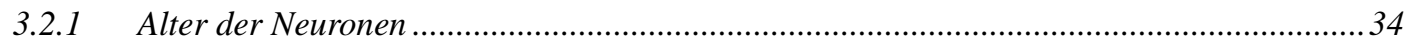

3.2.1.1 Besonderheiten der der Triple-Knockout-Kultur.................................................................. 34

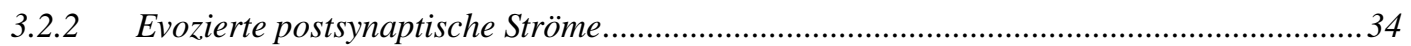

3.2.3 Die Poolgröße der sekretionsbereiten Vesikel …............................................................38

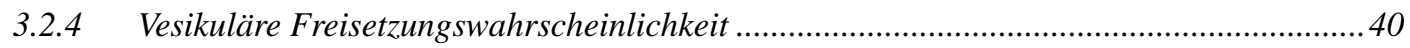

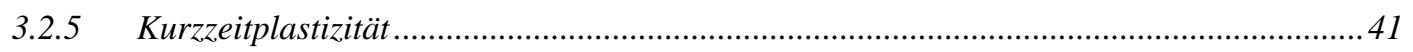

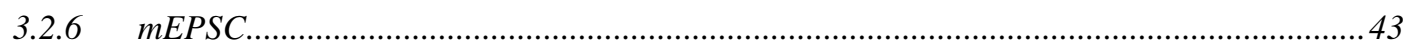

3.2.7 Synapsenzahl und Synapsendichte.................................................................................. 49

4 DISKUSSION ..................................................................................................................................

4.1 DiE FUNKTION VON APP UND APLP AN ZENTRALEN SYNAPSEN ……….................................51

4.2 MORBUS AlZHEIMER - EINE „SYNAPSENKRANKHEIT“? ............................................................58

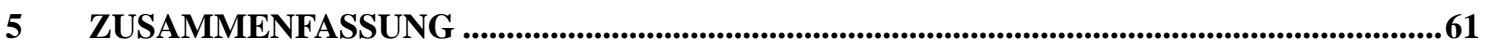

$6 \quad$ LITERATUR 


\section{Abbildungsverzeichnis}

Abb. 1 Elektronenmikroskopisches Bild und Schema einer Synapse............. 2

Abb. 2 Schema der Vesikelpools................................................... 5

Abb. 3 Proteine des synaptischen Vesikelzyklus............................... 5

Abb. 4 APP-Prozessierung durch verschiedene Sekretasen....................... 8

Abb. 5 Die APP-Familie........................................................ 9

Abb. 6 Gen-Targeting-Strategie des APP-Gens................................ 12

Abb. 7 Gen-Targeting-Strategie des APLP1-Gens............................. 13

Abb. 8 Gen-Targeting-Strategie des APLP2-Gens............................... 14

Abb.9 Agarosegel mit PCR-Produkten der APP-, APLP1- und APLP2-Reaktionen.................................................... 17

Abb. 10 Die autaptische Kultur.............................................. 21

Abb. 11 Schema der whole-cell-Konfiguration.................................. 23

Abb. 12 Schema des Perfusionssystems....................................... 25

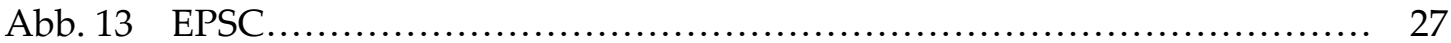

Abb. 14 Applikation hypertoner Lösung................................... 28

Abb. 15 Mini-Template............................................................ 29

Abb. 16 Genotypen...................................................... 33

Abb. 17 Amplitude und Ladung exzitatorischer postsynaptischer Ströme........ 37

Abb. 18 Evozierte exzitatorische postsynaptische Ströme $\ldots \ldots \ldots \ldots \ldots \ldots \ldots \ldots \ldots \ldots . \quad 38$

Abb. 19 Größe des readily releasable pool.......................................... 40

Abb. 20 Vesikuläre Freisetzungswahrscheinlichkeit............................ 41

Abb. 21 Kurzzeitplastizität................................................ 43

Abb. 22 Originalaufzeichnungen von mEPSC................................. 44

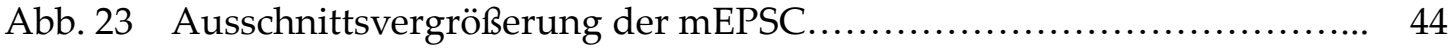

Abb. 24 Amplitude und Ladung der mEPSC der Tage 7 bis 15 in vitro............ 46

Abb. 25 Verteilung der mEPSC-Frequenzen ................................... 46 


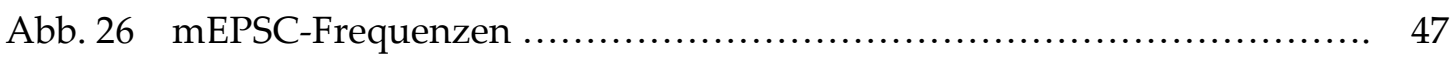

Abb. 27 Synapsenzahl und Synapsendichte .............................. 50

Abb. 28 Originalaufnahmen von mit Antikörpern behandelter Neuronen ........ 50

Abb. 29 APP und mögliche Interaktionen mit synaptischen Proteinen ........... 57 


\section{Tabellenverzeichnis}

Tab. 1 Primer zur Genotypisierung.................................... 15

Tab. 2 Temperatur-Protokoll des Thermocyclers........................... 16

Tab.3 Reaktionsansatz für die PCR und Zusammensetzung des Soriano-Puffers............................................... 16

Tab. 4 Pufferlösungen für die DNA-Extraktion und Agarose-Laufgele....... 18

Tab. 5 Lösungen und Medien für die Zellkultur........................... 22

Tab. 6 Extra- und Intrazellular-Lösungen.............................. 24

Tab. $7 \quad$ Aufstellung der Genotypen...................................... 32

Tab. 8 Amplitude und Ladung der EPSC.............................. 36

Tab. 9 Größe des Readily Releasable Pool (RRP)............................... 39

Tab. 10 Vesikuläre Freisetzungswahrscheinlichkeit....................... 41

Tab. 11 Kurzzeitplastizität................................................ 42

Tab. 12 Miniature Excitatory Postsynaptic Currents (mEPSC).................. 45

Tab. 13 Rechnerisch ermittelte Vesikelzahlen pro EPSC und im RRP.......... 48 


\section{Abkürzungen}

AICD APP-intrazellulär-Domäne

AMPA $\quad \alpha$-Amino-3-hydroxy-5-methyl-4-isoxazolepropionat

APLP Amyloid Precursor Like Protein

APP Amyloid Precursor Protein

ATP Adenosintriphosphat

$\mathrm{bp}$

Basenpaare

$\mathrm{C} 2$

Protein Kinase C Conserved Domain 2

CAST CAZ Associated Structural Protein

CAZ Zytomatrix der Aktiven Zone

CM Membrankapazität

DKO Doppel-Knockout

DMEM Dulbecco's Modified Eagle Medium

DNA Desoxyribonukleinsäure

dNTP Desoxyribonukleosidtriphosphat

DT Diphtherietoxin

E

embryonaler Tag

EDTA Ethylenediaminetetraacetic acid

EPSC Excitatory Postsynaptic Current

FBS fötales bovines Serum

FM1-43 N-(3-triethylammoniumpropyl)-4-(4-

(dibutylamino)styryl)

pyridinium dibromide

FUDR 5-Fluoro-2'-Deoxyuridin

GABA $\quad \gamma$-Aminobuttersäure

GluR1 Glutamatrezeptor Untereinheit 1

GTP Guanosintriphosphat 


\begin{tabular}{|c|c|}
\hline HBSS & Hank's Balanced Salt Solution \\
\hline HEPES & N-2-Hydroxyethylpiperazin-N'-ethansulfonsäure \\
\hline HSV & Herpes Simplex Virus \\
\hline $\mathrm{kb}$ & Kilobasen \\
\hline $\mathrm{kDa}$ & Kilodalton \\
\hline $\mathrm{KO}$ & Knockout \\
\hline KPI & Kunitz-Proteinase-Inhibitor \\
\hline LTP & Long-Term Potentiation \\
\hline MAP2 & Microtubulus-associated Protein 2 \\
\hline mEPSC & Miniatur EPSC \\
\hline Mint & Munc18-interacting protein \\
\hline mOsm & Milliosmolar \\
\hline Munc & Mammalian Homolog of unc \\
\hline $\mathrm{n}$ & Stichprobengröße \\
\hline NBA & Neurobasal-A-Medium \\
\hline neo & Neomycinresistenz \\
\hline NMDA & N-Methyl-D-aspartat \\
\hline NSF & N-Ethyl-maleimide Sensitive Fusion Protein \\
\hline $\mathrm{P}$ & postnataler Tag \\
\hline PCR & Polymerase-Kettenreaktion \\
\hline PSD & Postsynaptische Dichte \\
\hline PSD-95 & Postsynaptic Density Protein of 95 kDA \\
\hline RIM & Rab3a Interacting Molecule \\
\hline $\mathrm{R}_{\mathrm{M}}$ & Membranwiderstand \\
\hline RRP & Readily Releasable Pool \\
\hline Rs & Serienwiderstand \\
\hline SEM & Standard Error of the Mean \\
\hline SKO & Single-Knockout \\
\hline
\end{tabular}


SNAP-25 Soluble NSF Attachment Protein 25

SNARE Soluble NSF Attachment Protein Receptor

TAQ Thermophilus aquaticus

TBE Tris-Borat-EDTA

TE Tris-EDTA

TK Thymidinkinase

TKO Triple-Knockout

TS Tris- $\mathrm{NaCl}$

TTX Tetrodotoxin

UMS Upstream Mouse Sequence

Unc Uncoordinated movement mutant

UV Ultraviolett 


\section{$1 \quad$ Einleitung}

Das Nervensystem besteht aus einer Vielzahl von Zellen, die ständig Informationen aus ihrer Umwelt erhalten, prozessieren und weitergeben. Das Gehirn wandelt die Informationen in Wahrnehmungen oder Bewegung um. Kleinste Schalteinheit des Gehirns sind die untereinander verbundenen Neuronen.

Hochkomplexe Lebewesen haben über 100 Milliarden Nervenzellen, die miteinander auf verschiedene Arten kommunizieren. Das Neuron ist morphologisch in vier Bereiche unterteilt: das Soma, Dendriten, das Axon und die präsynaptische Endigung. Das Soma enthält den Zellkern mit der genetischen Information sowie Organellen, die für die Proteinsynthese verantwortlich sind. Die Zellfortsätze, mehrere Dendriten und zumeist nur ein einzelnes Axon, sind die Kommunikationsleitungen der Neuronen. Dendriten verzweigen sich baumartig, empfangen Signale und bilden mit dem Soma die hauptsächlich aufnehmende Oberfläche des Neurons, während das Axon sich erst terminal aufzweigt und die Signale weiterleitet. Am Axonhügel, dem Ursprung des Axons am Zellsoma, wird dabei ein Signal, das Aktionspotenzial, generiert. Synapsen sind u.a. an der axonalen Endigung des Neurons lokalisiert. Sie sind diejenigen Kontakte, die Neuronen erlauben zu interagieren. Synapsen sind also die Endpunkte in der Informationsvermittlung. Das Wort Synapse leitet sich vom Griechischen sunaptein her, was soviel wie sich verbinden bedeutet und wurde als Begriff bereits 1897 durch Sir Charles Scott Sherrington mit folgenden Worten geprägt: "So far as our present knowledge goes, we are led to think that the tip of a twig of the arborescence is not continuous with but merely in contact with the substance of the dendrite or cell body on which it impinges. Such a special connection might be called a synapse." [SCHÄFER 1900].

\section{Wie erfolgt jedoch die synaptische Informationsübertragung?}




\subsection{Arten der Informationsübertragung im}

\section{Nervensystem}

Die synaptische Informationsübertragung erfolgt im Wesentlichen auf zwei Wegen, a) elektrisch und b) chemisch. Während die elektrische Übertragung synchron, verzögerungsfrei und sehr schnell verläuft (ca. eine Millisekunde), kann die chemische Signalübertragung bis zu mehr als zehnmal so lang dauern.

Eine elektrische Synapse wird auch gap junction genannt und dient der verzögerungsfreien und synchronen Übertragung des elektrischen Signals. Gap junctions sind Proteinporen (Connexone), die die Zellmembranen zweier benachbarter Zellen durchqueren und so eine direkte Verbindung herstellen [MAKOWSKI et al. 1984]. Die elektrische Synapse spielt eine große Rolle z.B. am Herzmuskel, während im Nervensystem chemische Synapsen weitaus häufiger vorkommen.

Typische Nervenzellen haben ein Ruhemembranpotenzial, das ungefähr bei -60 bis $-70 \mathrm{mV}$ liegt. Wird die Membran depolarisiert, d. h. sprunghaft in den positiveren Bereich (je nach Schwelle) bis $\mathrm{zu}+30 \mathrm{mV}$ verschoben, entsteht ein elektrisches Signal, das Aktionspotenzial. Es wird über das Axon bis in die präsynaptischen Endigungen fortgeleitet. Dort befinden sich die Endpunkte der Signalübertragung, die chemischen Synapsen. Die Aktionspotenziale werden an den Synapsen in ein chemisches Signal umgewandelt. Die Mechanismen dieser Signalübertragung werden im folgenden Teil näher erläutert.
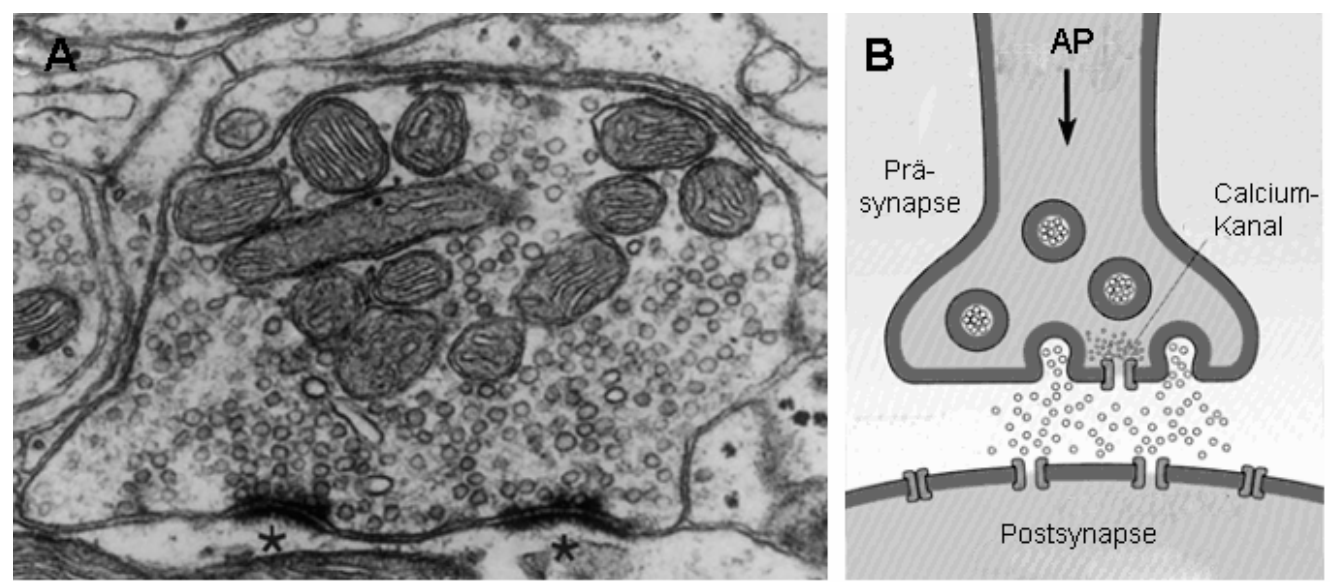

Abb. 1: Elektronenmikrospkopisches Bild und Schema einer Synapse

A: Darstellung eines präsynaptischen Terminals. Die Sternchen kennzeichen zwei Aktive Zonen [adaptiert nach DRESBACH et al. 2001, S. 96].

B: Schema einer Synapse. Ein eintreffendes Aktionspotenzial führt zum Calcium-Einstrom, der nachfolgend Transmitterfreisetzung aus den Vesikeln auslöst. Diese diffundieren in den synaptischen Spalt und binden auf der postsynaptischen Seite an ligandengesteuerte Ionenkanäle (Grafik: freundlicherweise von Prof. E. Neher zur Verfügung gestellt). 


\subsection{Prinzipien synaptischer Transmission}

Die Signalübertragung zwischen erregbaren Zellen wird auch als synaptische Transmission bezeichnet. Der Ort der Übertragung ist die Synapse, die in drei Kompartimente eingeteilt wird: die präsynaptische Endigung, die postsynaptische Zelle und den synaptischen Spalt. Wenn ein Aktionspotenzial die präsynaptische Endigung erreicht, werden spannungsgesteuerte Calciumkanäle geöffnet, und es kommt zum Einstrom der Calciumionen. Das Calciumsignal führt zur Exozytose, d.h. der Neurotransmitter wird aus den Vesikeln in den synaptischen Spalt freigesetzt und gelangt an die postsynaptische Seite, um dort an ligandengesteuerte Ionenkanäle zu binden. Die Ionenkanäle öffnen sich und damit ist das chemische Signal wieder in ein elektrisches Signal zurückverwandelt worden (siehe Abb. 1). Die Gesamtdauer der synaptischen Transmission an einer chemischen Synapse liegt bei nur wenigen Millisekunden.

Die postsynaptische Zelle kann entweder hyperpolarisiert oder depolarisiert werden. Welche Aktion ausgelöst wird, hängt dabei vom Transmitter und dem Umkehrpotenzial der beeinflussten Leitfähigkeit $a b$. Transmitter werden in inhibitorische und exzitatorische Transmitter eingeteilt. Glutamat ist der wichtigste exzitatorische Neurotransmitter, der z.B. an Rezeptoren des $\alpha$-Amino-3-hydroxy-5-methyl-4isoxazolepropionat (AMPA)-Typs bindet und zum Einstrom von Natrium- und Kalium-Ionen und somit zur Depolarisation führt. $\gamma$-Aminobuttersäure (GABA) und Glyzin sind hingegen wichtige inhibitorische Transmitter, die einen Chlorideinstrom und somit eine Hyperpolarisation herbeiführen.

Die Signalübertragung an chemischen Synapsen läuft zwar langsamer als an elektrischen Synapsen ab, sie kann aber an chemischen Synapsen in ihrer Sensitivität moduliert werden. Diese Modulierbarkeit heißt Plastizität und ist z.B. eine Grundvoraussetzung für das Gedächtnis. Besonders die Signalverstärkung ist ein wichtiges Charakteristikum einer chemischen Synapse. Durch sie kann eine einzelne kleine Synapse in die Lage versetzt werden, das Potenzial einer viel größeren postsynaptischen Zelle zu verändern.

Wie werden synaptische Vesikel freigesetzt und welche Proteine sind am Vesikelzyklus beteiligt?

\subsubsection{Der synaptische Vesikelzyklus}

Die Freisetzung des Transmitters aus synaptischen Vesikeln in den synaptischen Spalt ist nur ein Bestandteil eines kompletten Zyklus, der an dieser Stelle kurz skizziert werden soll.

Vesikel im präsynaptischen Terminal gelangen zu den Aktiven Zonen an der Plasmamembran. Der Kontakt mit der Aktiven Zone wird als Docking bezeichnet. 
Der nächste -ATP-abhängige- Schritt wird Priming genannt und überführt die Vesikel in einen fusionskompetenten Status. Erfolgt jetzt der Einstrom von Calciumionen, sind die nun fusionskompetenten Vesikel in der Lage, den Neurotransmitter in den synaptischen Spalt freizusetzen. Der Exozytose folgt das Recycling der Vesikel. Für diesen Schritt werden mehrere Möglichkeiten diskutiert. Höchstwahrscheinlich erfolgt eine Clathrin-vermittelte Endozytose. Die so zurück gewonnenen (leeren) Vesikel können mit dem Frühen Endosom innerhalb des präsynaptischen Terminals fusionieren. Eine andere Möglichkeit stellt die kiss-and-run-Hypothese dar, wobei nicht der gesamte Inhalt des Vesikels, sondern nur ein Teil entleert wird, und der Vesikel bei Beibehaltung der Membran in den Zyklus unter Umgehung des Frühen Endosoms wiedereintritt [HEUSER und REESE 1973; MELDOLESI und CECCARELLI 1981; FESCE et al. 1994]. Vom Frühen Endosom werden die Vesikel abgetrennt (Budding) und mit Wasserstoff-Ionen beladen. Entlang eines $\mathrm{pH}$-Gradienten erfolgt die Wiederbefüllung mit Neurotransmitter. Die befüllten Vesikel stehen somit wieder für das Docking bereit. Der gesamte Zyklus ist als synaptischer Vesikelzyklus bekannt [zur Übersicht SUDHOF 1995].

In der Abb. 2 sind die unterschiedlichen Vesikel-Populationen schematisch dargestellt.

Vesikel im Readily Releasable Pool (RRP) sind fusionskompetent, stehen sofort für die Exozytose zur Verfügung und können ihren Inhalt innerhalb von Millisekunden nach Stimulation freisetzen. Der proximale Pool ist in der Lage, die Vesikel des RRP schnell zu ersetzen. An einer hippokampalen Synapse enthält der Recycling-Pool in etwa 25 Vesikel, davon sind fünf bis neun fusionskompetent, demzufolge im RRP [MURTHY und STEVENS 1999]. Dagegen befinden sich im Reserve-Pool etwa 200 synaptische Vesikel [SCHIKORSKI und STEVENS 1997].

Wahrscheinlich sind an der Aufrechterhaltung der Pools oben beschriebene Mechanismen beteiligt. Der kiss-and-run-Mechanismus trägt vermutlich zur Auffüllung des Recycling-Pools bei. Die Clathrin-vermittelte Endozytose füllt wahrscheinlich den Reserve-Pool auf, während Vesikel des Reserve-Pools bei extensiver synaptischer Stimulation auch direkt den Recycling-Pool auffüllen könnten [zur Übersicht GUNDELFINGER et al. 2003]. 


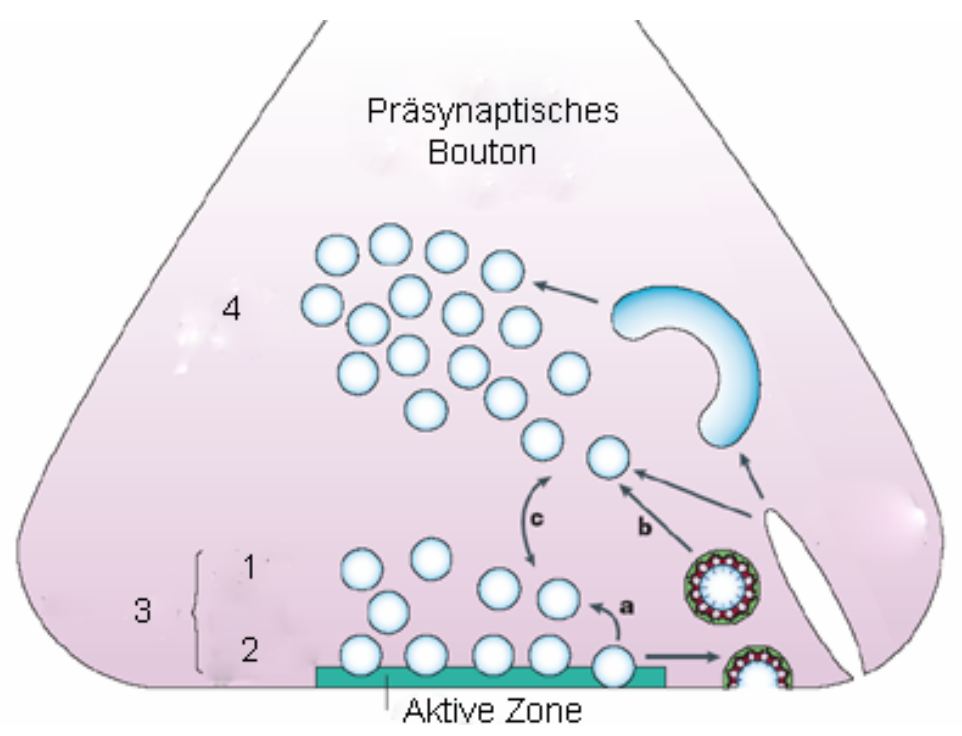

Abb. 2: Schema der Vesikel-Pools

Je nach Lokalisation im präsynaptischen Terminal oder nach Exozytose-Verfügbarkeit können die VesikelPools unterschieden werden. Bei physiologischer Stimulation nehmen nur der proximale (1) und der Readily Releasable Pool (RRP, 2), die als Recycling-Pool (3) zusammengefasst werden, teil. Der Reserve-Pool (4) wird nur bei starker synaptischer Stimulation in die Exozytose miteinbezogen [adaptiert nach GUNDELFINGER et al. 2003, S. 133].

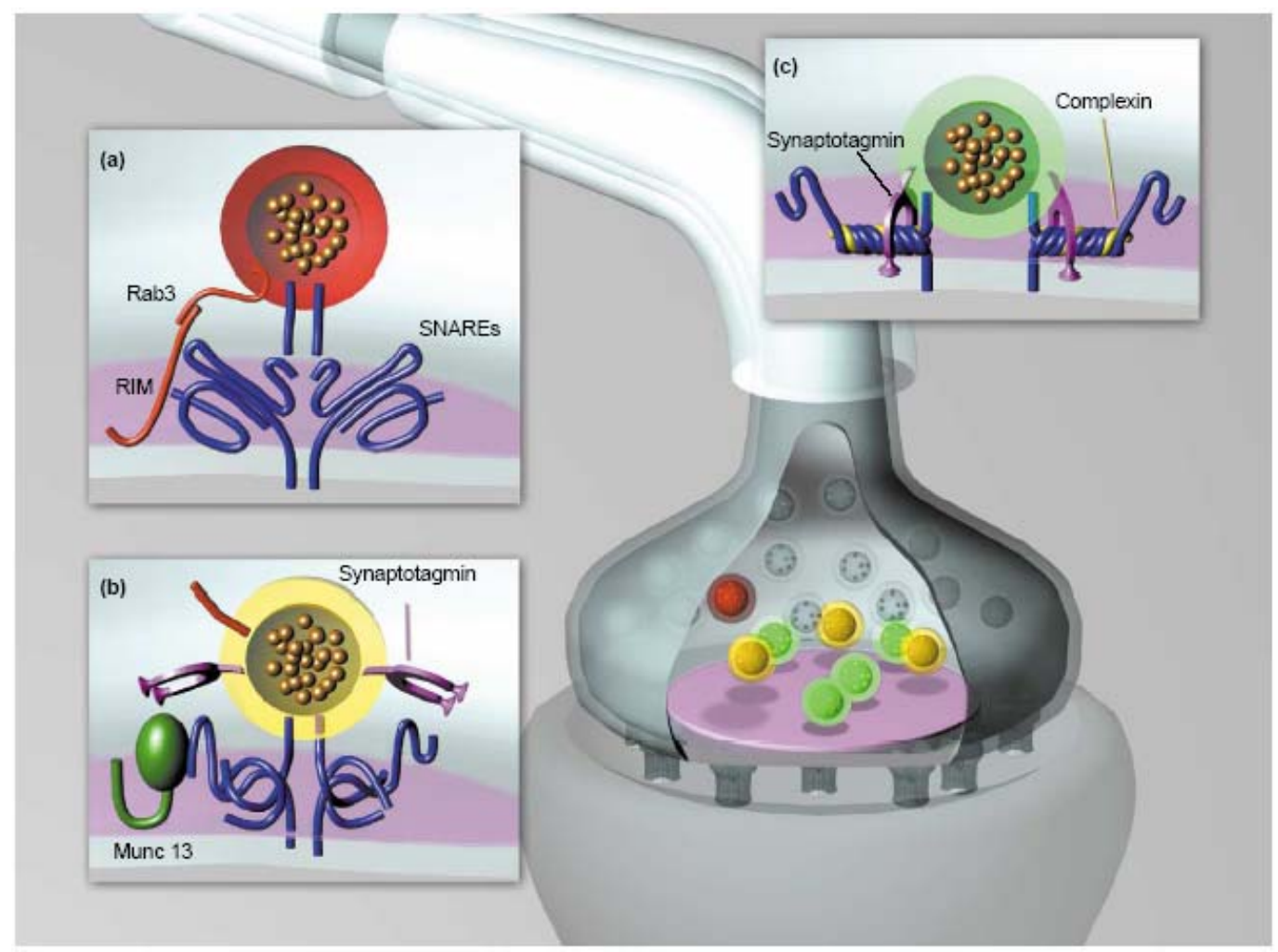

Abb. 3: Proteine des synaptischen Vesikelzyklus

In Abschnitt 1.2.3 werden die wichtigsten Proteine des synaptischen Vesikelzyklus näher beschrieben und ihre Funktionen erläutert [adaptiert nach ROSENMUND et al. 2003, S. 512]. 


\subsubsection{Proteine des synaptischen Vesikelzyklus}

Calcium-getriggerte Exozytose und damit verbundene Neurotransmitterfreisetzung ist ein Prozess, der mehrere Schritte umfasst. Schon vor dem Calciumsignal wird die Freisetzung synaptischer Vesikel vorbereitet, sodass mit dem eintreffenden Aktionspotenzial und Calciumionen-Einstrom die Exozytose sehr schnell induziert werden kann. Dazu sind mehrere Proteine notwendig, die unterschiedlich in der Präsynapse lokalisiert sind. Einerseits sind sie mit der synaptischen Vesikelmembran assoziiert, andererseits befinden sie sich an der Aktiven Zone.

Aktive Zonen sind elektronendichte Strukturen der präsynaptischen Plasmamembran. Die Aktive Zone besteht aus der zytoskeletalen Matrix der Aktiven Zone (CAZ, Cytoskeletal matrix of Active Zone) und befindet sich gegenüber der Postsynaptischen Dichte (PSD, postsynaptic density). Während in der CAZ Proteine versammelt sind, die wichtige Komponenten des Freisetzungsapparates koordinieren [zur Übersicht GARNER et al. 2000; GUNDELFINGER et al. 2003; ROSENMUND et al. 2003], sind in der PSD vor allem Rezeptoren lokalisiert, die die postsynaptische Signalweiterleitung ermöglichen [zur Übersicht SHENG 2001; SHENG und KIM 2002]. Andere CAZspezifische Proteine sind CAST (CAZ-associated structural protein), Piccolo und Bassoon [TOM DIECK et al. 1998; WANG X et al. 1999; FENSTER et al. 2000; OHTSUKA et al. 2002]. Für Bassoon wurde als erstes gezeigt, dass es für die strukturelle Organisation der Aktiven Zonen verantwortlich ist [DICK et al. 2003].

Während des Dockings interagieren RIM (Rab3 Interacting Molecule) und Rab3 miteinander und initiieren das Priming. RIM1 ist das einzige bekannte Protein, das sowohl mit der Aktiven Zone als auch mit synaptischen Vesikeln Kontakt aufnimmt (siehe Abb. 3a) [CASTILLO et al. 2002; SCHOCH et al. 2002]. Die roten Vesikel in Abb. 3 sind "gedockt", haben aber noch nicht das Priming abgeschlossen. Während des Primings wird eine lockere Form des SNARE-Komplexes mit Hilfe von Munc-13 gebildet (Abb. 3b, blau). SNARE-Proteine (soluble $N$-ethylmaleimide sensitive factor attachment receptor) sind aus Synaptobrevin, Syntaxin 1 und SNAP-25 zusammengesetzt [zur Übersicht JAHN und SUDHOF 1999; CHEN und SCHELLER 2001]. Munc-13-Proteine tragen essentiell zur Bereitstellung fusionskompetenter Vesikel bei, da sie die Umformung des SNARE-Komplexes ermöglichen, indem Munc-18 aus seiner Bindung zu Syntaxin verdrängt wird [BETZ et al. 1998; ARAVAMUDAN et al. 1999; AUGUSTIN et al. 1999]. Munc-18 ist ein regulatorisches Protein, das einen hemmenden Einfluss auf Syntaxin hat [zur Übersicht GARNER et al. 2000; ZHANG et al. 2000]. An Munc-18 binden wiederum Mint-Proteine (Munc-18 interacting protein), die auch unter dem Namen X11 bekannt sind [ZHANG et al. 2000; HO A et al. 2003].

Als nächstes tritt das Protein Synaptotagmin hinzu, das als Calciumsensor des Freisetzungsapparates fungiert (Abb. 3b, violett) [GEPPERT et al. 1994; FERNANDEZCHACON et al. 2001; zur Übersicht CHAPMAN ER 2002]. Synaptotagmine tragen zwei C2-Domänen (Protein Kinase C Conserved Domain 2), die Calcium und sekundär 
Phospholipide und/oder SNARES binden und damit in der Lage wären, Calciumeinstrom und Exozytose zu verbinden.

Synaptotagmin 1 und Complexin vervollständigen den Prozess des Primings, indem der SNARE-Komplex in seiner Struktur verdichtet wird (Abb. 3c). Complexine sind kleine Proteine, die an den vollständig zusammengesetzten SNARE-Komplex, aber nicht an einzelne Proteine des Komplexes, binden [REIM et al. 2001]. Sie tragen zur Erhöhung der Freisetzungswahrscheinlichkeit sowie zur Beschleunigung der Freisetzung bei [zur Übersicht ROSENMUND et al. 2003].

In synaptischen Strukturen ist jedoch noch eine Vielzahl weiterer Proteine lokalisiert, deren physiologische Funktionen weiterhin unklar sind.

Drei dieser Proteine sollen im nächsten Abschnitt vorgestellt werden.

\subsection{Die Amyloid-Precursor- und Amyloid-Precursor-}

\section{Like-Proteinfamilie}

Zur Familie der Amyloid-Vorläufer-Proteine gehören drei Proteine, das AmyloidPrecursor-Protein (APP), das Amyloid-Precursor-Like-Protein 1 (APLP1) und das AmyloidPrecursor-Like-Protein 2 (APLP2), die unterschiedlich exprimiert und prozessiert werden.

Die Entdeckung des APP als Ursprung von A $\beta$ führte zu zahlreichen Beschreibungen und Charakterisierungen des Proteins und der Mechanismen, die zur A $\beta$ Prozessierung führen. APP ist ein ubiquitär exprimiertes membranständiges Protein [KANG et al. 1987; YAMADA et al. 1987] mit einer großen Extrazellulär-Domäne und einem kleinen intrazellulären Rest. Zahlreiche Isoformen entstehen durch alternatives Spleißen des humanen APP-Gens, das 19 Exons umfasst. Die wichtigsten Isoformen sind APP695 mit den Exons 1 bis 6 und 9 bis 18, APP751 mit den Exons 1 bis 7 und 9 bis 18 sowie APP770, das alle Exons enthält. Alle Isoformen sind Multi-DomänenProteine mit einer einzelnen Transmembran-Domäne. APP751 und 770 unterscheiden sich vom APP695 durch das Exon 7, das einen Serin-Proteasen-Inhibitor umfasst (Kunitz-Proteinase-Inhibitor (KPI)). Hauptsächlich im Nervengewebe kommt die Isoform APP695 vor, während APP751 ubiquitär auftritt [zur Übersicht LING et al. 2003]. A $\beta$, ein neurotoxisches Amyloid, entstammt den Proteinregionen, die durch die Exons 16 und 17 codiert werden.

APP kann auf zwei verschiedenen Wegen prozessiert werden. $\alpha$ - oder $\beta$-Sekretasen führen zu großen löslichen N-terminalen $(\mathrm{sAPP} \alpha, \mathrm{sAPP} \beta)$ und C-terminalen Fragmenten (C 83, C99), die durch $\gamma$-Sekretasen weiter prozessiert werden, wodurch es zur Freisetzung von $p 3$-Peptiden und $A \beta$ kommt (siehe Abb. 4). $A \beta$ unterteilt sich in $A \beta 40$ und $A \beta 42$, wobei nur intrazelluläres $A \beta 42$ zu neuronalem Zelltod führt, indem es zu 
unlöslichen Komplexen aggregieren kann [zur Übersicht LING et al. 2003]. A $\beta 42-$ Aggregation steht im Verdacht, hauptsächlich zur Neurodegeneration und Demenz beizutragen [WALSH et al. 2002].

APLP1 und APLP2 gehören ebenfalls zur APP-Familie und werden ähnlich prozessiert [WASCO et al. 1992; WASCO et al. 1993; PALIGA et al. 1997; EGGERT et al. 2004]. APLP1 wird ähnlich dem APP695 nur im Nervensystem exprimiert [KIM et al. 1995], während APLP2 ubiquitär vorkommt. APP, APLP1 und APLP2 weisen eine große Homologie auf, einzig die A $\beta 4$-Region tritt nur im APP auf (siehe Abb. 5).

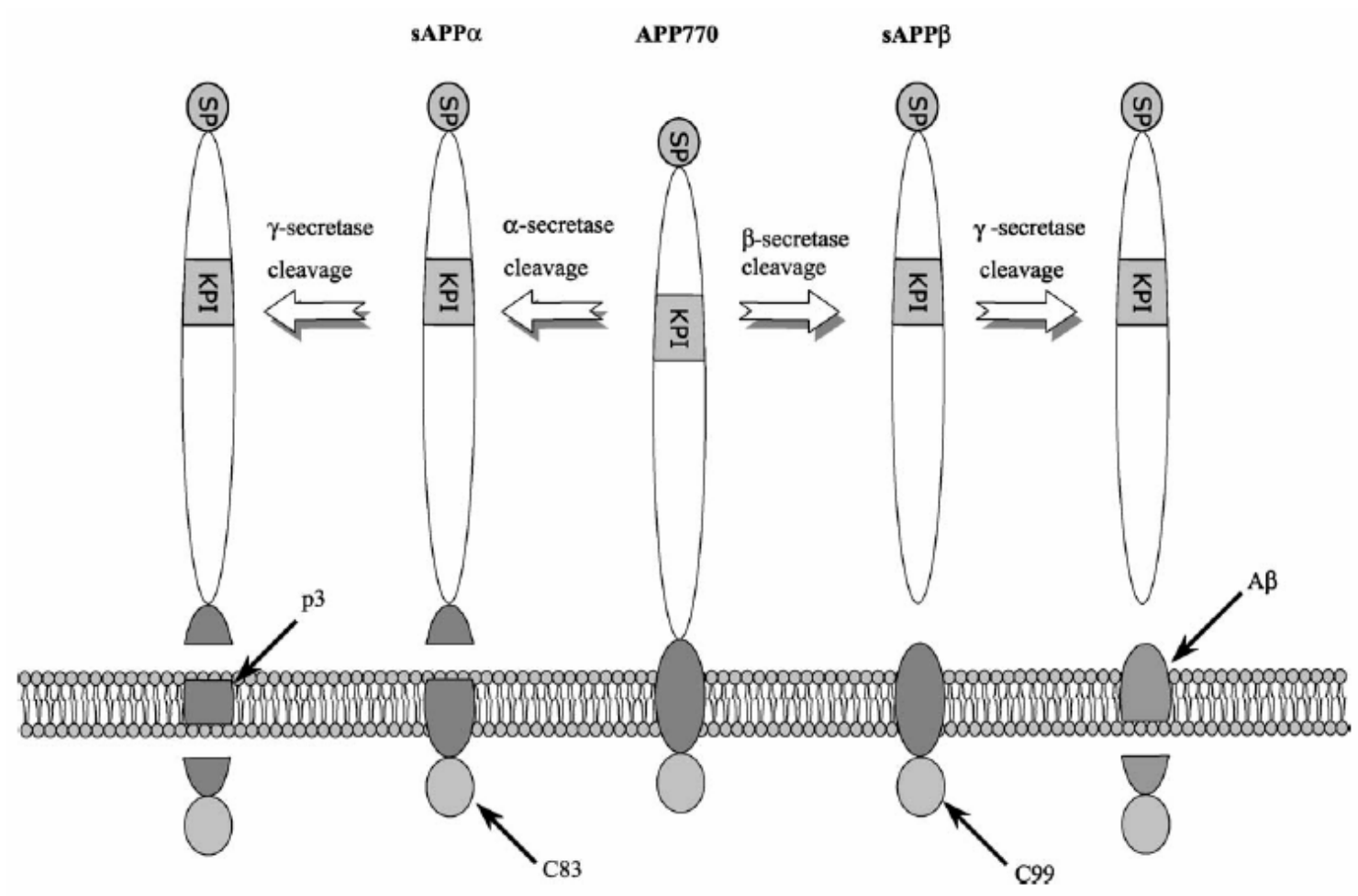

Abb. 4: APP-Prozessierung durch verschiedene Sekretasen

Am Beispiel der Isoform APP 770 sind die verschiedenen Prozessierungen durch Sekretasen gezeigt. Vorangehende Spaltung durch $\alpha$-Sekretasen führt letztendlich zu p3-Peptiden, vorangehende Prozessierung durch $\beta$-Sekretasen ruft durch $\gamma$-Sekretasen-Spaltung A $\beta$ hervor [aus LING et al. 2003, S. 1508]. 


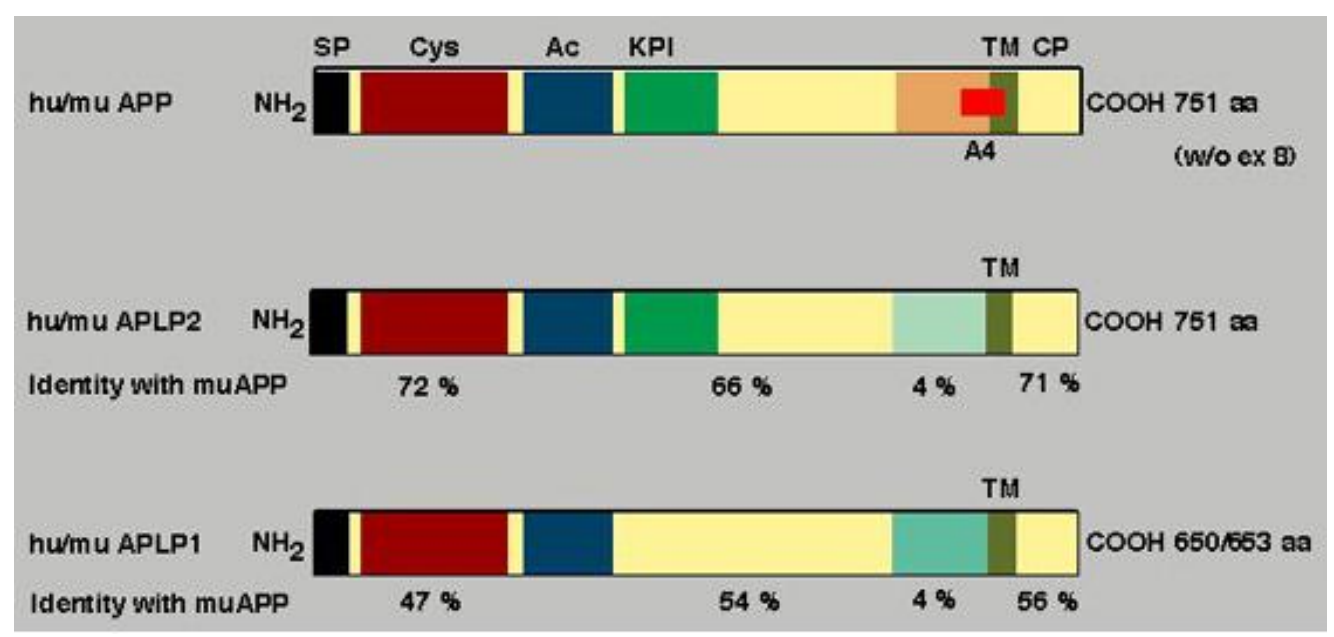

Abb. 5: Die APP-Familie

Die APP-Familie ist hoch homolog. Jedoch nur aus APP kann A $\beta 4$ entstehen (hellrotes Kästchen im APP). APP und APLP2 besitzen einen Kunitz-Proteinasen-Inhibitor (KPI). Die Prozentzahlen geben die Homologie von humanem und Maus-Protein wieder.

[adaptiert nach MULLER 2005]

Zur physiologischen Funktion der Protein-Familie ist bisher wenig bekannt. Spekuliert wird, dass die Proteine eine Schlüsselrolle in der Synaptogenese, synaptischer Plastizität, Neuritenwachstum, intrazellulärem Proteintransport oder postnatalem Wachstum einnehmen [MOYA et al. 1994; ZHENG et al. 1995; MORIMOTO et al. 1998; BAYER et al. 1999; TURNER et al. 2003].

Einem Produkt der APP-Familie wird jedoch eine ursächliche Bedeutung in der Entstehung des Morbus Alzheimer zugeschrieben, es handelt sich hierbei um A $\beta 4$ [zur Übersicht SELKOE 2002]. Im folgenden Kapitel soll der Morbus Alzheimer kurz vorgestellt werden.

\subsection{Der Morbus Alzheimer}

1911 beschrieb Alois Alzheimer erstmals eine Patientin, die sowohl kognitive Defizite in Form von Gedächtnisbeeinträchtigung als auch neuropathologische Veränderungen aufwies. Einige Jahre später prägte Kraepelin den Begriff „Alzheimer-Krankheit“. Die Alzheimer-Krankheit ist die häufigste Form der Demenz (50 bis $60 \%$ aller Fälle). Im Jahr 2004 litten weltweit mehr als 24 Millionen Menschen an Demenz, man vermutet, dass sich diese Zahl alle 20 Jahre verdoppelt. Für diese Krankheit sind zahlreiche Risikofaktoren bekannt; neben dem Alter als hauptsächlicher Risikofaktor sind Hypercholesterinämie, Bluthochdruck, Atherosklerose, Koronare Herzkrankheit, Rauchen, Adipositas und Diabetes als relative Risikofaktoren bekannt [zur Übersicht BLENNOW et al. 2006]. 
Die Alzheimer-Krankheit kann autosomal dominant vererbt werden und dann bereits vor dem 65. Lebensjahr auftreten. Ursächlich sind vorwiegend Mutationen im APPund Presenilin-Gen [zur Übersicht BLENNOW et al. 2006]. Diese familiären Formen der Krankheit sind jedoch selten. Der sporadischen Krankheitsform wird ein bestimmtes Allel des Apolipoproteins E ( $\varepsilon 4)$ zugeschrieben, das die Ablagerung von A $\beta$ begünstigt.

Pathogenetisch treten charakteristische Läsionen als Plaques (Ablagerungen eines APPSpaltproduktes) oder Fibrillen (Ablagerungen des tau-Proteins) auf. Mittlerweile werden die Ablagerungen als Hauptursache für die Alzheimer-Krankheit angesehen [zur Übersicht BLENNOW et al. 2006].

Die Alzheimer-Krankheit schreitet nur langsam fort und drückt sich in einer zunehmenden Beeinträchtigung des episodischen Gedächtnisses, in Aphasien, Apraxien und Agnosien aus. Kognitive Funktionen, z.B. Urteilsfindung, Entscheidungen und Orientierung, sind ebenfalls betroffen. Die bildgebende Diagnostik zeigt eine generelle Hirnatrophie mit vergrößerten Ventrikeln und kortikalen Sulci, besonders betroffen ist dabei die Temporallappen-Region (u.a. der Hippocampus).

Mittlerweile gibt es zahlreiche Behandlungsmöglichkeiten, die u.a. SekretasenModulatoren oder A $\beta$-Immuntherapien umfassen. Alle bekannten therapeutischen Strategien sind bisher lediglich symptomatisch.

\subsection{Ziel dieser Arbeit}

Bisherige Studien des Amyloid Precursor Proteins wurden vorrangig an transgenen Tieren, die APP oder Isoformen des Proteins überexprimieren, durchgeführt. Rückschlüsse auf die physiologische Funktion des Proteins sind sehr widersprüchlich. Die beiden anderen Proteine der Familie, APLP1 und APLP2, wurden nur selten in die Studien miteinbezogen. Bekannt ist jedoch die sowohl prä- als auch postsynaptische Lokalisation der Proteinfamilie.

Ziel dieser Arbeit ist es, die Funktion der Proteinfamilie in der synaptischen Transmission zu evaluieren. Dazu werden genetisch modifizierte Mäuse, die für eines oder alle drei Proteine der Familie defizient sind, mit biophysikalischen Methoden charakterisiert. Es sollen basale Charakteristika der synaptischen Transmission erstellt und so eine mögliche Rolle der Proteinfamilie an der Synapse ermittelt werden.

In der vorliegenden Arbeit wird erstmals die synaptische Transmission mittels elektrophysiologischer (patch-clamp-Technik) Methoden in APP/APLP1/APLP2-defizienten Tieren untersucht. Dazu werden Nervenzellen des Hippocampus der Maus als Modell gewählt, die in autaptischen Neuronenkulturen gezüchtet werden. 


\section{Material und Methoden}

\subsection{Knockout-Mäuse}

Diese Arbeit wurde an neuronalen Primärkulturen durchgeführt, die aus genetisch modifizierten Tieren gewonnen wurden. In dieser Mauslinie wurden die Gene für APP, APLP1 und APLP2 molekulargenetisch verändert. Diese Methode erfordert sehr viel Zeit und fundiertes molekularbiologisches Wissen, das weit über die Möglichkeiten eines elektrophysiologischen Labors hinausgeht. Aus diesen Gründen erfolgte die Erstellung der Mauslinie in einer Kooperation mit einem molekularbiologisch ausgerichteten Labor. Die Haltung, Zucht und Genotypisierung der Nachkommen erfolgte vor Ort.

\subsubsection{Die APP-Knockout-Linie}

Es sind mehrere Mauslinien bekannt, deren APP-Gen modifiziert wurde [MULLER et al. 1994; ZHENG et al. 1995; LI et al. 1996]. In dieser Arbeit wird die Mauslinie von LI et al. als Grundlage für die spätere Erstellung der Triple-Knockout-Linie vorgestellt werden. Mittels homologer Rekombination wurden Teile des APP-Gens gelöscht [LI et al. 1996]. Insgesamt wurden $200 \mathrm{~kb}$ des APP-Gens deletiert. Die Exons 2 bis 17 wurden durch eine pNEOUM-SLOX(-)TKDT-Kassette und eine pHYGROLOX(+)TKDTKassette ersetzt, die aus folgenden Einzelsequenzen bestanden: einem NeomycinResistenz-Gen (NEO), das von einem Phosphoglycerolkinase-Promotor („upstream mouse sequence", UMS) kontrolliert wird; der 34 bp loxP-Sequenz; die HerpesSimplex-Thymidinkinase (TK) und einem TK-Promotor/Diphtherietoxin (DT) sowie dem Hygromycin-Resistenz-Gen und der loxP-Sequenz. Mittels Cre-Rekombinase wurden die von loxP flankierten Exons ausgeschnitten. Bei der folgenden Analyse der Genprodukte bestätigte sich, dass ein 200 kb-Fragment des APP-Gens fehlte.

Die Resistenz-Gene dienten der positiven Selektion von embryonalen Stammzellen, die dann in Maus-Blastozysten injiziert und nachfolgend in Maus-Uteri transloziert wurden (siehe Abb. 6). 

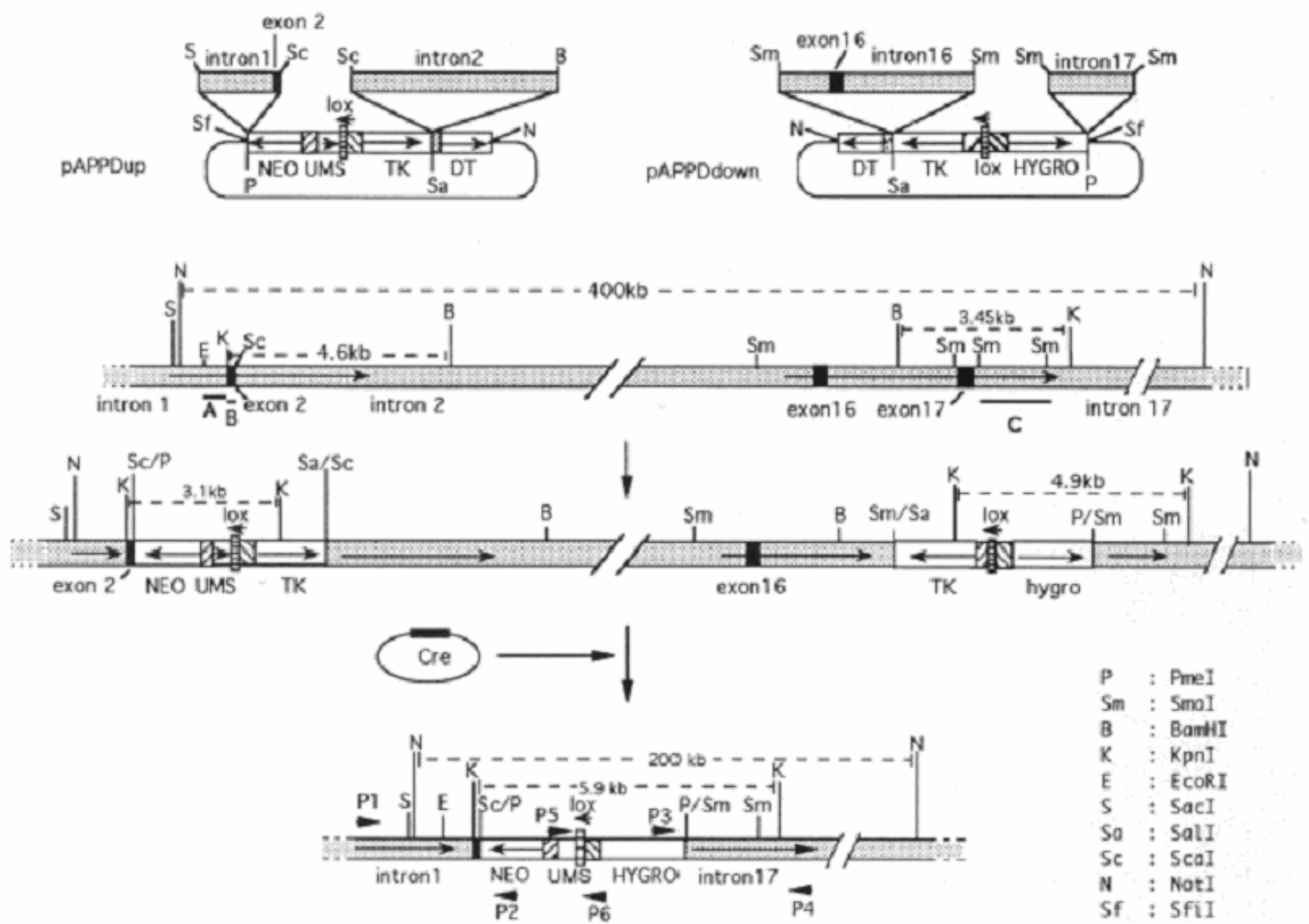

Abb. 6: Gen-Targeting-Strategie des APP-Gens

In der oberen Reihe ist pAPPDup der Target-Vektor, der die Insertion der pNEOUMSLOX(-)TKDTKassette in Exon 2 bewirkt. pAPPDdown ersetzt Exon 17 sowie angrenzende Regionen durch die pHYGROLOX(+)TKDT-Kassette. In der Reihe darunter ist das nicht modifizierte APP-Gen dargestellt. Nachfolgend ist das mit beiden Kassetten modifizierte APP-Gen gezeigt. In der untersten Reihe ist das modifizierte APP-Gen nach homologer Rekombination mit Cre-Rekombinase dargestellt [aus LI et al. 1996, S. 6159].

\subsubsection{Die APLP1-Knockout-Linie}

Für die Erzeugung der APLP1-Knockouts wurden ebenfalls die NEO-, UMS- sowie HSV-TK-Kassetten benutzt. Homologe Rekombination führte zu einer 8 kb großen Deletion im APLP1-Gen [HEBER et al. 2000] (siehe Abb. 7). 


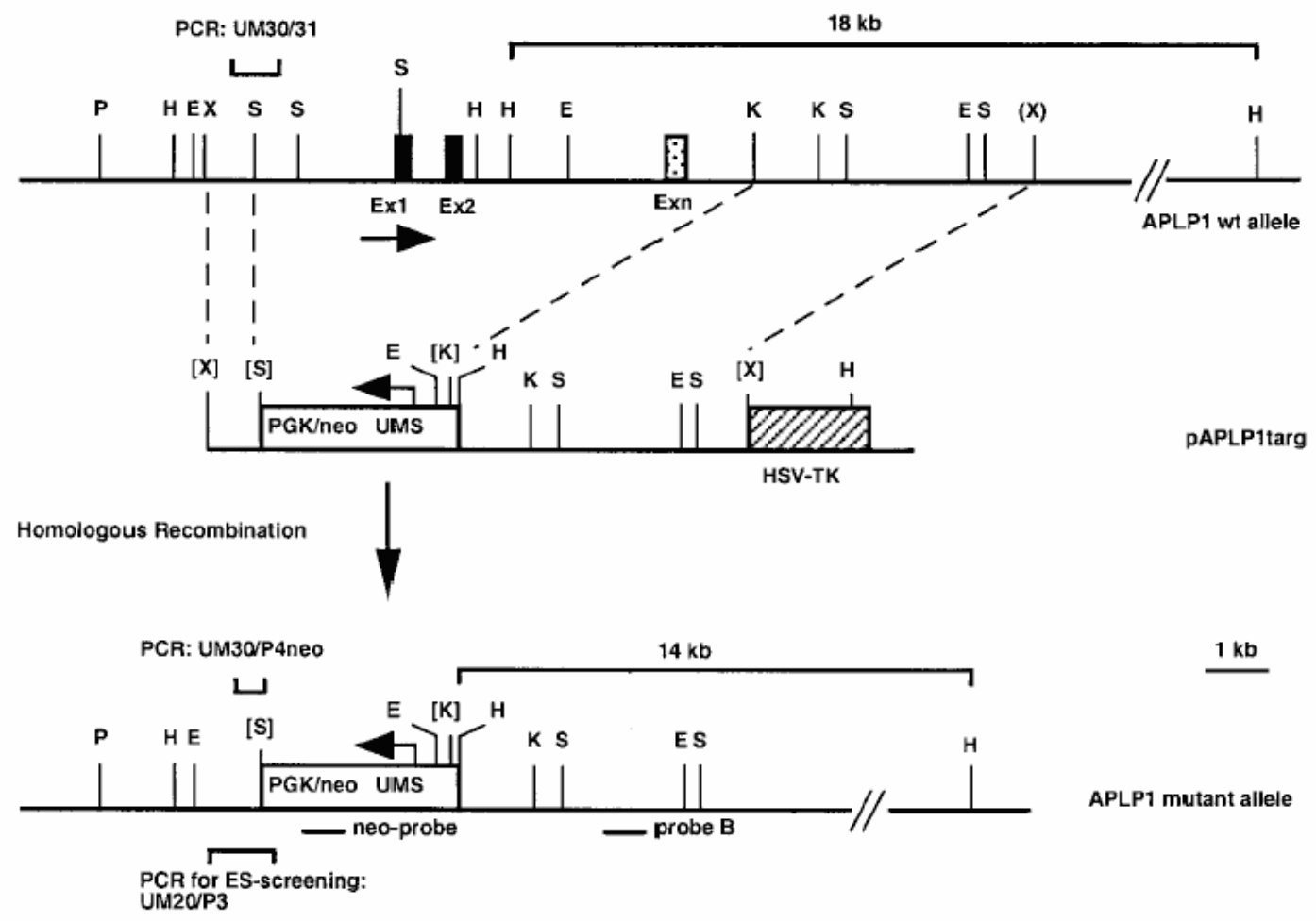

Abb. 7: Gen-Targeting-Strategie des APLP1-Gens

Homologe Rekombination führte zu einer $\sim 8 \mathrm{~kb}$ Deletion. Im oberen Teil sind die Exons noch enthalten. Im mittleren Teil ist der Targeting-Vektor dargestellt. Die schraffierte Box repräsentiert eine Herpessimplex-Thymidinkinase (HSV-TK). Im unteren Teil befindet sich das mutierte APLP1-Allel nach homologer Rekombination [aus HEBER et al. 2000, S. 7953].

\subsubsection{Die APLP2-Knockout-Linie}

Die APLP2-Knockout-Linie wurde erstmals 1997 publiziert [VON KOCH et al. 1997]. Im Wesentlichen wurden das Exon 1 sowie Teile des Promotors durch eine PGKneoKassette ersetzt. In der gleichen Publikation wurden APP/APLP2-Doppel-KnockoutMäuse (Doppel-Knockout nachfolgend nur noch DKO genannt) erstmals beschrieben (siehe Abb. 8). 


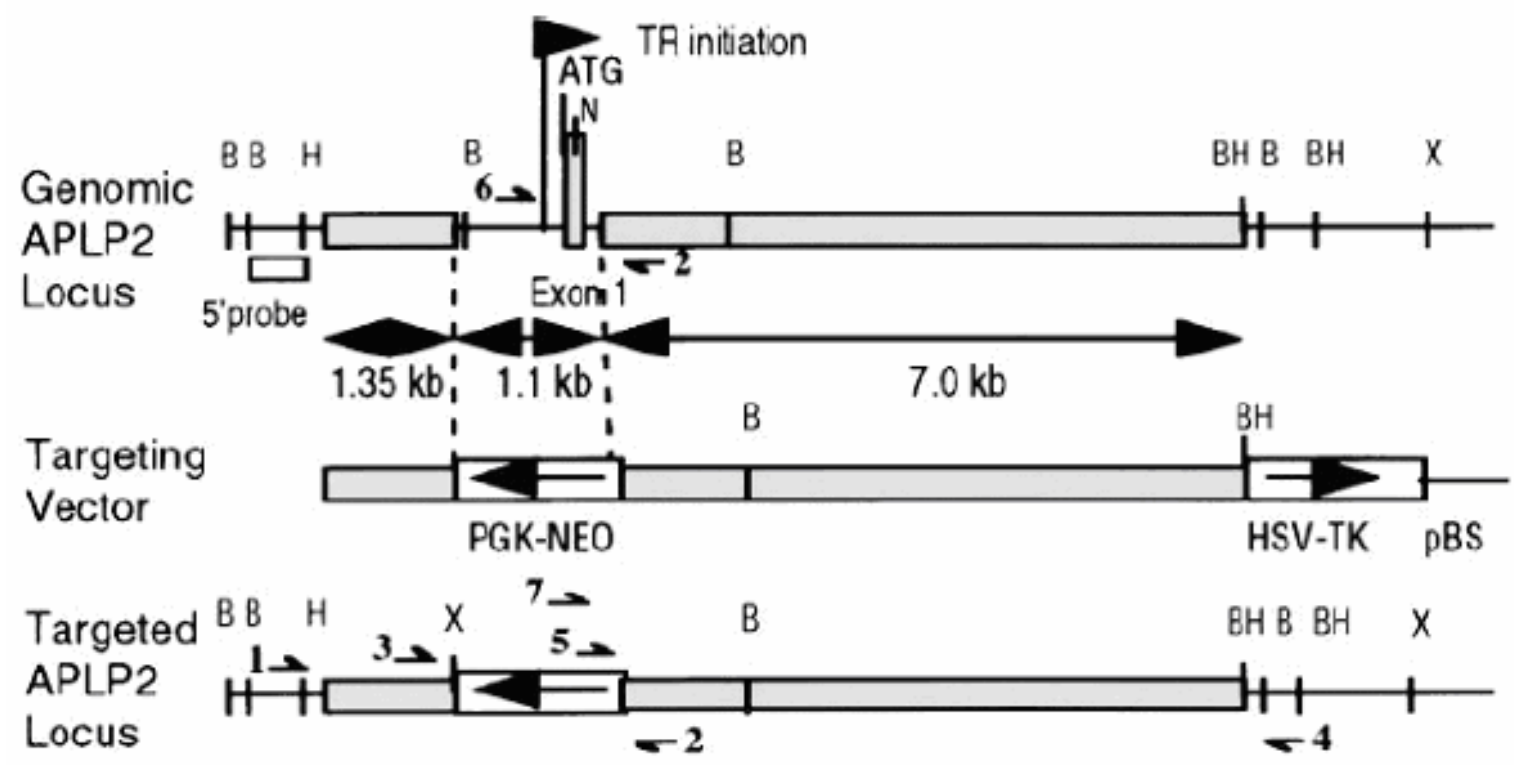

Abb. 8: Gen-Targeting-Strategie des APLP2-Gens

In der oberen Reihe ist das APLP2-Gen dargestellt. Nachfolgend ist der Target-Vektor gezeigt. In der unteren Reihe befindet sich das modifizierte APLP2-Gen [aus VON KOCH et al. 1997, S. 664].

\subsubsection{Die APP/APLP1/APLP2-Triple-Knockout-Linie}

In unserer Arbeit wurden APP/APLP1/APLP2-Triple-Knockout-Mäuse (nachfolgend nur noch TKO genannt) verwendet, die wir im Rahmen einer Kooperation von Ulrike Müller erhielten [HERMS et al. 2004]. Züchtung und Haltung erfolgte vor Ort. Es wurden Tiere mit dem Genotyp APP/APLP1/APLP2 -///+/-/+/- für die Züchtung verwendet. Als Kontrollgruppe fungierten Mäuse aus demselben Wurf, die aber nur defizient für APP waren.

\subsubsection{Genotypisierung}

Die Nachkommen heterozygoter Elterntiere werden in Verteilungsverhältnissen geboren, die nach den Mendelschen Regeln wie folgt zu erwarten sind: 1:2:1:2:4:2:1:2:1, d.h. APP/APLP1/APLP2 -/-/+/+/+/+, -/-/+/-/+/+, -/-/-/-/+/+, -/-/-/-/+/-, -/-/+/-/+/-, -/-/+/+/+/-, $-/-/+/+/-/-,-/-/+/-/-/-,-\mid-/-/-/-/-$.

Mittels der Polymerase-Kettenreaktion wurden die Tiere genotypisiert. In zwei Reaktionen wurde geprüft, ob das Wildtyp- bzw. das mutierte Allel vorlagen. Das Protokoll findet sich in Tab. 2. Die Reaktion wurde in Thermocyclern der Firma Biometra, Göttingen, durchgeführt. 
Die amplifizierten Fragmente wurden mittels Elektrophorese bei 150-200 V in einem 1,3 bis 1,5 \%igen Agarosegel aufgetrennt (Abb.9). Der Laufpuffer war TBE (Tab. 4). Ethidiumbromid wurde dem Gel zugefügt. Es interkaliert mit der DNA und bewirkt, dass die PCR-Produkte unter UV-Licht fluoreszieren und so als Banden im Gel sichtbar sind. Ein Standard mit Fragmenten definierter Länge wurde ebenfalls auf das Gel gebracht, um die Größenbestimmung der amplifizierten Fragmente zu erlauben.

Die Firma Life-Technologies Gibco-BRL GmbH/Invitrogen, Eggenstein-Leopoldshafen war Bezugsquelle für alle Produkte, die bei der Gelelektrophorese verwendet wurden.

Die Primer für die PCR wurden von IBA, Göttingen, hergestellt (Tab. 1). Sonstige Chemikalien (wenn nicht anders aufgeführt) wurden von Sigma-Aldrich, München, bezogen.

APP

Wildtyp-Reaktion $\left(5^{\prime} \rightarrow 3^{\prime}\right)$

UM 42 ATC ACC TGG TTC TAA TCA GAG GCC C

UM 44 GAG ACG AGG ACG CTC AGT CCT AGG G 660 bp

Knockout-Reaktion $\left(5^{\prime} \rightarrow 3^{\prime}\right)$

UM 42 ATC ACC TGG TTC TAA TCA GAG GCC C

p3hygro CGA GAT CAG CAG CCT CTG TTC CAC A $~ 410$ bp

APLP1

Wildtyp-Reaktion $\left(5^{\prime} \rightarrow 3^{\prime}\right)$

UM 31 ACT TTG GCT GAA CTG AGT GTA CAC C

UM 30 GCT TTC TGC CTT CAT GCC TAT CTC TAG $\sim 600 \mathrm{bp}$

Knockout-Reaktion $\left(5^{\prime} \rightarrow 3^{\prime}\right)$

p4neo ATG CGG TGG GCT CTA TGG CTT CTG A

UM 30 GCT TTC TGC CTT CAT GCC TAT CTC TAG $\sim 450 \mathrm{bp}$

APLP2

Wildtyp-Reaktion $\left(5^{\prime} \rightarrow 3^{\prime}\right)$

APLP2-1 GCC AAG CTT GAG TCG GTG TAT CCG TGC T

APLP2-2 GCG ACC GGA GGA GAC GCA GAT CGG GAG CTC GCC 400bp

Knockout-Reaktion $\left(5^{\prime} \rightarrow 3^{\prime}\right)$

APLP2-2 GCG ACC GGA GGA GAC GCA GAT CGG GAG CTC GCC

APLP2-3 CCA TTG CTC AGC GGT GCT G 350bp

Tab. 1: Primer zur Genotypisierung 


\begin{tabular}{ccc} 
Temperatur $\left({ }^{\circ} \mathrm{C}\right)$ & Zeit (min:s) & Zyklen \\
\hline 95 & $3: 00$ & \\
94 & $0: 45$ & \\
55 & $0: 45$ & \\
65 & $2: 00$ & $38 x$ \\
65 & $5: 00$ & \\
4 & oo &
\end{tabular}

Tab. 2: Temperatur-Protokoll des Thermocyclers

Das Protokoll ist für APP, APLP1, APLP2 identisch.

\section{PCR-Mix}

pro Reaktion $(25 \mu \mathrm{l})$

2,5 $\mu \mathrm{l}$ 10x Soriano-Puffer

$0,1 \mu \mathrm{dNTPs}(25 \mathrm{mM})$

$0,03 \mu \mathrm{l}$ Primer $1(0,1 \mathrm{nmol} / \mu \mathrm{l})$

$0,03 \mu \mathrm{l}$ Primer $2(0,1 \mathrm{nmol} / \mu \mathrm{l})$

0,03 $\mu \mathrm{l}$ Primer $3(0,1 \mathrm{nmol} / \mu \mathrm{l})$

0,2 $\mu$ l Promega Taq (5 U/ $\mu \mathrm{l})$

$18,3 \mu \mathrm{l} \mathrm{H}_{2} \mathrm{O}$

in $\mathrm{H}_{2} \mathrm{O}$

$10 \times$ Soriano-Puffer

166 mM Ammoniumsulfat

670 mM Tris-HCL pH 8,8

$67 \mathrm{mM} \mathrm{Mg} \mathrm{Cl}_{2}$

$50 \mathrm{mM} \beta$-Mercaptoethanol

$67 \mu \mathrm{M}$ EDTA

1,0 $\mu$ l DNA-Template

Tab. 3: Reaktionsansatz für die PCR und Zusammensetzung des Soriano-Puffers 


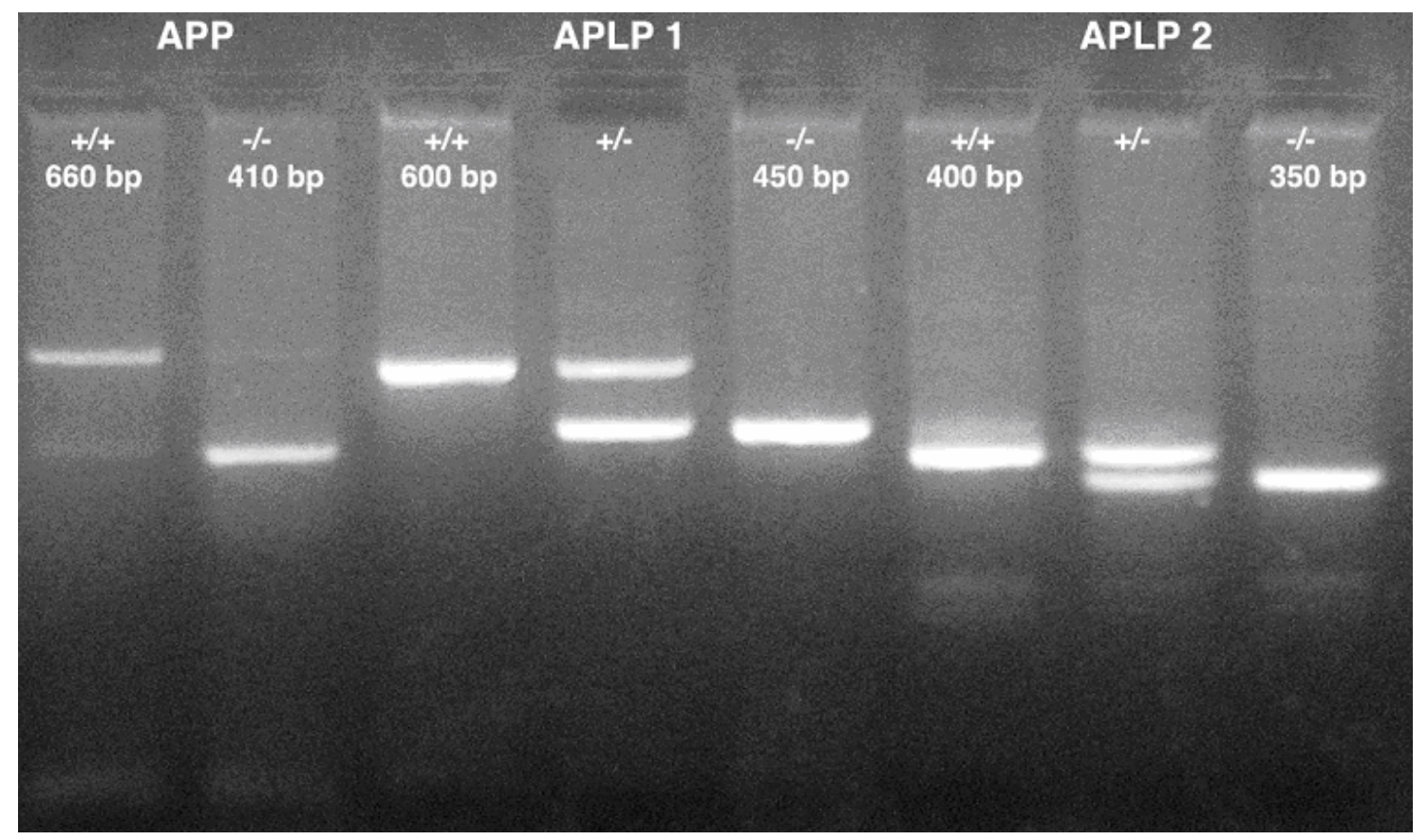

Abb. 9: Agarosegel mit PCR-Produkten der APP-, APLP1- und APLP2-Reaktionen

Die Größe der Banden ist jeweils mit angegeben.

Die DNA wurde bei embryonalen Tieren aus Hirngewebe, bei älteren Tieren aus Schwanzbiopsien gewonnen. Das Material wurde in $300 \mu$ SNET-Puffer (Tab. 4) und 3 $\mu l$ Proteinase-K $(10 \mu \mathrm{g} / \mu \mathrm{l})$ (Roche Diagnostics, Mannheim) bei $55{ }^{\circ} \mathrm{C}$ über Nacht verdaut. Die DNA-Extraktion erfolgte mit $300 \mu \mathrm{l}$ Phenol/Chloroform (USB Chemicals, Cleveland, USA), das in einer 1:1 Mischung vorlag. Nach 15-minütiger Zentrifugation bei $13000 \mathrm{U} / \mathrm{min}$ in einer Tischzentrifuge wurde aus dem Überstand die DNA mit 300 $\mu 1$ Isopropanol gefällt. Es folgte ein Waschschritt in 70\%vol Ethanol und anschließende Trocknung in einer Lyophille (Eppendorf AG, Hamburg). Das DNA-Pellet wurde in $200 \mu \mathrm{l}$ resuspendiert und war als Vorlage für die PCR verfügbar. Die DNA-Gewinnung mittels der eben beschriebenen Prozedur ist sehr zeitaufwändig und war deshalb für die Genotypisierung während der Präparation der Neuronen für die primäre Zellkultur nicht verwendbar. Die sogenannte Online-Genotypisierung wurde nach folgendem Schema durchgeführt: In $500 \mu$ l TS-Puffer ohne Detergenz (Tab. 4) wurde Hirngewebe trituriert, d.h. mechanisch zerkleinert. $5 \mu$ l Proteinase-K $(10 \mu \mathrm{g} / \mu \mathrm{l})$ waren dem Puffer beigefügt. Bei $55^{\circ} \mathrm{C}$ über 5-10 Minuten erfolgte die Andauung im Schüttler. Die Proben wurden danach kurz anzentrifugiert und dann 10 Minuten im Heizblock gekocht, um die Proteinase-K zu inaktivieren. Die Sedimentation des unverdauten Gewebes wurde durch weiteres Zentrifugieren über 2 Minuten bei 13000 U/min erreicht. Als DNAVorlage konnte der Überstand für die PCR verwendet werden. Diese DNA ist jedoch nur begrenzt haltbar. 


\begin{tabular}{ccccc} 
& SNET & TE & TS & TBE \\
\hline Tris-HCl pH 8.0 & $20 \mathrm{mM}$ & $10 \mathrm{mM}$ & $10 \mathrm{mM}$ & $100 \mathrm{mM}$ \\
Na2EDTA pH 8.0 & $5 \mathrm{mM}$ & $1 \mathrm{mM}$ & & $1 \mathrm{mM}$ \\
NaCl & $400 \mathrm{mM}$ & & $100 \mathrm{mM}$ & \\
SDS & $1 \%$ & & & \\
Borsäure & & & & $90 \mathrm{mM}$
\end{tabular}

Tab. 4: Pufferlösungen für die DNA-Extraktion und Agarose-Laufgele

\subsection{Zellkulturen}

Alle hier vorgestellten Ergebnisse wurden mittels neuronaler Primärkulturen von der Maus gewonnen. Die Neuronen stammten aus dem Hippocampus der Maus und wurden nach Gewinnung auf sogenannten „Mikroinseln“ gezüchtet.

\subsubsection{Präparation der Astrozyten und Microdots}

Die Kulturplatten mussten vor dem Aufbringen der Beschichtung gereinigt werden. Dazu wurden die Glasplättchen über Nacht in $1 \mathrm{~N} \mathrm{HCl}$ geschwenkt. Danach wurden die Platten mit destilliertem Wasser mehrmals und anschließend ein- oder zweimal in $70 \%$ vol Ethanol gewaschen. Die Aufbewahrung erfolgte in 95\%vol Ethanol.

Bevor die Glasplättchen in die Kulturplatten gebracht werden konnten, mussten diese über einer Glasflamme getrocknet werden. Danach wurden die Plättchen in die Kulturplatte gelegt.

Sobald die Glasplättchen getrocknet und positioniert waren, konnte die Beschichtung erfolgen. Für die Beschichtung gab es zwei Möglichkeiten: Kontinental (oder konventionell) und Microdots (oder auch Mikroinseln genannt). Die hier beschriebenen Experimente wurden nur an Neuronen durchgeführt, die auf Microdots wuchsen. Dazu wird das Glasplättchen zunächst dünn mit Agarose beschichtet. Die negative Ladung der Agarose verhindert, dass sich Zellen am Glasplättchen anhaften können. Danach wird auf die Agarose-Beschichtung eine Mischung aus Kollagen und Poly-D-Lysin mittels eines Stempels aufgebracht. Dieser Stempel erzeugt beschichtete Mikroinseln von ca.

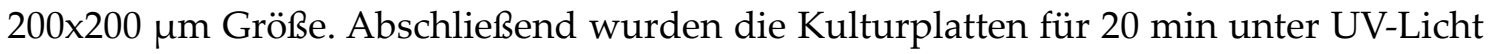
sterilisiert.

Für die Astrozytenkultur wurde Hirngewebe aus dem Cortex neonataler Mäuse enzymatisch mittels einer Papain-Lösung $(20 \mathrm{U} / \mathrm{ml}$ ) für eine Stunde verdaut, anschließend 
inaktiviert und trituriert. Die so erhaltenen Zellen wurden in einer Kulturflasche mit 5 $\mathrm{ml} 10 \%$ FBS-Medium bei $37^{\circ} \mathrm{C}$ inkubiert und bis zur Konfluenz der Gliazellen kultiviert. Die Cortex-Neuronen sterben bei diesem Vorgang ab. Nach ca. einer Woche war die Astrozytenkultur am Boden der Flasche konfluent. Die Mikroglia wurde durch kurzes Schütteln gelöst und anschließenden Medienwechsel entfernt. Die am Boden der Kulturflasche haftenden Astrozyten wurden durch Behandlung mit Trypsin-EDTA (Trypsin-EDTA, Biochrom) abgelöst, in 10\% FBS-Medium aufgenommen und trituriert. Danach erfolgte die Zentrifugation bei 1000 Umdrehungen pro Minute über ca. 3 Minuten. Anschließende Resuspendierung wurde mit 10\% FBS-Medium durchgeführt. Die Astrozyten wurden gezählt und mit einer Dichte von 5000-10000 Zellen pro 35 mm-Kammer in eine 6-Kammer-Kulturplatte pipettiert. $2 \mathrm{ml} \mathrm{10 \%} \mathrm{FBS-Medium} \mathrm{wurden}$ pro Kammer dazugegeben. Nach ca. fünf Tagen in Kultur wurde das weitere Wachstum der Astrozyten durch Zugabe von $20 \mu$ l FUDR-Lösung gestoppt. Die Kulturplatten konnten einige Tage bei $37^{\circ} \mathrm{C}, 5 \%$ Kohlendioxid aufbewahrt werden. Direkt vor dem Aufbringen exzitatorischer Neurone erfolgte ein Mediumwechsel von FBS auf Neuronenmedium NBA.

\subsubsection{Präparation und Kultur exzitatorischer Neurone}

Vor der Präparation wurden $300 \mu \mathrm{l}$ der Papain-Lösung pro Hippocampus vorbereitet und anschließend mit 5\% Kohlendioxid/95\% Sauerstoff für 10 bis 20 Minuten begast bis sich das Papain vollständig löste. Die Lösung wurde steril in einzelne EppendorfCups filtriert und bei $37^{\circ} \mathrm{C}$ bis zur Verwendung inkubiert.

Die exzitatorischen Neurone wurden aus Hippocampi embryonaler (E17-18) Mäuse gewonnen. Dazu wurde das Muttertier mittels Halothan kurz betäubt und getötet. Die Embryonen wurden aus dem maternalen Uterus präpariert und nach Größe sortiert. Die Präparation der Hippocampi erfolgte in Reihenfolge der Mausgröße. Alle entnommenen Embryonen wurden dekapitiert, und das Hirn wurde entnommen. Die Präparation des Hippocampus erfolgte in eiskalter Hanks-balancierter Salzlösung (HBSS, GibcoBRL, Grand Island, NY, USA). Die Hippocampus-Region wurde nach Entfernung der Meningen dargestellt und der Hippocampus entnommen. Der Gyrus dentatus wurde zur Reduktion des Anteils inhibitorischer Neurone ebenfalls entfernt. Ziel der folgenden Präparation war es, möglichst viele einzelne Neurone aus dem Gewebsverband enzymatisch herauszulösen. Dazu wurden die Hippocampi in $300 \mu \mathrm{l}$ Papain-Lösung über eine Stunde bei $37^{\circ} \mathrm{C}$ unter Schütteln inkubiert. Anschließend erfolgte eine 10-minütige Inaktivierung mit Inhibitionslösung. Der Hippocampus wurde in NBA-Medium transferiert und konnte in diesem angedauten Zustand für einige Zeit unter Schütteln bei $37^{\circ} \mathrm{C}$ bis zum Ergebnis der Genotypisierung aufbewahrt werden.

Ein weiterer Teil des Hirngewebes wurde nach der in Abschnitt 2.1.5 beschriebenen DNA-Gewinnung für die Genotypisierung verwendet. Nach ca. 120 min für den Thermocycler und ca. 25 min für das Agarosegel lag das Ergebnis der Genotypisierung 
nach ca. 2:40 h nach Ende der Präparation vor. Die Neuronen waren nach dieser Zeit in einem sehr guten Zustand.

Nach dem Ergebnis der Genotypisierung wurden die Hippocampi der homozygoten Tiere in NBA-Lösung trituriert. Dazu wurden die Hippocampi sechs bis achtmal vor-

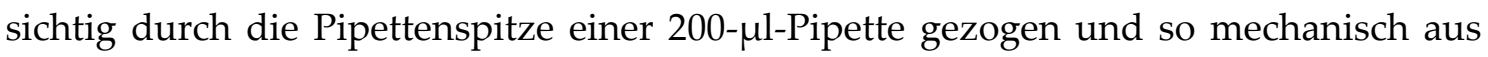
dem Gewebeverband gelöst. Die dissoziierten Neurone befanden sich somit im Überstand. Nach kurzer Sedimentation wurde der Überstand abpipettiert und in $1000 \mu \mathrm{l}$ NBA-Lösung gebracht. Für die Neuronensuspension wurde die Zelldichte mittels einer Neubauer-Zählkammer bestimmt. Pro 35-mm-Deckglas in einer 6-KammerKulturplatte wurden 4000 bis 6000 Neurone pipettiert. Diese Dichte erwies sich als ideal, um Mikroinseln mit einem einzelnen Neuron zu erhalten.

Die 6-Kammer-Kulturplatten wurden bei $37^{\circ} \mathrm{C}$, 5\% Kohlendioxid und 95\% Luftfeuchtigkeit im Inkubator gelagert. Um den Einfluss von Variationen zwischen Kulturplatten $\mathrm{zu}$ verringern, wurden jeweils APP-SKO-Neuronen und APP/APLP1/APLP2-TKONeuronen zusammen auf einer Kulturplatte ausgesät.

Schon kurz nach dem Aufbringen der Neuronen begannen diese, Fortsätze auszubilden. Nach etwa sieben bis acht Tagen ließen sich erste synaptische Ströme nachweisen.

\subsubsection{Besonderheiten der autaptischen Kultur}

Die exzitatorischen Nervenzellen wuchsen auf den Mikroinseln, im Idealfall wuchs nur ein Neuron pro Mikroinsel. Da sich zwischen den Mikroinseln keine Glia befindet, sind die Neuronen und deren Fortsätze nicht in der Lage, diesen Bereich zu überwinden. So kam es zu keinem Kontakt zwischen Neuronen auf benachbarten Mikroinseln.

Das einzelne Neuron auf einer Mikroinseln beginnt hingegen, Autapsen zu formen, d.h. das neu auswachsende Axon formt Synapsen auf den Dendriten der eigenen Zelle (Abb. 10). Autapsen weisen die gleiche Morphologie und Funktion wie normale Synapsen auf [SCHIKORSKI und STEVENS 1997]. Die autaptische Kultur eignet sich somit sehr gut, um die synaptische Transmission zu untersuchen. Der Vorteil gegenüber dem konventionellen Hirnschnitt-Modell besteht darin, dass nur eine Elektrode nötig ist, sowohl für die Stimulation als auch die Ableitung der Reizantwort [BEKKERS und STEVENS 1991].

Somit können verschiedene Parameter der synaptischen Transmission untersucht werden. Eingeschlossen sind die spontane Neurotransmitterfreisetzung, die Stimulation durch ein hervorgerufenes Aktionspotential sowie die Stimulation durch hypertone Lösung. Da alle Mechanismen an der gleichen einzelnen Zelle untersucht werden, eignet sich dieses Modell sehr gut, um verschiedene Parameter untereinander zu vergleichen und eine große Variabilität der Datensätze zu reduzieren. 

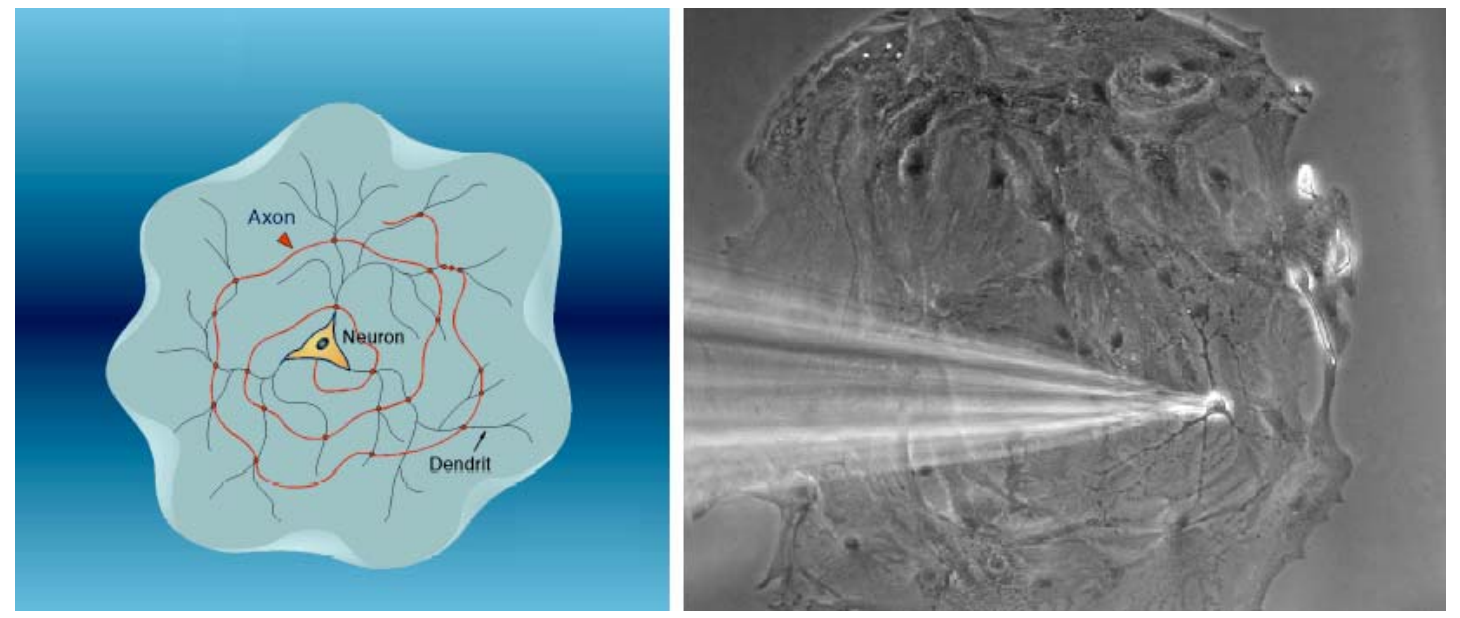

Abb. 10: Die autaptische Kultur

Links ist ein Neuron schematisch abgebildet, dagegen ist rechts ein Neuron auf einem Microdot mit patchPipette zu sehen.

\subsubsection{Lösungen und Medien}

Alle Lösungen und Medien der Zellkultur wurden von folgenden Anbietern bezogen: Roche Diagnostics, Mannheim; Worthington, Lakewood, NJ, USA; Becton Dickinson Labware, Bedford, USA; Collaborative Biomedical Products; Life-Technologies GibcoBRL GmbH/Invitrogen, Eggenstein-Leopoldshafen (Übersicht in der Tab. 5). 


\begin{tabular}{|c|c|c|}
\hline Kollagen/Poly-D-Lysin & $\begin{array}{l}\text { Poly-D-Lysin } \\
\text { Kollagen } \\
\text { Essigsäure }\end{array}$ & $\begin{array}{l}0,1 \mathrm{mg} / \mathrm{ml} \\
0,2 \mathrm{mg} / \mathrm{ml} \\
0,1 \mathrm{mM}\end{array}$ \\
\hline FUDR & $\begin{array}{l}\text { 5-Fluoro-2'-Deoxyuridin } \\
\text { Uridin } \\
\text { in DMEM }\end{array}$ & $\begin{array}{l}8,1 \mathrm{mM} \\
20,4 \mathrm{mM}\end{array}$ \\
\hline NBA & $\begin{array}{l}\text { Neurobasal A } \\
\text { B27-Supplement } \\
\text { Glutamax-Supplement } \\
\text { Penicillin } \\
\text { Streptomycin }\end{array}$ & $\begin{array}{l}400 \mathrm{ml} \\
1 \times \\
1 \times \\
100 \mathrm{U} / \mathrm{ml} \\
100 \mu \mathrm{g} / \mathrm{ml}\end{array}$ \\
\hline $10 \%$ FBS & $\begin{array}{l}10 \% \text { fetales bovines Serum } \\
\text { MITO } \\
\text { Penicillin } \\
\text { Streptomycin } \\
\text { in DMEM }\end{array}$ & $\begin{array}{l}1 \mathrm{x} \\
100 \mathrm{U} / \mathrm{ml} \\
100 \mu \mathrm{g} / \mathrm{ml}\end{array}$ \\
\hline Enzym-Lösung & $\begin{array}{l}\text { Cystein } \\
\text { CaCL2 } \\
\text { EDTA } \\
\text { Papain } \\
\text { in DMEM, } 20 \text { min mit Carbogen } \\
\text { begast }\end{array}$ & $\begin{array}{l}0,2 \mathrm{mg} / \mathrm{ml} \\
1 \mathrm{mM} \\
0,5 \mathrm{mM} \\
25 \mathrm{U} / \mathrm{ml}\end{array}$ \\
\hline Inhibitionslösung & $\begin{array}{l}\text { Albumin } \\
\text { Trypsin-Inhibitor } \\
\text { in } 10 \% \text { FBS }\end{array}$ & $\begin{array}{l}2,5 \mathrm{mg} / \mathrm{ml} \\
2,5 \mathrm{mg} / \mathrm{ml}\end{array}$ \\
\hline
\end{tabular}

Tab. 5: Lösungen und Medien für die Zellkultur

\subsection{Elektrophysiologie}

Der überwiegende Anteil der hier dargestellten Messungen wurde mittels der patchclamp-Technik erhoben. Diese in den Neurowissenschaften etablierte Technik wird ausführlich in Publikationen beschrieben [HAMILL et al. 1981; SAKMANN und NEHER 1995] und hier nur zusammenfassend vorgestellt. 


\subsubsection{Die patch-clamp-Technik}

Erwin Neher und Bert Sakmann entwickelten am Göttinger Max-Planck-Institut für biophysikalische Chemie die patch-clamp-Technik. Diese Technik erlaubt eine biophysikalische Analyse von elektrischen Eigenschaften einer Zelle.

Dazu wird eine feine Glaspipette auf die Zellmembran aufgesetzt und angepresst. Ein kleines Areal der Zelle (patch) wird in die Pipettenspitze hereingesaugt. Die Glasoberfläche liegt der Zellmembran sehr dicht an; in der Regel entsteht spontan ein sehr hoher Abdichtungswiderstand im Bereich von mehreren Gigaohm, ein sogenannter Gigaseal. Der Membranfleck ist somit elektrisch isoliert, die cell-attached-Konfiguration ist erreicht. Von dieser Konfiguration ausgehend sind weitere Konfigurationen möglich. Relevant für die vorliegende Arbeit war die whole-cell-Konfiguration (siehe Abb. 11). Nach Erreichen des Gigaseals wurde durch vorsichtiges Saugen an der Pipette die Zellmembran durchbrochen und so die Ganzzellableitung erreicht. Diese Konfiguration erlaubt die Beurteilung der Gesamtleitfähigkeit einer Zelle.

Die Zelle wird auf ein negatives Haltepotential "geklemmt", da dauernde Depolarisation im Bereich von $0 \mathrm{mV}$ zum raschen Zelltod führt. Das weitere Vorgehen wird anhand der autaptischen Kultur beschrieben.

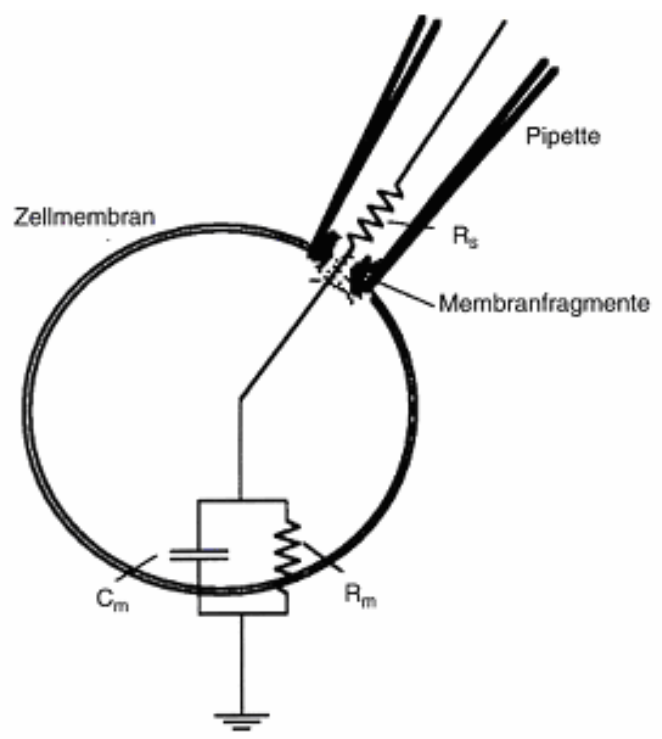

Abb. 11: Schema der whole-cell-Konfiguration Nach Durchbrechen der Membran ist die whole-cellKonfiguration hergestellt. Membranfragmente und anderes Zellmaterial gelangen dabei in die Pipettenöffnung, wodurch der Serienwiderstand (Rs) erhöht wird. RM ist der Membranwiderstand, $C_{M}$ die Membrankapazität [aus NUMBERGER und DRAGUHN 1996, S. 88]. 


\subsubsection{Lösungen}

Extra- und Intrazelluläre Lösungen waren wie in Tab. 6 beschrieben zusammengesetzt.

\section{Extrazellular-Lösung}

„Base + “-Kontrolle

„Base +“-Saccharose

$\mathrm{NaCl}$

$140 \mathrm{mM}$

$\mathrm{KCl}$

$2,4 \mathrm{mM}$

HEPES

$10 \mathrm{mM}$

Glukose

$10 \mathrm{mM}$

$\mathrm{CaCl}_{2}$

$4 \mathrm{mM}$

$\mathrm{MgCl}_{2}$

$4 \mathrm{mM}$

Saccharose

$500 \mathrm{mM}$

pH 7,3 300 mOsm

$800 \mathrm{mOsm}$

Intrazellular-Lösung

K-Gluconat

HEPES

$\mathrm{Mg}^{2+}-\mathrm{ATP}$

$\mathrm{Na}^{+}-\mathrm{GTP}$

EGTA

$\mathrm{MgCl}_{2}$

Kreatinphosphat

Kreatinphosphokinase

$$
\begin{gathered}
135 \mathrm{mM} \\
10 \mathrm{mM} \\
4 \mathrm{mM} \\
0,3 \mathrm{mM} \\
1 \mathrm{mM} \\
4,6 \mathrm{mM} \\
15 \mathrm{mM} \\
50 \mathrm{U} / 1
\end{gathered}
$$

pH 7,3 300 mOsm

Tab. 6: Extra- und Intrazellular-Lösungen

\subsubsection{Messplatz für die patch-clamp-Ableitungen}

Die für diese Arbeit verwendeten patch-clamp-Messplätze bestanden aus folgenden Komponenten.

Über einem schwingungsgedämpften Tisch (TMC, Peabody, USA; Landefeld, Kassel) wurde ein Faraday-Käfig zur Abschirmung aufgebaut. Auf dem Tisch wurde ein Olympus-Forschungsmikroskop (IX 50 bzw. 70; Olympus, Hamburg) in invertierter Bauweise fest montiert. Die Mikroskope waren z.B. mit 20x Objektiven (Olympus U/UM PlanFI 20x 0,5 NA) und Phasenkontrastoptik ausgestattet. 
Auf einem Verschiebetisch war die Badkammer mit Aufnahmemöglichkeit für die Deckgläschen mit den kultivierten Neuronen eingelassen. Zusätzlich waren alle Messplätze mit einem Perfusionssystem ausgestattet, das einen schnellen Lösungswechsel innerhalb von 20-50 ms garantierte. Gewährleistet war der schnelle Lösungsaustausch durch die Postionierung des Düsensystems (Flowpipe) in unmittelbarer Nähe der Zelle und die damit verbundene Möglichkeit einer laminaren Applikation von Lösungen an der Zelle (Abb. 12). Zum Perfusionssystem gehörte ebenfalls eine mit der Flowpipe verbundene Ventilbank mit Vorratsbehältern (alles Eigenbau) sowie ein Schrittmotorsystem zum genauen und schnellen Positionswechsel der Flowpipe (SF-77B Perfusion FastStep, Warner Instruments, Hamden, USA). Ein geregeltes Pumpensystem (MPCU-3, Lorenz, Lindau) war für konstante Flüssigkeitsspiegel in der Badkammer verantwortlich.

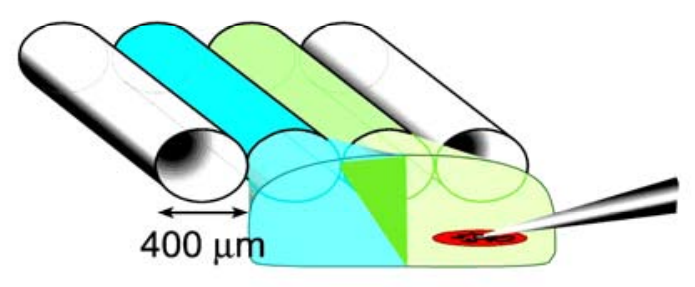

\begin{abstract}
Abb. 12: Schema des Perfusionsystems Der rote Fleck repräsentiert ein Microdot mit patch-Pipette. Davor wird das Düsensystem positioniert. Der Lösungsaustausch erfolgt innerhalb von Millisekunden.
\end{abstract}

Der Vorverstärker (Headstage) mit dem Halter für die patch-Pipetten war an ein kombiniertes Makro- und Mikromanipulatorensystem montiert und konnte mit dessen Hilfe bewegt werden. So war es möglich die patch-Pipette mikrometergenau der Zelle zu nähern. Drei über Kreuz angeordnete Verschiebetische (Linos Photonics, Göttingen) wurden dazu mit einem 3D-Piezo-Mikromanipulatorblock (Piezo Jena, Jena) zusammen montiert.

\title{
2.3.4 Datenakquisition und -analyse
}

Die synaptischen Ströme wurden mit einem Axon patch-clamp-Verstärker (Axopatch 200A bzw. 200B, Axon Instruments, Union City, CA, USA) bei Raumtemperatur (20$23^{\circ} \mathrm{C}$ ) gemessen. Die Digitalisierung erfolgte bei $10 \mathrm{kHz}$ mit einem Digidata 1321A (Axon Instruments, Union City, CA, USA). Die Steuerungs- und Aquisitionssoftware Clampex 8.03 (Axon Instruments, Union City, CA, USA) lief auf einem PIII-Computer unter Windows 2000 Professional. Auch das Perfusionssystem wurde mittels Clampex 8.03 gesteuert. 
Die Analyse der Rohdaten erfolgte mit Axograph 4.5 (Axon Instruments, Union City, CA, USA). Die abschließende statistische Auswertung und Erstellung der Graphen erfolgte in Kaleidagraph 3.0.5 (Abelbeck Software) und 4.0 (Synergy Software, Reading, PA, USA). Als statistischer Test wurde der ungepaarte $t$-Test verwendet. Die angegebenen Fehlerbalken stellen, soweit nicht anders vermerkt, den Standardfehler dar (Standard Error of the Mean, S.E.M.). Das Signifikanzniveau ist wie folgt angegeben:

- $\mathrm{p}<0,05$ entspricht *

- $\mathrm{p}<0,01$ entspricht ${ }^{* *}$

- $\mathrm{p}<0,001$ entspricht ${ }^{* * *}$.

Soweit keine nähere Angabe erfolgt, ist der Unterschied nicht signifikant.

\subsubsection{Autaptisch kultivierte Neuronen und deren Ableitung in whole-cell-Konfiguration}

Die Herstellung der patch-Pipetten erfolgte mit einem horizontalen Puller (Modell P-87, Sutter Instruments, Novato, USA) aus Borosilikat-Kapillaren (Typ GB150F-8P, Science Products, Hofheim) Die Pipetten wurden so weit ausgezogen, dass die Größe der Pipettenöffnung einem Widerstand von 2,2-3 M $\Omega$ in Chlorid-basierter Lösung entsprach.

Für Messungen an exzitatorischen Neuronen wurden die Pipetten mit Gluconatbasierter intrazellulärer Lösung befüllt.

Bei patch-clamp-Ableitungen an exzitatorischen autaptischen Neuronen wurde die whole-cell-Konfiguration verwendet. Nach Erreichen dieser wurde die nominelle Haltespannung am Verstärker auf $-60 \mathrm{mV}$ eingestellt, was unter Berücksichtigung des liquid junction potentials eine tatsächliche Klemmspannung von ca. $-75 \mathrm{mV}$ ergab.

Als weiterer wichtiger Parameter wurde der Zugangswiderstand (Serienwiderstand Rs) betrachtet. Normalerweise betrug der Serienwiderstand 4,5 bis $9 \mathrm{M} \Omega$; war der Serienwiderstand größer als $15 \mathrm{M} \Omega$, wurde die Zelle verworfen. Weiterhin wurde die manuelle Serienwiderstandskompensation des Axopatch 200A bzw. 200B verwendet. Somit konnte Rs zu mehr als 70\% kompensiert werden.

Der Leckstrom war möglichst gering und lag üblicherweise unter 200 pA. Bei größerem Leckstrom wurde das Experiment an der Zelle abgebrochen, bzw. die Zelle von der weiteren Analyse ausgeschlossen.

Nach Erreichen der whole-cell-Konfiguration und Einstellung des Haltepotentials wurde durch kurze Depolarisation auf $0 \mathrm{mV}$ über $2 \mathrm{~ms}$ am Soma des autaptischen Neurons ein Aktionspotential ausgelöst. Das Aktionspotential breitete sich über das Axon aus und löste letztendlich die Transmitterfreisetzung in den synaptischen Spalt aus. Die postsynaptischen Rezeptoren wurden durch den freigesetzten Transmitter aktiviert. 
Diese Aktivierung konnte kurz nach dem Aktionspotential als exzitatorischer postsynaptischer Strom (excitatory postsynaptic current, EPSC) registriert werden (Abb. 13).

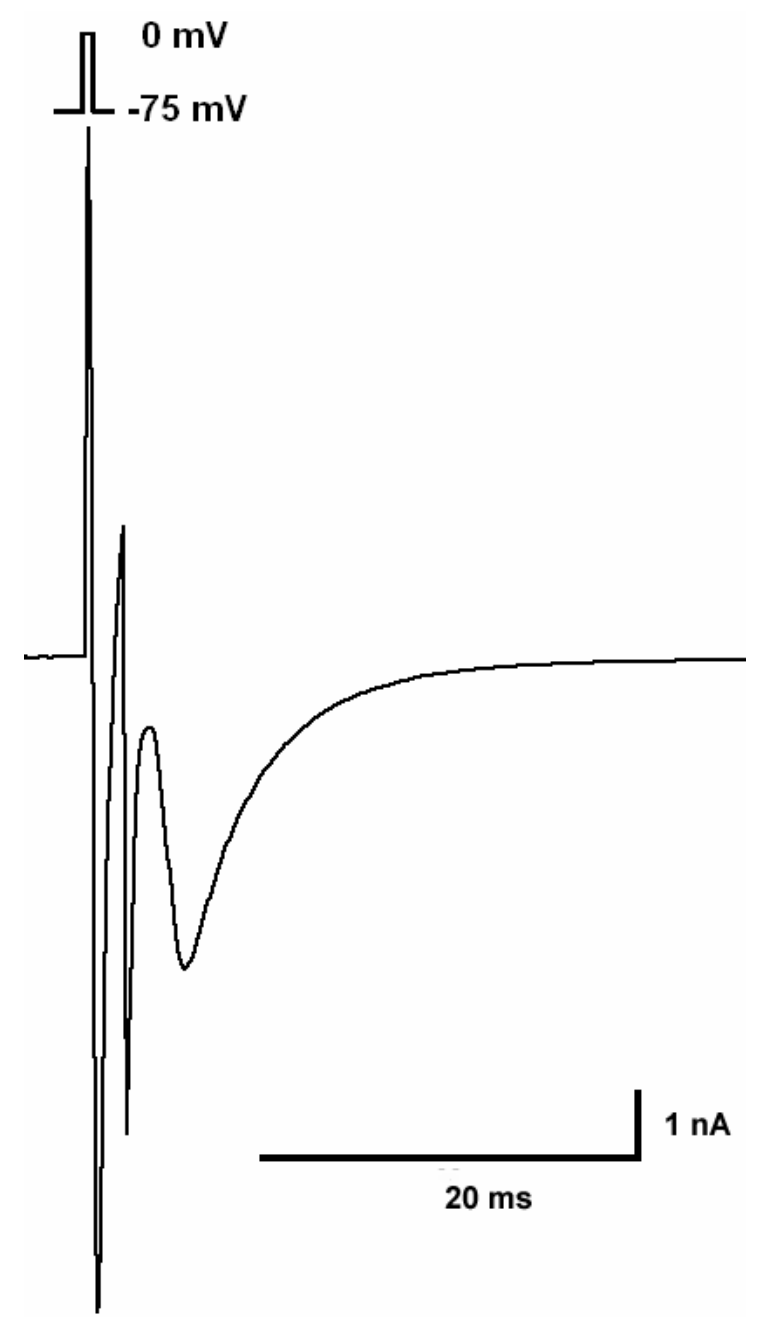

\section{Abb. 13: EPSC}

Es ist ein typisches EPSC gezeigt. Nach kurzer Depolarisation (2 ms) auf $0 \mathrm{mV}$ wird ein Aktionspotenzial am Zellsoma ausgelöst. Man sieht einen $\mathrm{Na}^{+}$-Einstrom sowie $\mathrm{K}^{+}$-Ausstrom. Danach erfolgt der exzitatorische postsynaptische Strom (EPSC).

\subsubsection{Messung der Poolgröße}

Die Applikation hypertoner Lösung während weniger Sekunden führt zu einer Freisetzung aller sekretionsbereiten Vesikel (Readily Releasable Pool, RRP) [ROSENMUND und STEVENS 1996]. Dazu wird $500 \mathrm{mM}$ Saccharose über mehr als $3 \mathrm{~s}$ appliziert, was zur Freisetzung des RRP führt (Abb. 14). Saccharose ist osmotisch aktiv, wird aber von den Neuronen nicht verstoffwechselt. Fusionskompetente Vesikel zeichnen sich durch abgeschlossenes Docking und Priming aus. Durch Calciumeinstrom kommt es zur Transmitterfreisetzung. Bei der Applikation hypertoner Lösung handelt es sich jedoch um einen Weg der Transmitterfreisetzung, die calciumunabhängig ist. 
Die postsynaptische Antwort bei Applikation hypertoner Lösung setzt sich aus einem Transienten und einem Gleichgewicht zusammen. Der einwärts gerichtete Transient steht hierbei für die plötzliche Freisetzung aller fusionskompetenten mit Transmitter gefüllten Vesikel. Für die Berechnung der absoluten Anzahl fusionsbereiter Vesikel wird das Integral des einwärts gerichteten Transienten nach Abzug der Gleichgewichtskomponente gebildet. Mit Kenntnis der durchschnittlichen Ladung, die nach Fusion eines Vesikels fließt (bekannt aus Analyse der mEPSC, s. Kapitel 2.3.8) kann somit die Gesamtzahl aller fusionskompetenten Vesikel ermittelt werden. Die Gleichgewichtskomponente präsentiert hingegen einen ausgeglichenen Zustand zwischen Freisetzung und Wiederauffüllung des Pools. Das Integral über diesem Abschnitt gibt die Anzahl der Vesikel wieder, die gerade in den RRP aufgenommen wurden. Um die vesikuläre Freisetzungswahrscheinlichkeit zu berechnen, wird der Quotient aus der Ladung des EPSC und der Ladung des einwärts gerichteten Transienten gebildet.

Die Transmitterfreisetzung erfolgt bei diesem Experiment unabhängig vom extra- oder intrazellulären Calcium. Deshalb können mit diesem Experiment alle prä- und postsynaptischen Schritte der Transmission, außer der calciumabhängigen, geprüft werden.

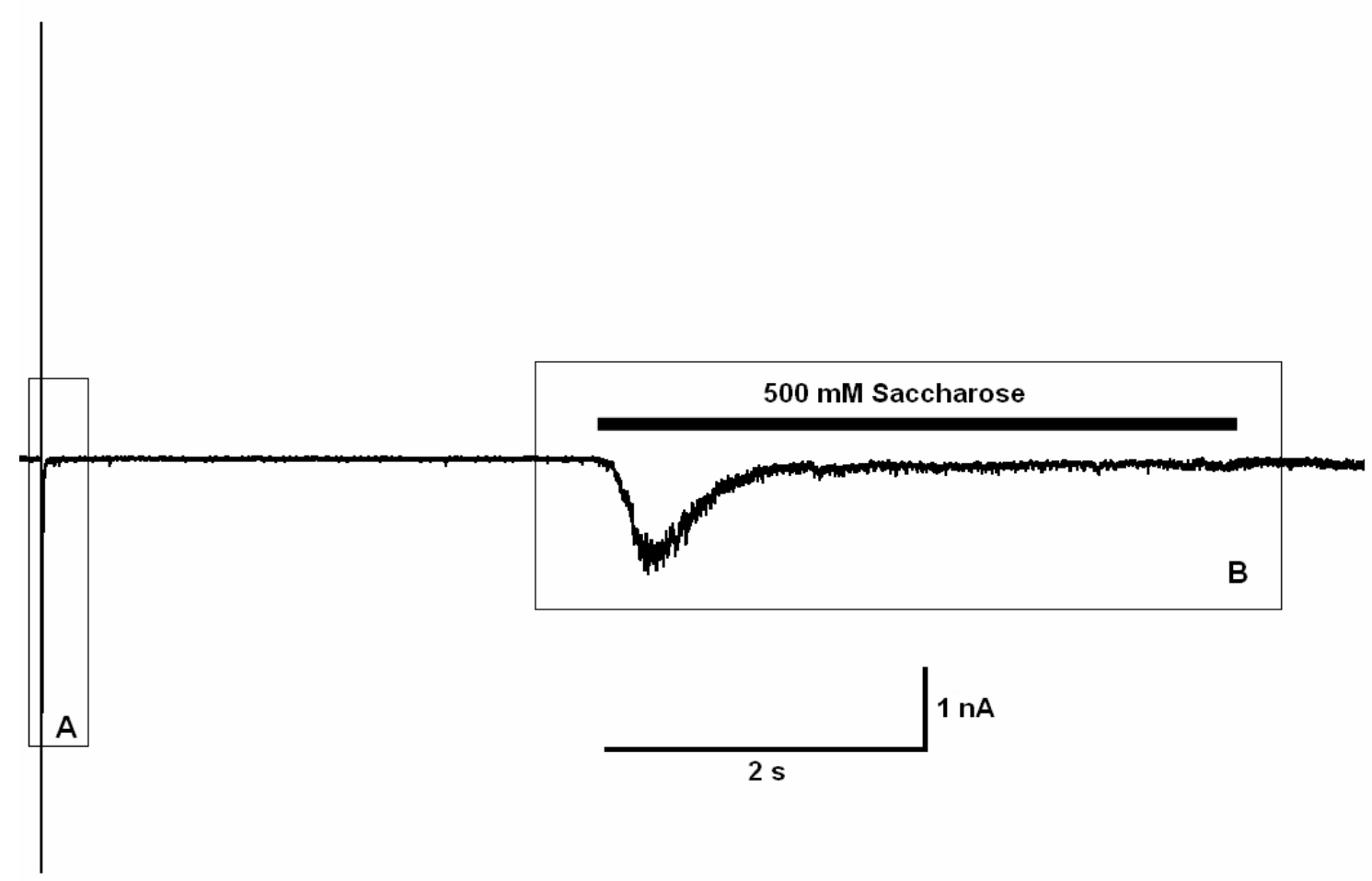

Abb. 14: Applikation hypertoner Lösung

A: Stimulation eines EPSC.

B: Applikation von $500 \mathrm{mM}$ Saccharose über $4 \mathrm{~s}$ verursacht eine komplette Entleerung des RRP. Die einwärts gerichtete transiente Komponente wird über die Zeit integriert und entspricht dem RRP. 


\subsubsection{Messung der Kurzzeitplastizität}

Um die Kurzzeitplastizität zu untersuchen, wurden die autaptisch kultivierten Neuronen mit einer $10 \mathrm{~Hz}$-Frequenz stimuliert. Um große Zell-zu-Zell-Variationen zu verhindern, wurden die EPSC jeweils auf das erste gemessene EPSC normalisiert.

\subsubsection{Messung der mEPSC}

Selbst ohne vorausgehendes Aktionspotential werden synaptische Vesikel freigesetzt. Da die Anzahl fusionsbereiter Vesikel im RRP normalerweise hoch ist, kommt es zu diesen Ereignissen mit einer Frequenz zwischen 0,3 und $20 \mathrm{~Hz}$. Ein einzelnes Vesikel ist im Durchschnitt in der Lage, einen postsynaptischen Strom zwischen 5 und 100 pA hervorzurufen. Man spricht dann von miniature excitatory postsynaptic currents (mEPSC).

mEPSCs wurden bei $-75 \mathrm{mV}$ über $60 \mathrm{~s}$ und Applikation von 0,3 $\mu \mathrm{M}$ Tetrodotoxin (TTX) aufgezeichnet. Das TTX wurde verwendet, um unerwünschte Aktionspotentiale durch selektive Blockung von Natrium-Kanälen möglichst zu verhindern. Der Leckstrom war möglichst konstant und unter 100 pA. Vor der weiteren Analyse wurden die Rohdaten bei $1 \mathrm{kHz}$ gefiltert. Das $50 \mathrm{~Hz}$-Netzbrummen wurde mit einem Notch-Filter entfernt.

Zur Detektion der mEPSC wurde die Funktion Scaled Template in Axograph 4.5 verwendet [CLEMENTS und BEKKERS 1997]. Zuerst wurde folgende doppelt exponentielle Funktion als Template definiert.

\section{$f(t)=\exp (-t /$ rise-time $)-\exp (-t /$ decay-time $)$}

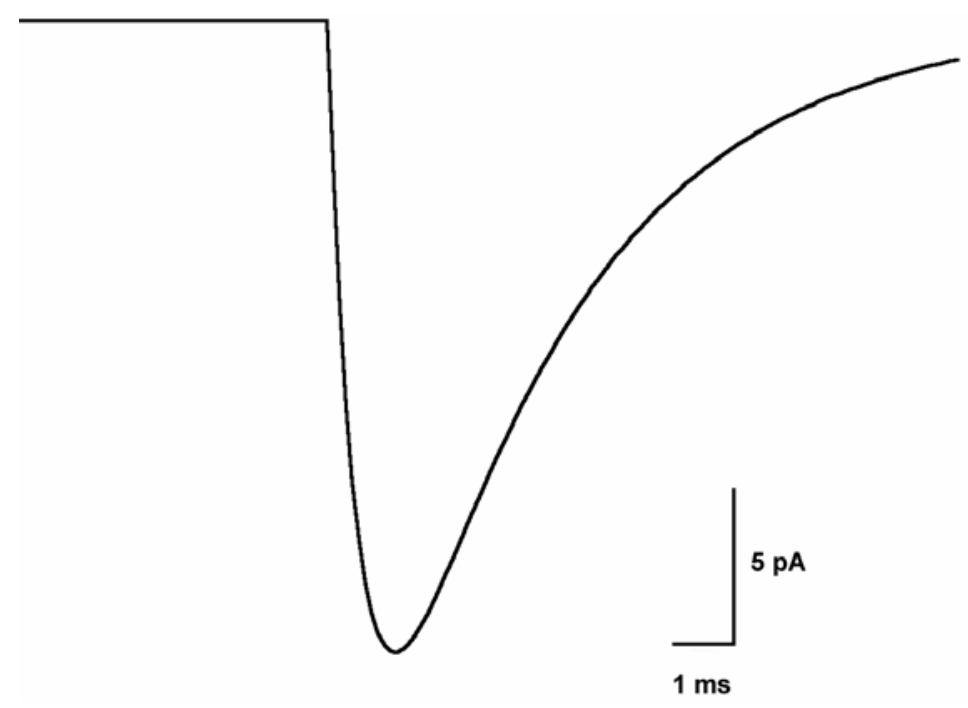

Abb. 15: Mini-Template

Auf das Muster treffen die im Text beschriebenen Parameter zu. Es stellt ein idealisiertes mEPSC dar und kann so als Detektionsvorlage bei der Analyse genutzt werden. 
Weitere Parameter wurden wie folgt festgelegt: Template Amplitude -20 pA; Template risetime 0,5 ms; Template decay-time $5 \mathrm{~ms}$; Ausgangslinie vor dem nächsten Ereignis $5 \mathrm{~ms}$ und totale Template-Länge $30 \mathrm{~ms}$ (s. Abb.). Diese Parameter entsprechen möglichst genau dem mittleren Zeitverlauf der mEPSC. Dieses Template lief als Detektionsvorlage über die Datenspur und erkannte so mEPSC.

Die detektierten mEPSC wurden pro Zelle gemittelt und nach Amplitude, Ladung und Frequenz analysiert. 


\section{Ergebnisse}

\subsection{Makroskopischer Phänotyp der APP- und APLP- Knockout-Linien}

Im Folgenden werden Vorarbeiten aus anderen Publikationen zusammengefasst. Danach wird in dieser Arbeit ausführlich die Charakterisierung der APP/APLP1/APLP2TKO gegenüber dem APP-SKO vorgestellt.

\subsubsection{Die APP-Knockout-Linie}

Es sind drei unterschiedliche APP-Knockouts beschrieben [MULLER et al. 1994; ZHENG et al. 1995; LI et al. 1996]. Es soll nur auf den in unserer Arbeit verwendeten Knockout, die 200 kb-Deletion im APP-Gen, eingegangen werden [LI et al. 1996]. Der makroskopische Phänotyp wurde erstmals 1999 beschrieben [MAGARA et al. 1999].

MAGARA et al. fiel auf, dass bei APP-defizienten Mäusen das Hirngewicht durchschnittlich um 10\% reduziert ist und Defekte im Bereich der hippocampalen Commissuren auftreten. Ebenfalls wurde mit erhöhter Frequenz eine Agenesie bzw. Dysgenesie des Corpus Callosum beobachtet.

\subsubsection{Die APP/APLP1-Doppel-Knockout-Linie}

Der APLP1-KO ist lebensfähig, hat normale lokomotorische Aktivität, keine morphologischen Besonderheiten in Hirnschnitten, nur ein um 10\% reduziertes Körpergewicht. Auch die nachfolgende Analyse der APP/APLP1-DKO-Mäuse ergab keinen ersichtlichen makroskopischen Phänotyp. Sie sind lebens- und fortpflanzungsfähigund weisen keine offensichtlichen Abweichungen auf. Lediglich ein geringfügig reduziertes Körpergewicht fiel auf [HEBER et al. 2000].

\subsubsection{Die APP/APLP2-Doppel-Knockout-Linie}

APLP2-KO-Mäuse sind ebenfalls lebens- und fortpflanzungsfähig und weisen keine morphologischen Besonderheiten auf. Währenddessen sind APP/APLP2-DKO-Mäuse nur eingeschränkt lebens- und fortpflanzungsfähig. 80\% der Mäuse sterben innerhalb einer Woche nach Geburt. Die verbliebenen Mäuse haben ein um 20-30\% reduziertes 
Körpergewicht sowie neurologische Auffälligkeiten [VON KOCH et al. 1997; HEBER et al. 2000].

\subsubsection{Die APP/APLP1/APLP2-Triple-Knockout-Linie}

Morphologisch wurden die APP/APLP1/APLP2-TKO-Mäuse bereits von einer anderen Arbeitsgruppe charakterisiert. Die TKO-Mäuse werden in Verhältnissen nach den Mendelschen Regeln geboren und sterben kurz nach der Geburt. Es treten Schädelund Hirndysplasien gehäuft auf [HERMS et al. 2004].

Für unsere Arbeit wurden aufgrund der erhöhten postnatalen Letalität die Tiere embryonal präpariert (E17 bis E18). Die erhaltenen Embryonen wurden genotypisiert; wie erwartet entsprach die Verteilung der Genotypen den Mendelschen Regeln.

Die aufgetretene Abweichung in der Anzahl der TKO-Tiere ist nicht signifikant. In Abb. 16 und Tab. 7 findet sich eine Gegenüberstellung der aufgetretenen und erwarteten Anzahl von Tieren.

Bei der Präparation fiel auf, dass einige Tiere kleiner als der Rest des Wurfes waren. Bei der nachfolgenden Bestimmung des Genotyps zeigte sich, dass diese Tiere präferentiell TKO waren.

\begin{tabular}{lccccccccc} 
& $\mathbf{1}$ & $\mathbf{2}$ & $\mathbf{3}$ & $\mathbf{4}$ & $\mathbf{5}$ & $\mathbf{6}$ & $\mathbf{7}$ & $\mathbf{8}$ & $\mathbf{9}$ \\
\hline Genotyp & & & & & & & & & $-/-$ \\
APP & $-/-$ & $-/-$ & $-/-$ & $-/-$ & $-/-$ & $-/-$ & $-/-$ & $-/-$ & $-/-$ \\
APLP1 & $+/+$ & $+/-$ & $-/-$ & $-/-$ & $+/-$ & $+/+$ & $+/+$ & $+/-$ & $-/-$ \\
APLP2 & $+/+$ & $+/+$ & $+/+$ & $+/-$ & $+/-$ & $+/-$ & $-/-$ & $-/-$ & -1 \\
geboren & 21 & 34 & 25 & 41 & 91 & 41 & 21 & 27 & 11 \\
& $(6,7 \%)$ & $(10,9 \%)$ & $(8 \%)$ & $(13,1 \%)$ & $(29,2 \%)$ & $(13,1 \%)$ & $(6,7 \%)$ & $(8,6 \%)$ & $(3,5 \%)$ \\
erwartet & 19,5 & 39 & 19,5 & 39 & 78 & 39 & 19,5 & 39 & 19,5 \\
& $(6,25 \%)$ & $(12,5 \%)$ & $(6,25 \%)$ & $(12,5 \%)$ & $(25 \%)$ & $(12,5 \%)$ & $(6,25 \%)$ & $(12,5 \%)$ & $(6,25 \%)$
\end{tabular}

Tab. 7: Aufstellung der Genotypen

Es wurden insgesamt 6 Kulturen mit einer Gesamtzahl von 312 Tieren durchgeführt. Die Nummerierung der Genotypen findet sich auch in Abb. 16 wieder. 


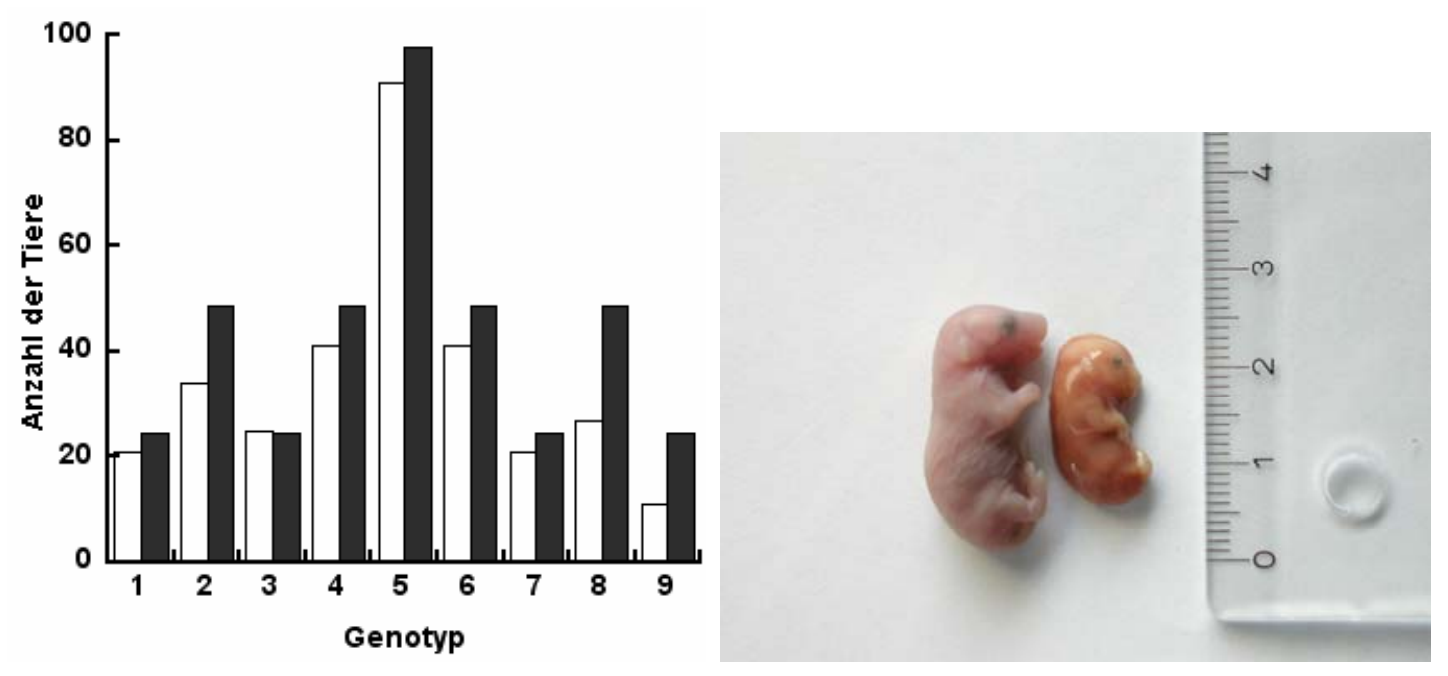

Abb. 16: Genotypen

Grafische Darstellung der Genotypen (links). Rechts sind Tiere eines Wurfes abgebildet. Das linke Tier ist ein SKO, während das deutlich kleinere Tier rechts genotypisch ein TKO ist.

\subsection{Synaptische Transmission}

In der Einleitung wurde bereits die Bedeutung einiger synaptischer Proteine beschrieben. Auch die Proteine der APP-Familie werden mit synaptischer Transmission in Verbindung gebracht. Um die Funktion der Proteine der APP-Familie in der synaptischen Transmission näher aufzuklären, eignen sich elektrophysiologische Methoden besonders gut.

Es sind unterschiedliche Einzelschritte der synaptischen Transmission mittels der patch-clamp-Technik überprüfbar. Defekte in der synaptischen Transmission in Knockout-Tieren geben Hinweise auf Wirkungsart und -ort der ausgeschalteten Proteine.

Besonders mutante Mauslinien, deren homozygote Nachkommen nicht lebensfähig sind, können sehr gut mittels der autaptischen Kultur elektrophysiologisch charakterisiert werden [AUGUSTIN et al. 1999; REIM et al. 2001; VAROQUEAUX et al. 2002]. Die so kultivierten Neuronen können sich bis zu einem Alter von mehreren Wochen normal weiterentwickeln und erlauben so in vitro-Studien. Wie in Kapitel 2 beschrieben, sind autaptische Kulturen elektrophysiologisch einfach zugänglich durch die Verwendung von nur einer Elektrode. Die Applikation von Pharmaka ist mittels schneller Perfusion ebenfalls leicht möglich. Ein weiterer Vorteil besteht darin, das bildgebende Techniken (z.B. Immunfärbungen, FM 1-43-Experimente) leicht anwendbar sind.

Nachteilig ist dagegen, dass besonders viele Einzelschritte für die autaptische Kultur notwendig sind. Daraus ergibt sich die Gefahr von Qualitätsschwankungen, die jedoch dahingehend eingedämmt werden sollten, dass jeweils Material zweier Gruppen von Nachkommen kultiviert wurde. 
Mittlerweile sind viele neuronale Phänotypen in autaptischen Kulturen molekulargenetisch modifizierter Mauslinien bekannt.

\subsubsection{Alter der Neuronen}

Die Präparation exzitatorischer Neurone erfolgte am Tag E17-E18. Nach Ausbringen der Neurone auf Kulturplatten wird normalerweise acht bis zehn Tage gewartet, damit sich die Fortsätze, Axon und Dendriten, ausbilden können. Dann lassen sich erste synaptische Ströme nachweisen, die mit dem Alter der Neuronen in der Amplitude ansteigen.

\subsubsection{Besonderheiten der der Triple-Knockout-Kultur}

Bei in unserer Arbeit beschriebenen autaptischen Kulturen exzitatorischer Neuronen zeigte sich, dass bereits ab Tag 7 deutliche synaptische Transmission stattfand.

Da die Präparation überwiegend embryonal erfolgte, konnten aussagekräftige postsynaptische Ströme durchschnittlich 48 Stunden früher als in Kulturen anderer Mauslinien gemessen werden. Um diese Unterschiede noch feiner aufzulösen, erfolgt die Darstellung der Ergebnisse untergliedert in folgende Kategorien: Tag 7 \& 8, Tag 9, Tag 10 und Tage 11 bis 15. Es sind jeweils die Tage in Kultur (in vitro) angegeben.

\subsubsection{Evozierte postsynaptische Ströme}

Um die synaptische Funktion zu überprüfen, werden zunächst Aktionspotenziale ausgelöst. Dazu wird am Zellsoma für $2 \mathrm{~ms}$ auf $0 \mathrm{mV}$ depolarisiert. Die Ausbreitung erfolgt entlang des Axons und erreicht die Präsynapse. Infolge der Depolarisation öffnen spannungsgesteuerte Calciumkanäle. Der Einstrom von Calciumionen und die damit verbundene Erhöhung der intrazellulären Calciumkonzentration bewirkt die Aktivierung des synaptischen Freisetzungsapparates. Unsere Arbeit hat ihren Fokus auf exzitatorischen Neuronen, demzufolge wird hauptsächlich Glutamat aus den Vesikeln in den synaptischen Spalt freigesetzt. Es aktiviert an der postsynaptischen Membran Glutamatrezeptoren vom AMPA- und NMDA-Typ. Die Bindung des Agonisten bewirkt die Porenöffnung der Rezeptoren, und $\mathrm{Na}^{+}-, \mathrm{K}^{+}-$und auch $\mathrm{Ca}^{2+}-$ Ionen strömen einwärts. Bei dem eingestellten Haltepotenzial von $-75 \mathrm{mV}$ ist der Strom größtenteils durch $\mathrm{Na}^{+}$-Ionen bedingt und hat durch die Einwärtsrichtung ein negatives Vorzeichen. Diese Depolarisation mit nachfolgendem Strom wird als excitatory postsynaptic current (EPSC) bezeichnet. In den Abbildungen und im Text sind jedoch jeweils Absolutwerte angegeben. 
Da die Depolarisation somatisch erfolgt, werden alle aktiven Synapsen stimuliert, die Antwort ist eine sogenannte Summenantwort. Der erste wichtige Schritt in der funktionellen Charakterisierung der synaptischen Transmission ist die Bestimmung der initialen Amplitude und Ladung des postsynaptischen Stroms. Dieser sensitive, aber unspezifische Test kann erste Schlussfolgerungen zulassen und bestimmt weiterführende Experimente.

Es wurden Neuronen von APP-defizienten Mäusen sowie Mäusen, denen alle drei Proteine der APP-Familie fehlten, gemessen. Nachfolgend werden Mäuse mit dem Genotyp APP-//APLP1 ${ }^{++/} / \mathrm{APLP}^{+/+}$als Single-Knockout (SKO) und Mäuse mit dem Genotyp APP-//APLP1-//APLP2---als Triple-Knockout (TKO) bezeichnet.

Bestimmt wurden zunächst Amplitude und Ladung (Abb. 17 und 18, Tab. 8).

Bereits ab dem 7. Tag in Kultur (wie unter 3.2.1.1. erwähnt 48 Stunden früher als in einer üblichen Kultur P0) konnten deutliche postsynaptische Antworten gemessen werden.

Die EPSC in der SKO-Gruppe ergaben eine mittlere Amplitude von 3,09 \pm 0,26 nA und eine mittlere Ladung von 19,40 \pm 1,78 pC (jeweils $n=93$ aus sechs Kulturen). Dagegen waren die EPSC der TKO-Gruppe signifikant verändert. Die Amplitude war um 24,2\% auf 3,84 \pm 0,21 nA erhöht, während die Ladung um 30,6\% auf 25,33 $\pm 1,9$ pC vergrößert war $(\mathrm{n}=116, \mathrm{p}<0,05)$.

Ein genaueres Bild ergibt sich bei der Betrachtung der Einzeltage.

An den Tagen 7 und 8 war die EPSC-Amplitude in der TKO-Gruppe um 83,7\% größer als in der SKO-Gruppe (SKO: 1,47 $\pm 0,29 \mathrm{nA}, \mathrm{n}=18$; TKO: 2,69 $\pm 0,32 \mathrm{nA}, \mathrm{n}=19$; $\mathrm{p}<$ 0,01). Die EPSC-Ladung erhöhte sich um 95,5\% (SKO: 8,07 $\pm 1,7$ pC, n = 18; TKO: 15,79 $\pm 2,5$ pC, $\mathrm{n}=19 ; \mathrm{p}<0,05)$ (Abb. 17 und 18, Tab. 8).

Auch in den Folgetagen waren Amplitude und Ladung größer, aber nicht signifikant verändert (Tab. 8). 


\begin{tabular}{cccc} 
Tage in vitro & Genotyp & Amplitude (nA \pm S.E.M.) & Ladung (pC \pm S.E.M.) \\
\hline \multirow{2}{*}{$+\mathbf{8}$} & $\mathrm{SKO}(\mathrm{n}=18)$ & $1,47 \pm 0,29$ & $8,07 \pm 1,7$ \\
& $\mathrm{TKO}(\mathrm{n}=19)$ & $2,69 \pm 0,32$ & $15,79 \pm 2,5$ \\
$\mathbf{9}$ & $\mathrm{SKO}(\mathrm{n}=20)$ & $2,65 \pm 0,39$ & $14,56 \pm 3,02$ \\
& $\mathrm{TKO}(\mathrm{n}=25)$ & $3,32 \pm 0,38$ & $20,43 \pm 3,2$ \\
\multirow{2}{*}{$\mathbf{1 0}$} & $\mathrm{SKO}(\mathrm{n}=22)$ & $4,13 \pm 0,57$ & $24,7 \pm 3,32$ \\
& $\mathrm{TKO}(\mathrm{n}=26)$ & $4,51 \pm 0,48$ & $26,72 \pm 3,03$ \\
\multirow{2}{*}{$\mathbf{1 1 - 1 5}$} & $\mathrm{SKO}(\mathrm{n}=33)$ & $3,54 \pm 0,49$ & $24,96 \pm 3,52$ \\
& $\mathrm{TKO}(\mathrm{n}=46)$ & $4,20 \pm 0,37$ & $31,15 \pm 3,87$ \\
\multirow{2}{*}{$\mathbf{7 - 1 5}$} & $\mathrm{SKO}(\mathrm{n}=93)$ & $3,09 \pm 0,26$ & $19,40 \pm 1,78$ \\
& $\mathrm{TKO}(\mathrm{n}=116)$ & $3,84 \pm 0,21$ & $25,33 \pm 1,9$
\end{tabular}

Tab. 8: Amplitude und Ladung der EPSCs 

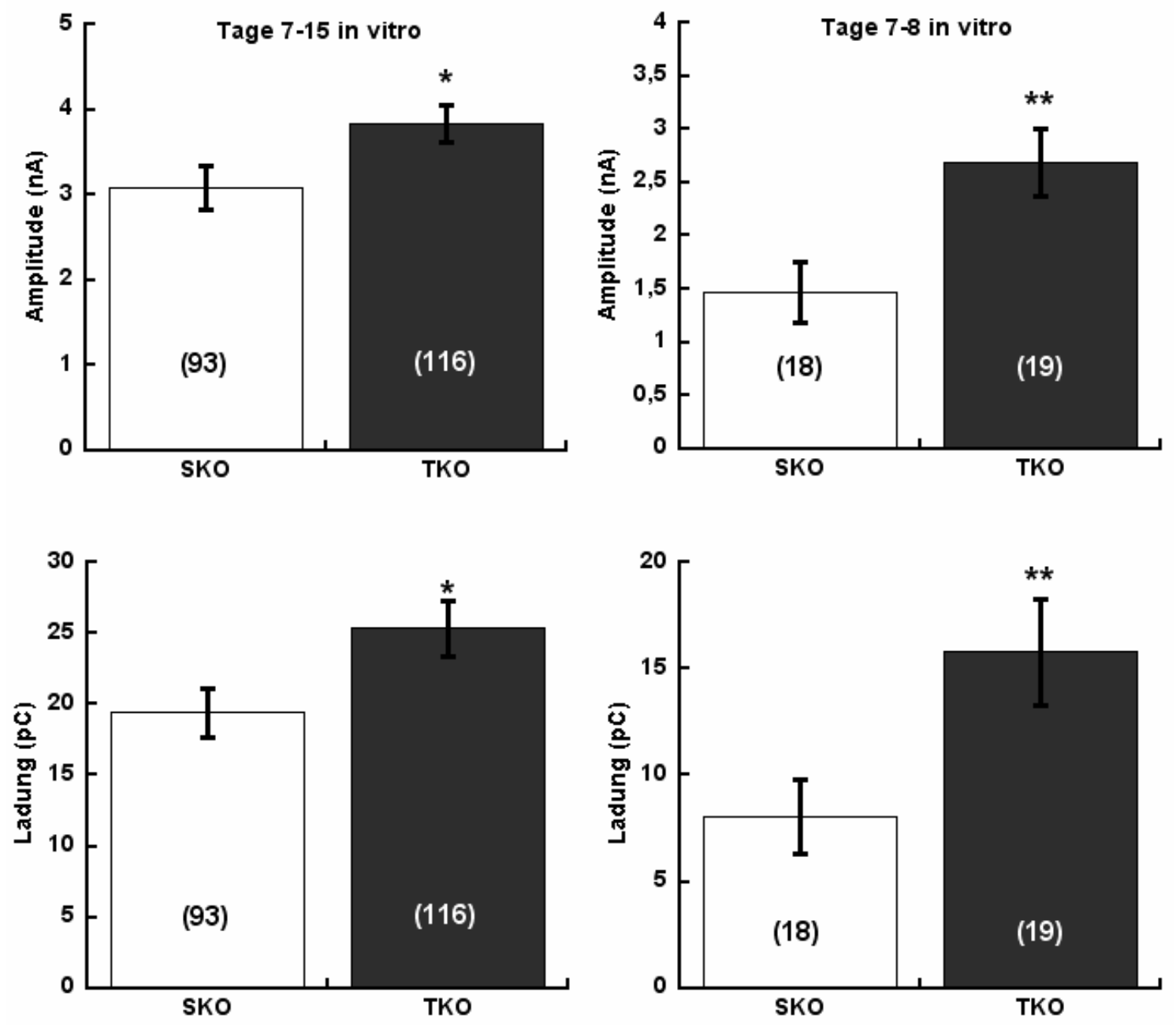

Abb. 17: Amplitude und Ladung exzitatorischer postsynaptischer Ströme Obere Reihe: Mittlere Amplitude von SKO- und TKO-Tieren.

Untere Reihe: Mittlere Ladung von SKO- und TKO-Tieren.

Jeweils links die Tage 7 bis 15 in vitro, rechts die Tage 7 und 8 in vitro.

Zahlen in Klammern geben die Stichprobengröße an. Signifikanzniveau wie unter 2.3.4. beschrieben. 


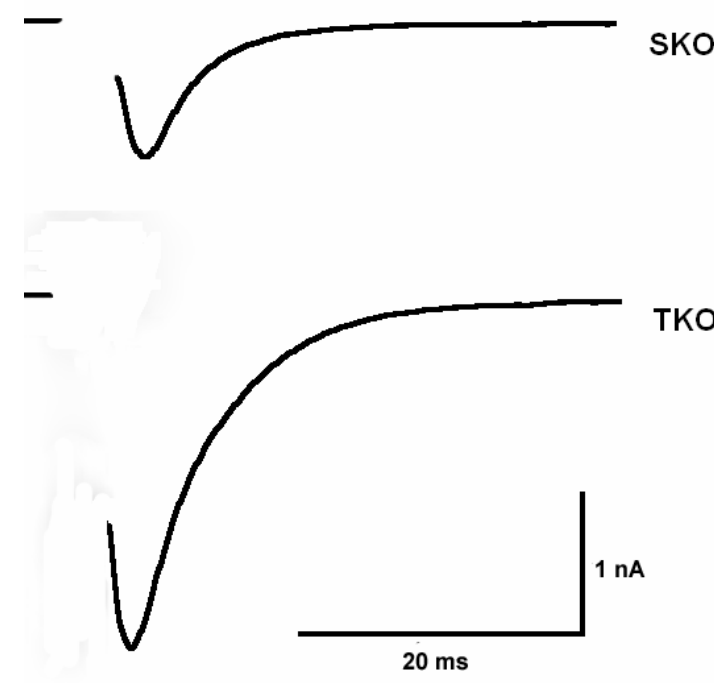

7-8 Tage in vitro
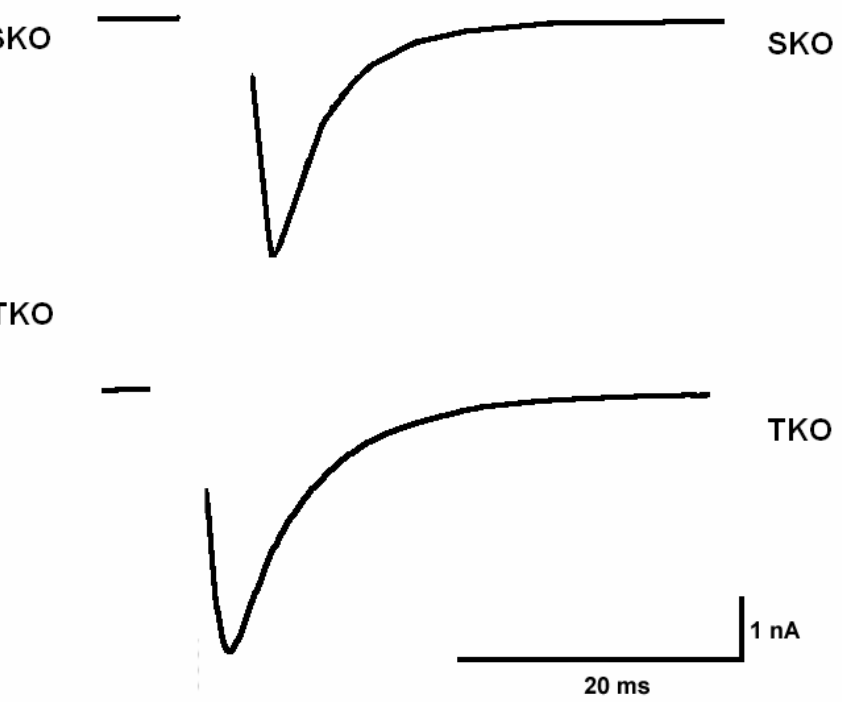

7-15 Tage in vitro

Abb. 18: Evozierte exzitatorische postsynaptische Ströme

Stimulationsartefakt und Ströme des Aktionspotenzials sind ausgeblendet. Man beachte die unterschiedlichen Skalen.

Demzufolge ist synaptische Transmission in TKO-Mäusen nicht nur möglich, sondern sogar tendenziell stärker. Um diesen überraschenden Befund näher zu untersuchen, wurden weitere Experimente durchgeführt, die den möglichen Wirkungsort der Proteine aus der APP-Familie eingrenzen sollten.

Sowohl prä- als auch postsynaptische Veränderungen können zu einer Veränderung der synaptischen Transmission beitragen. Auf der präsynaptischen Ebene kann eine Veränderung in der Anzahl fusionsbereiter Vesikel oder eine erhöhte Freisetzungswahrscheinlichkeit vorliegen. Auch auf der postsynaptischen Seite trägt z. B. eine größere Rezeptordichte zu einer größeren Antwort bei. Letztendlich führen auch morphologische Veränderungen zu einer Veränderung der synaptischen Transmission. Die Neuronen können sich in Größe und/oder Anzahl der Synapsen unterscheiden.

Bei Mäusen, die für eines oder mehrere Proteine der APP-Familie defizient sind, stellt sich außerdem die Frage, inwieweit redundante Funktionen der Proteine untereinander zur Kompensation beitragen.

\subsubsection{Die Poolgröße der sekretionsbereiten Vesikel}

Fusionskompetente Vesikel müssen mehrere Schritte durchlaufen, um diesen Status zu erlangen. Sobald ein Vesikel die präsynaptische Aktive Zone erreicht, nähert es sich der Plasmamembran. Der Kontakt mit der Plasmamembran wird Docking genannt. Nach 
dem Docking findet das ATP-abhängige Priming statt, welches dazu dient, die Vesikel in einen fusionskompetenten Zustand zu versetzen. Priming fasst alle Prozesse zusammen, die den Aufbau des Freisetzungsapparates an der Präsynapse beinhalten. Nachdem das Priming abgeschlossen ist, ist ein Vesikel fusionskompetent und steht für die Freisetzung bereit. Wenn ein Aktionspotenzial an der Präsynapse eintrifft, nachfolgend Calcium einströmt, wird durch diese Mechanismen die Fusion der Vesikel mit der Plasmamembran komplettiert.

Fusionskompetente Vesikel sind in einem Pool zusammengefasst, der als Readily Releasable Pool (RRP) bezeichnet wird. Dem gegenüber steht der Reserve-Pool, in dem Vesikel zusammengefasst sind, die nach extensiver synaptischer Stimulation den RRP wiederauffüllen [MURTHY und STEVENS 1999]. RRP und der Reserve-Pool werden gemeinsam als Recycling-Pool bezeichnet.

Nicht nur Aktionspotenziale können zur Freisetzung aus dem RRP führen, auch hyperosmotische Stimulation führt zur Transmitterausschüttung [ROSENMUND und STEVENS 1996]. Wie bereits in Kapitel 2 beschrieben, erfolgte die Stimulation mit 500 mM Saccharose über mehrere Sekunden. Zur Berechnung des RRP wurde die transiente Komponente des Einwärtsstroms integriert und führte zu folgenden Ergebnissen:

Die Pool-Größe der fusionskompetenten Vesikel war nicht signifikant verändert. Auch eine Auflösung in einzelne Tage in vitro ergab keine Veränderung (siehe Tab. 9, Abb. $19)$.

\begin{tabular}{ccc} 
Tage in vitro & Genotyp & Größe des RRP (pC \pm S.E.M.) \\
\hline \multirow{2}{*}{$+\mathbf{8}$} & SKO $(\mathrm{n}=11)$ & $101 \pm 28$ \\
& TKO $(\mathrm{n}=15)$ & $127 \pm 28$ \\
\multirow{2}{*}{$\mathbf{4}$} & $\mathrm{SKO}(\mathrm{n}=17)$ & $130 \pm 52$ \\
& $\mathrm{TKO}(\mathrm{n}=18)$ & $115 \pm 40$ \\
\multirow{2}{*}{$\mathbf{1 0}$} & $\mathrm{SKO}(\mathrm{n}=17)$ & $223 \pm 46$ \\
& $\mathrm{TKO}(\mathrm{n}=22)$ & $122 \pm 27$ \\
\multirow{2}{*}{$\mathbf{1 1 - 1 5}$} & $\mathrm{SKO}(\mathrm{n}=27)$ & $164 \pm 23$ \\
& $\mathrm{TKO}(\mathrm{n}=37)$ & $248 \pm 50$ \\
\multirow{2}{*}{$\mathbf{7 - 1 5}$} & $\mathrm{SKO}(\mathrm{n}=72)$ & $166 \pm 19$ \\
& $\mathrm{TKO}(\mathrm{n}=92)$ & $172 \pm 23$
\end{tabular}

Tab. 9: Größe des Readily Releasable Pool (RRP) 

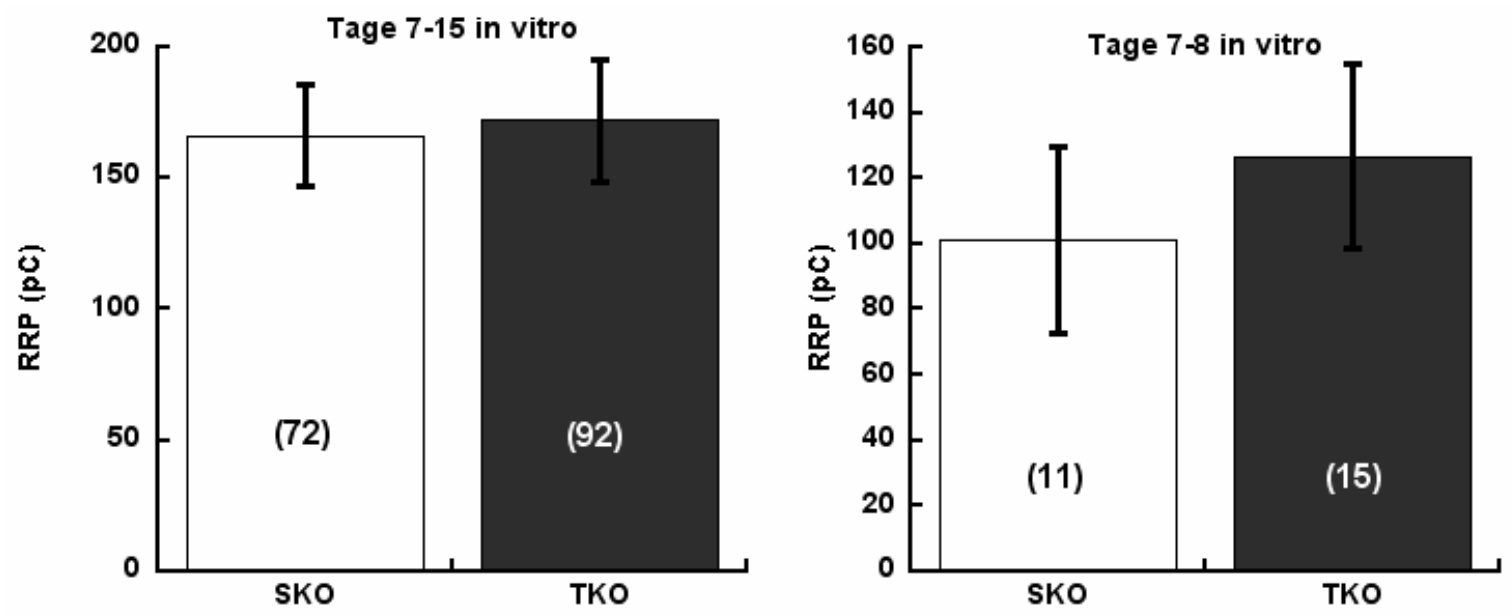

Abb. 19: Größe des Readily Releasable Pool

Die Ladung der transienten Komponente bei Applikation hypertoner Lösung ergibt die Größe des RRP.

\subsubsection{Vesikuläre Freisetzungswahrscheinlichkeit}

Es muss zwischen vesikulärer und synaptischer Freisetzungswahrscheinlichkeit unterschieden werden.

Die synaptische Freisetzungswahrscheinlichkeit ist die Wahrscheinlichkeit, mit der mindestens ein Vesikel nach einem Aktionspotenzial an einer Aktiven Zone ausgeschüttet wird. Wenn sowohl die durchschnittliche Ladung eines EPSC als auch die Gesamtladung des RRP bekannt ist, lässt sich der Anteil des RRP berechnen, der durchschnittlich nach einem Aktionspotenzial freigesetzt wird. Dieser Anteil wird als vesikuläre Freisetzungswahrscheinlichkeit bezeichnet.

In dieser Arbeit haben wir uns vornehmlich auf die vesikuläre Freisetzungswahrscheinlichkeit konzentriert.

Der Quotient aus der Ladung des EPSC und der Ladung des RRP ist das errechnete Resultat der vesikulären Freisetzungswahrscheinlichkeit.

Im Vergleich der beiden untersuchten Gruppen zeigte sich, dass die vesikuläre Freisetzungswahrscheinlichkeit nicht signifikant verändert war (SKO: 20,3 $\pm 1,7 \%, \mathrm{n}=72$; TKO: $24,4 \pm 1,6 \%$, n=92). Auch eine Auflösung in Einzeltage erbrachte erneut keine Veränderung (Tab. 10 und Abb. 20). 


\begin{tabular}{ccc}
$\begin{array}{c}\text { Tage } \\
\text { in vitro }\end{array}$ & Genotyp & Vesikuläre Freisetzungswahrscheinlichkeit (\% \pm S.E.M.) \\
\hline \multirow{2}{*}{$+\mathbf{8}$} & $\mathrm{SKO}(\mathrm{n}=11)$ & $17,5 \pm 3,5$ \\
& $\mathrm{TKO}(\mathrm{n}=15)$ & $18,4 \pm 3,4$ \\
$\mathbf{9}$ & $\mathrm{SKO}(\mathrm{n}=17)$ & $20,2 \pm 3,6$ \\
& $\mathrm{TKO}(\mathrm{n}=18)$ & $29,5 \pm 3,1$ \\
\multirow{2}{*}{$\mathbf{1 0}$} & $\mathrm{SKO}(\mathrm{n}=17)$ & $24,8 \pm 4,9$ \\
& $\mathrm{TKO}(\mathrm{n}=22)$ & $31,4 \pm 3,5$ \\
\multirow{2}{*}{$\mathbf{1 1 - 1 5}$} & $\mathrm{SKO}(\mathrm{n}=27)$ & $18,8 \pm 2,3$ \\
& $\mathrm{TKO}(\mathrm{n}=37)$ & $20,1 \pm 2,5$ \\
\multirow{2}{*}{$\mathbf{7 - 1 5}$} & $\mathrm{SKO}(\mathrm{n}=72)$ & $20,3 \pm 1,7$ \\
& $\mathrm{TKO}(\mathrm{n}=92)$ & $24,4 \pm 1,6$
\end{tabular}

Tab. 10: Vesikuläre Freisetzungswahrscheinlichkeit
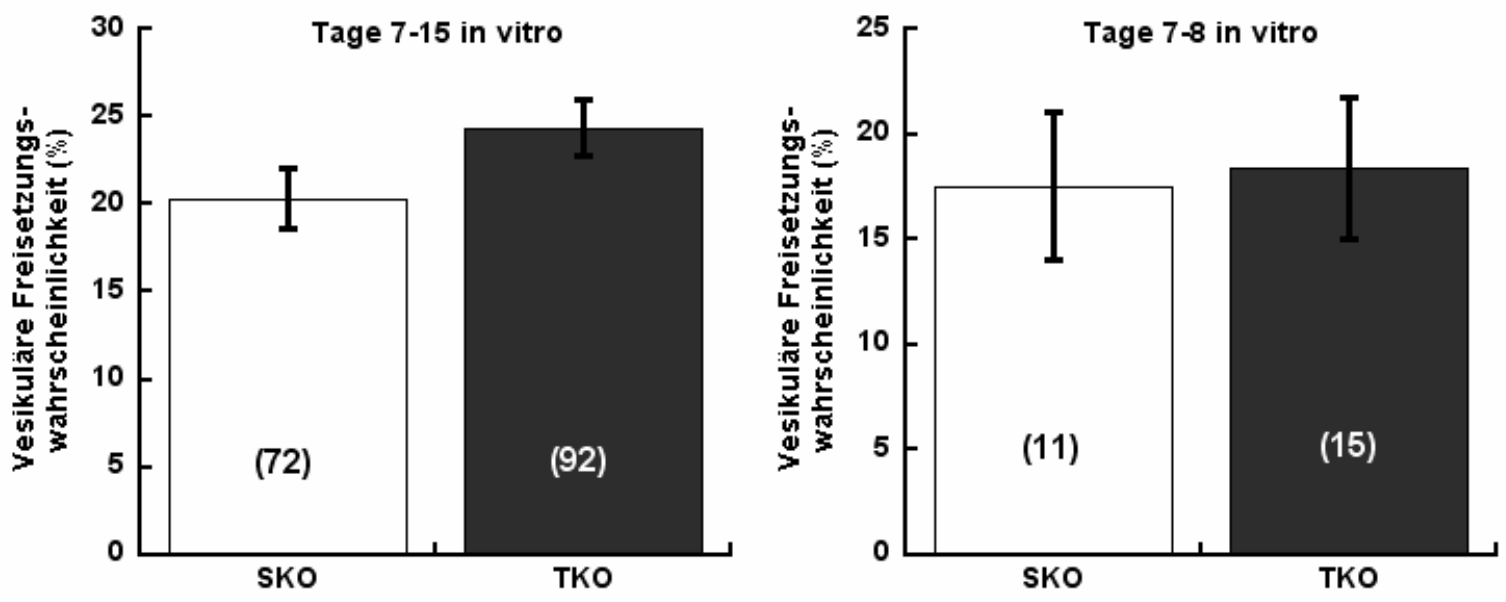

Abb. 20: Vesikuläre Freisetzungswahrscheinlichkeit

Sie ergibt sich aus dem Quotienten der Ladung eines einzelnen EPSC und der Ladung des RRP.

\subsubsection{Kurzzeitplastizität}

Synaptische Transmission ist ein dynamischer Prozess. Wiederholte Aktionspotenzialreizung führt zu Veränderungen sowohl auf der prä- als auch auf der postsynaptischen Seite, die potenzierend und/oder reduzierend auf die Amplitude der synaptischen Antwort wirken. 
Kurzzeitplastizität bezeichnet die Veränderung der synaptischen Antwort bei Stimulation, die nur Sekunden bis Minuten andauert. Die synaptische Antwort wird durch diese Stimulation moduliert.

Eine Veränderung der Kurzzeitplastizität reflektiert oft eine Veränderung der Effizienz der synaptischen Transmission und wird daher zur Detektion von eventuellen Veränderungen im synaptischen Apparat herangezogen.

Es wurden in beiden Gruppen Experimente zur Kurzzeitplastizität durchgeführt. Gewählt wurde dazu eine mittlere Stimulationsfrequenz von $10 \mathrm{~Hz}$.

Die Quantifizierung der synaptischen Depression erfolgte nach folgendem Prinzip: Von den letzten vier Stimuli der $10 \mathrm{~Hz}$-Stimulation wurde der Durchschnitt gebildet und auf den ersten Stimulus normalisiert.

Sowohl in Neuronen der SKO- als auch der TKO-Gruppe war nur synaptische Depression ohne signifikanten Unterschied zwischen den Gruppen zu beobachten (SKO 37,4 \pm $3,3 \%, \mathrm{n}=85$; TKO: $35,8 \pm 3,4 \%, \mathrm{n}=106$ ).

Auch bei der Auflösung in Einzeltage wurde kein signifikanter Unterschied gefunden (Tab. 11, Abb. 21).

\begin{tabular}{ccc} 
Tage in vitro & Genotyp & Depression $(\% \pm$ S.E.M.) \\
\hline \multirow{2}{*}{$+\mathbf{8}$} & $\mathrm{SKO}(\mathrm{n}=16)$ & $30,4 \pm 7,1$ \\
& $\mathrm{TKO}(\mathrm{n}=18)$ & $37,0 \pm 9,1$ \\
$\mathbf{9}$ & $\mathrm{SKO}(\mathrm{n}=19)$ & $27,9 \pm 5,2$ \\
& $\mathrm{TKO}(\mathrm{n}=23)$ & $35,8 \pm 9,0$ \\
$\mathbf{1 0}$ & $\mathrm{SKO}(\mathrm{n}=21)$ & $40,4 \pm 6,1$ \\
& $\mathrm{TKO}(\mathrm{n}=25)$ & $25,5 \pm 5,0$ \\
\multirow{2}{*}{$\mathbf{1 1 - 1 5}$} & $\mathrm{SKO}(\mathrm{n}=29)$ & $43,6 \pm 6,8$ \\
& $\mathrm{TKO}(\mathrm{n}=40)$ & $41,8 \pm 5,3$ \\
$\mathbf{7 - 1 5}$ & $\mathrm{SKO}(\mathrm{n}=85)$ & $37,4 \pm 3,3$ \\
& $\mathrm{TKO}(\mathrm{n}=106)$ & $35,8+3,4$
\end{tabular}

Tab. 11: Kurzzeitplastizität 

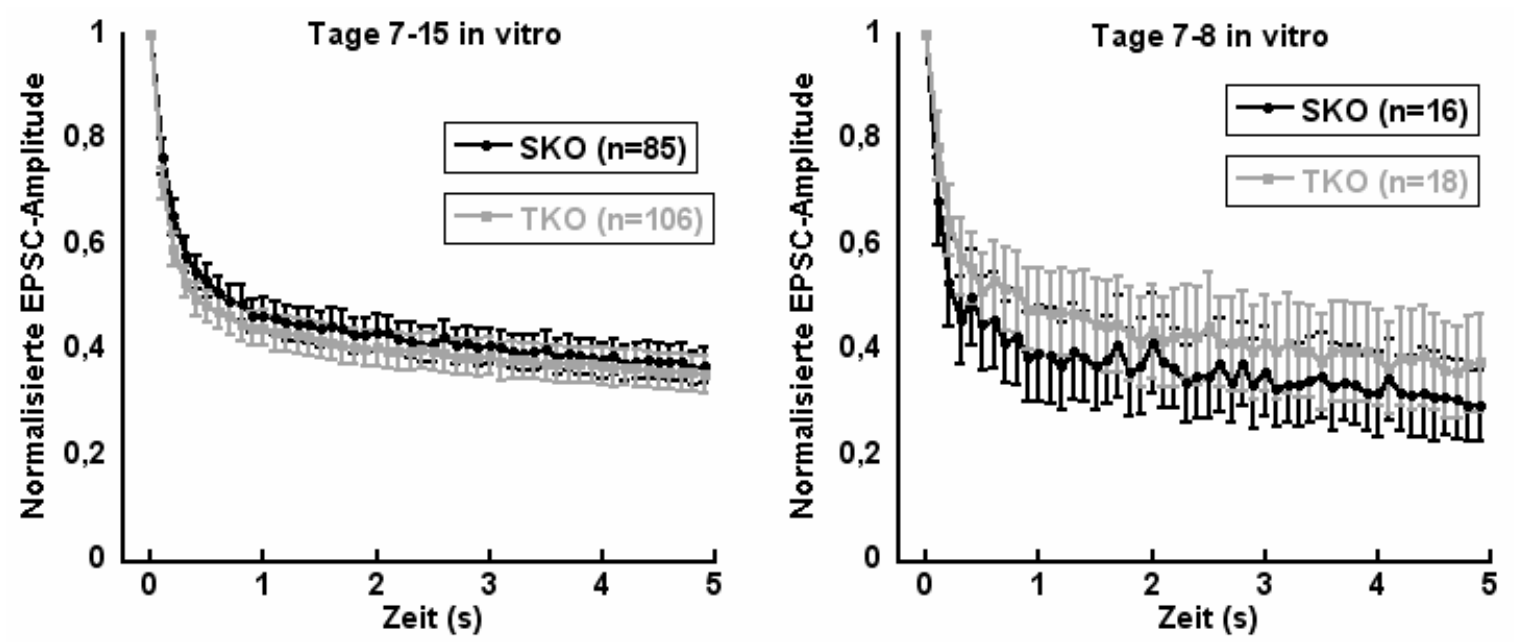

Abb. 21: Kurzzeitplastizität

Es erfolgte eine Stimulation bei $10 \mathrm{~Hz}$. 50 depolarisierende Pulse zu $0 \mathrm{mV}$ verursachten eine deutliche Depression des postsynaptischen Stromes.

Es wurden somit weder Unterschiede in der Größe des RRP noch der vesikulären Freisetzungswahrscheinlichkeit noch in der Kurzzeitplastizität gefunden. Alle drei Ergebnisse ergänzen sich gut. Es ist zu schlussfolgern, dass der zusätzliche Verlust von APLP1 und APLP2 im TKO keinen Einfluss auf die Größe des RRP, die vesikuläre Freisetzungswahrscheinlichkeit und die Kurzzeitplastizität im Vergleich mit SKO-Tieren (nur für APP defizient) hat.

\subsection{6 mEPSC}

Miniature excitatory postsynaptic currents, kurz mEPSC oder Minis genannt, treten ohne vorangehende Stimulation durch Aktionspotenziale oder hypertone Lösung auf. Diese spontane synaptische Transmission wird in ihren Eigenschaften durch verschiedene Parameter bestimmt. Eine eingehende Analyse der Minis gibt weitreichende Einsichten in die Funktion der Synapsen. Die Größe und die Kinetik der Antwort werden durch die postsynaptische Rezeptordichte, die Füllung der Vesikel mit Neurotransmitter und das Schaltverhalten der Glutamat-Rezeptoren bestimmt. Die Frequenz der spontanen synaptischen Transmission korreliert mit der Gesamtzahl der Vesikel im RRP und drückt auch aus, wie effizient Vesikel nach dem Priming fusionieren können.

Es wurden daher Amplitude, Ladung und Frequenz der mEPSC sowohl in der SKOals auch in der TKO-Gruppe bestimmt. Um spontane Aktionspotenziale zu verhindern, wurde während der Messung 0,3 $\mu \mathrm{M}$ TTX appliziert (Abb. 22 und 23). 

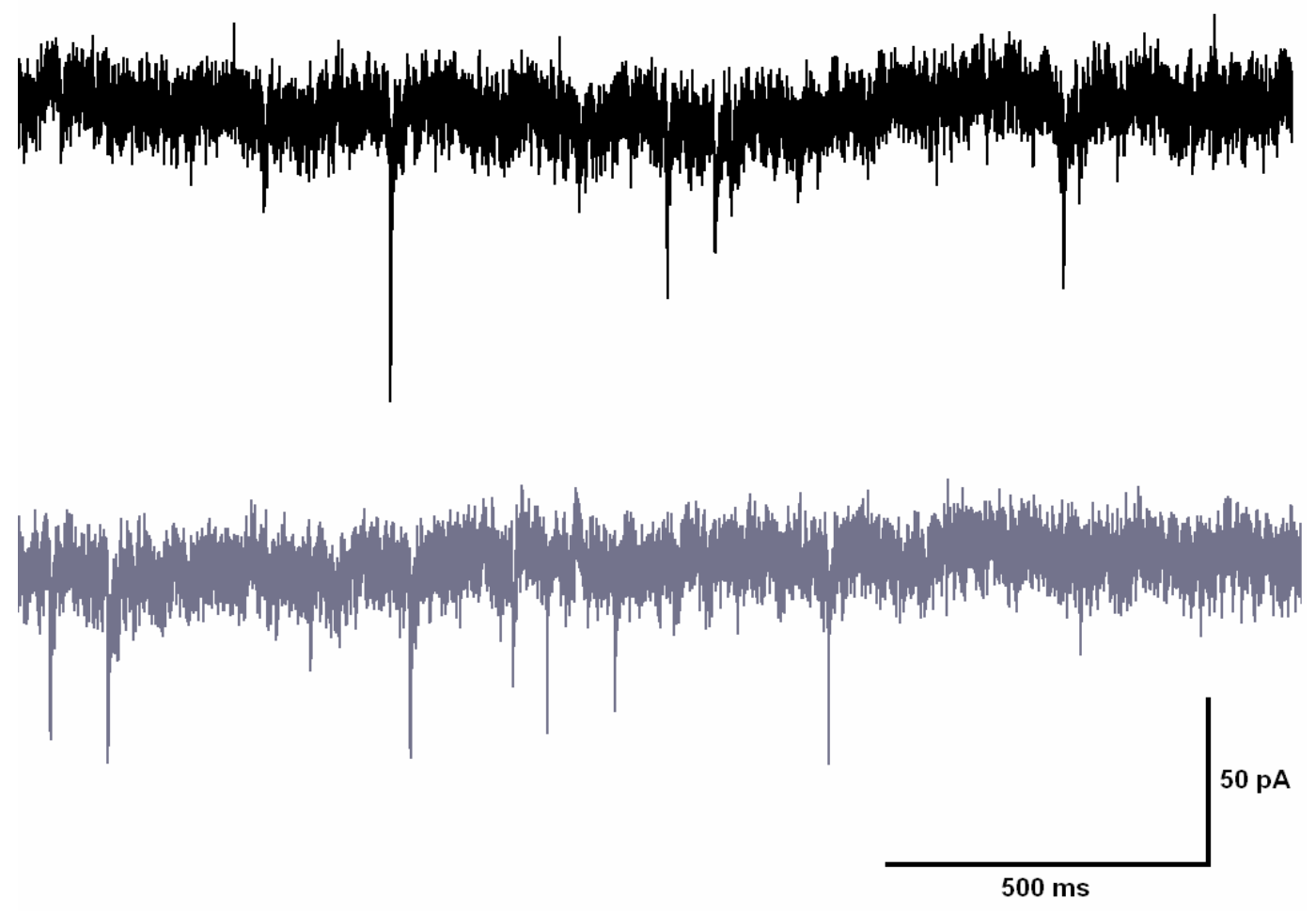

Abb. 22: Originalaufzeichnungen von mEPSC

Spontane synaptische Transmission wurde in Anwesenheit von 0,3 $\mu \mathrm{M}$ TTX gemessen. Oben SKO, unten TKO.
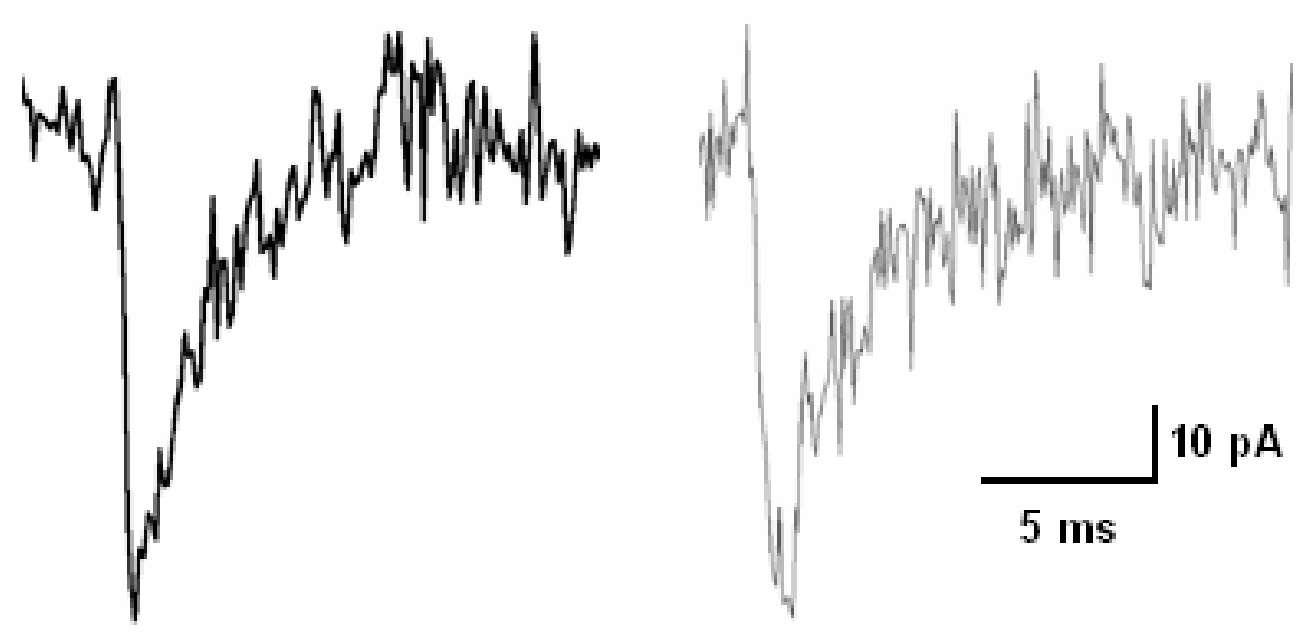

Abb. 23: Ausschnittsvergrößerung der mEPSC

Zur Verdeutlichung wurde aus der Originalaufzeichnung ein Ausschnitt vergrößert. Die mEPSC der SKOStichprobe (in schwarz, links) und TKO-Stichprobe (in grau, rechts) unterscheiden sich hinsichtlich Amplitude und Ladung nicht voneinander. 
Die Minis unterschieden sich weder in Amplitude noch in der Ladung (siehe Tab. 12, Abb. 24). Dafür wurde ein signifikanter Unterschied in der Mini-Frequenz festgestellt (SKO: 2,5 \pm 0,3 Hz, n=59; TKO: 4,5 $\pm 0,5 \mathrm{~Hz}, \mathrm{n}=66$; $\mathrm{p}<0,001$; Abb. 26). Bei der Auflösung in Einzeltage ergab sich ein genaueres Bild (Tab. 12, Abb. 26). Am Tag 7 und 8 zeichnete sich bereits ein Trend ab. Die Frequenz war zwar höher in der TKO-Gruppe, der Unterschied aber nicht signifikant (SKO: 1,5 \pm 0,3 Hz, n=11; TKO: 2,5 $\pm 1,0 \mathrm{~Hz}, \mathrm{n}=12$ ). Am Tag 9 war die Mini-Frequenz in der TKO-Gruppe signifikant erhöht (SKO: 1,9 \pm 0,2 Hz, $\mathrm{n}=14$; TKO: 3,9 $\pm 0,6 \mathrm{~Hz}, \mathrm{n}=16 ; \mathrm{p}<0,01)$. Am Tag 10 war die Mini-Frequenz noch deutlicher erhöht (SKO: 2,5 \pm 0,4 Hz, n=17; TKO: 6,9 $\pm 1,0 \mathrm{~Hz}, \mathrm{n}=21$; $\mathrm{p}<0,001$ ), während am Tag 11 bis 15 wiederum kein Unterschied festzustellen war (SKO: 3,9 $\pm 1,0 \mathrm{~Hz}, \mathrm{n}=17$; TKO: $3,6 \pm 0,9 \mathrm{~Hz}, \mathrm{n}=17)$.

\begin{tabular}{ccccc}
$\begin{array}{c}\text { Tage } \\
\text { in vitro }\end{array}$ & Genotyp & $\begin{array}{c}\text { Amplitude } \\
\text { (pA } \pm \text { S.E.M.) }\end{array}$ & $\begin{array}{c}\text { Ladung } \\
\text { (pC } \pm \text { S.E.M.) }\end{array}$ & $\begin{array}{c}\text { Frequenz } \\
\text { (Hz } \pm \text { S.E.M.) }\end{array}$ \\
\hline \multirow{2}{*}{$+\mathbf{8}$} & SKO(n=11) & $23,2 \pm 2,7$ & $68,4 \pm 9,8$ & $1,5 \pm 0,3$ \\
& TKO(n=12) & $23,3 \pm 2,1$ & $83,9 \pm 8,0$ & $2,5 \pm 1,0$ \\
$\mathbf{9}$ & SKO(n=14) & $22,9 \pm 2,0$ & $58,0 \pm 7,4$ & $1,9 \pm 0,2$ \\
& TKO(n=16) & $25,4 \pm 1,9$ & $70,0 \pm 8,8$ & $3,9 \pm 0,6$ \\
\multirow{2}{*}{$\mathbf{1 0}$} & SKO(n=17) & $28,1 \pm 3,3$ & $107,0 \pm 12,0$ & $2,5 \pm 0,4$ \\
& TKO(n=21) & $25,3 \pm 3,3$ & $77,3 \pm 8,0$ & $6,9 \pm 1,0$ \\
$\mathbf{1 1 - 1 5}$ & $\mathrm{SKO}(\mathrm{n}=17)$ & $28,1 \pm 2,5$ & $121,1 \pm 10,7$ & $3,9 \pm 1,0$ \\
& $\mathrm{TKO}(\mathrm{n}=17)$ & $23,0 \pm 1,4$ & $112,2 \pm 14,9$ & $3,6 \pm 0,8$ \\
$\mathbf{7 - 1 5}$ & $\mathrm{SKO}(\mathrm{n}=59)$ & $27,7 \pm 2,3$ & $91,7 \pm 6,1$ & $2,5 \pm 0,3$ \\
& $\mathrm{TKO}(\mathrm{n}=66)$ & $24,3 \pm 1,3$ & $85,7 \pm 5,5$ & $4,5 \pm 0,5$
\end{tabular}

Tab. 12: Miniature Excitatory Postsynaptic Currents (mEPSC) 

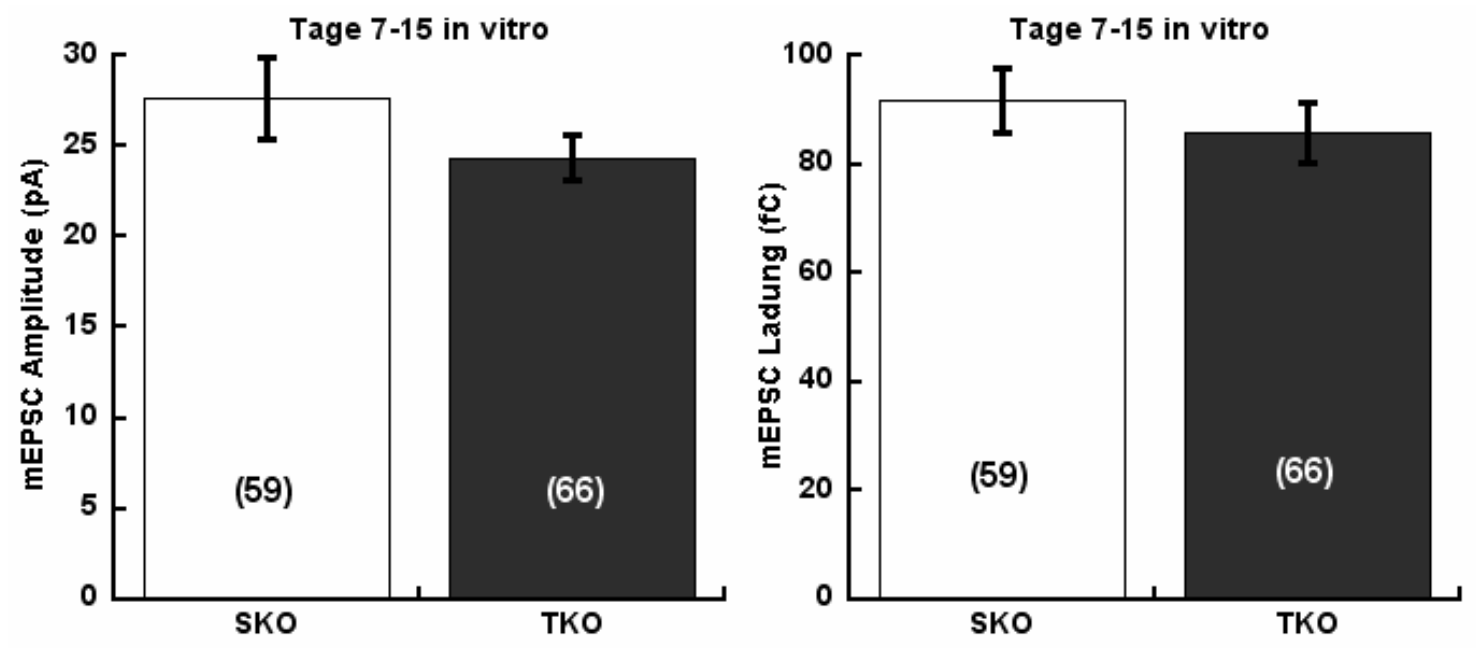

Abb. 24: Amplitude und Ladung der mEPSC der Tage 7 bis 15 in vitro

Weder Amplitude (links) noch Ladung (rechts) sind signifikant verändert.

Die Erhöhung der mEPSC-Frequenz ist vorsichtig zu interpretieren, da bei der Messung große Schwankungen auftreten können (Abb. 25). Die Befunde sind trotzdem in Einklang mit der veränderten RRP-Größe, da in der TKO-Stichprobe größere Pools gemessen wurden.

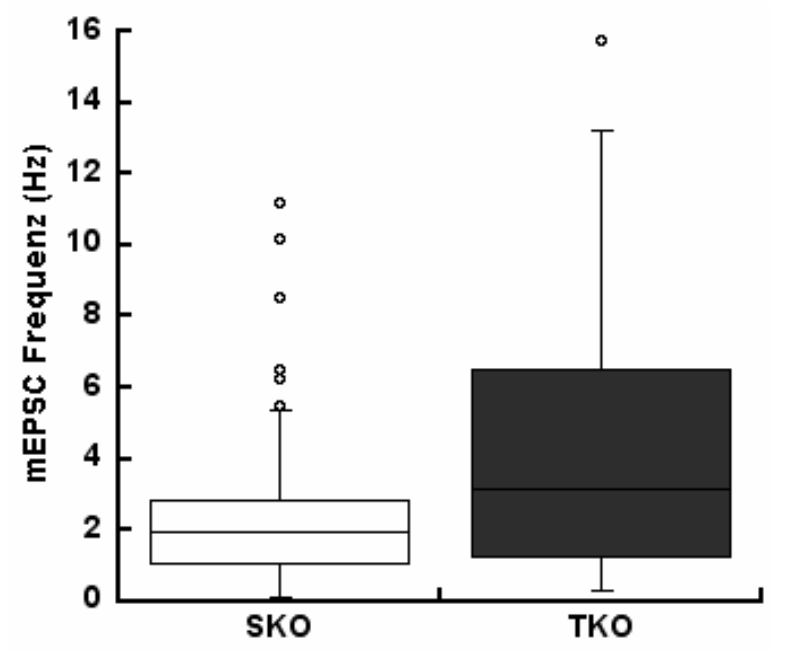

Abb. 25: Verteilung der mEPSC-Frequenzen In der TKO-Stichprobe variieren die Frequenzen stärker als in der SKO-Stichprobe. 

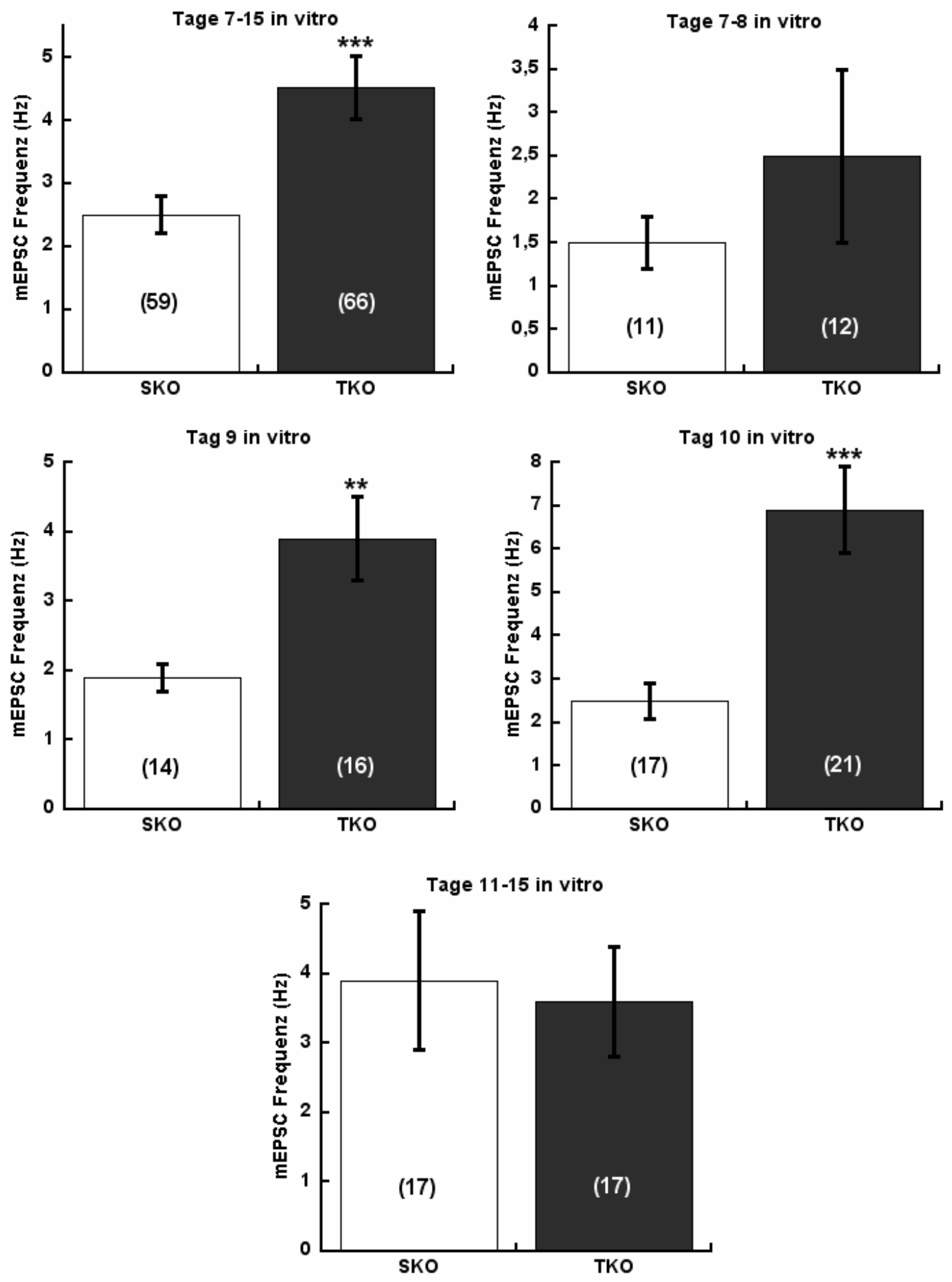

Abb. 26: mEPSC-Frequenzen

mEPSC ereignen sich im Mittel (und je nach Tag in vitro) mit einer Frequenz von 1,5 bis 6,9 Hz. Signifikanzniveaus wie unter 2.3.4. beschrieben. 
Da sich in beiden Gruppen weder Amplitude noch Ladung signifikant unterschieden, ist davon auszugehen, dass eine APP/APLP1/APLP2-Defizienz sich weder auf den Füllungsprozess der Vesikel auswirkt noch die postsynaptische Rezeptordichte und -funktion beeinflusst ist.

Der Vergleich von Mini-Ladung, RRP-Ladung und EPSC-Ladung erlaubt eine Kalkulation der Anzahl freigesetzter Vesikel pro Aktionspotenzial und der Gesamtzahl der fusionskompetenten Vesikel. Diese Werte beziehen sich jedoch nicht nur auf eine Synapse, sondern auf die Summe aller Synapsen.

Die Ladung eines mEPSC entspricht der Freisetzung eines einzelnen Vesikel. Um die Zahl der Vesikel zu berechnen, die während eines EPSC freigesetzt werden, muss man demzufolge nur die Ladung des EPSC durch die Ladung des mEPSC teilen. Da Unterschiede in der EPSC-Ladung zwischen beiden Gruppen beobachtet wurden, müssten auch die Vesikelzahlen verschieden sein. Die Zahl der pro EPSC freigesetzten Vesikel war entsprechend größer, aber dieser Unterschied ist nicht signifikant (SKO: $233 \pm 39$, $\mathrm{n}=59$; TKO: $271 \pm 18, \mathrm{n}=66$ ).

Es kann auch die Gesamtzahl der Vesikel im RRP rechnerisch ermittelt werden. Dazu wird der Quotient aus dem RRP und der mEPSC-Ladung gebildet. Hier ist aufgrund der vorangegangenen Experimente kein Unterschied zu erwarten.

Die Daten sind in Tab. 13 dargestellt.

\begin{tabular}{ccc} 
Genotyp & Vesikel pro EPSC & Vesikel im RRP \\
\hline SKO & $233 \pm 39(\mathrm{n}=59)$ & $2267 \pm 718(\mathrm{n}=51)$ \\
TKO & $271 \pm 18(\mathrm{n}=66)$ & $1625 \pm 212(\mathrm{n}=60)$
\end{tabular}

Tab. 13: Rechnerisch ermittelte Vesikelzahlen pro EPSC und im RRP

Eine Auflösung in Einzeltage war hier nicht möglich, da zu geringe n-Zahlen vorliegen. Es zeichnet sich aber der gleiche Trend ab, dass die Anzahl der Vesikel in frühen Kulturtagen größer ist und sich mit steigendem Alter der Kultur wieder angleicht. Die Gesamtzahl der Vesikel im RRP ist in beiden Gruppen aufgrund großer Schwankungen nur sehr eingeschränkt aussagekräftig, da mit zwei Größen gerechnet wurde, die jeweils schon mit großen Standardfehlern behaftet sind.

Die Erhöhung der Frequenz in den frühen Kulturtagen sowie die Angleichung beider Gruppen in der späteren Entwicklung passen gut in das Gesamtbild, das durch optische Methoden ergänzt wird, worauf im nächsten Kapitel eingegangen wird. 


\subsubsection{Synapsenzahl und Synapsendichte}

Die Zunahme der synaptischen Stärke kann nicht durch eine höhere Freisetzungswahrscheinlichkeit erklärt werden. Eine Erklärungsmöglichkeit besteht jedoch darin, dass sich Synapsenzahl und -dichte in der TKO-Gruppe von der SKO-Stichprobe unterscheiden. Deshalb wurden weitere Experimente durchgeführt, um Synapsenzahl und -dichte zu bestimmen. Dazu wurden optische Methoden ${ }^{1}$ angewandt (Abb. 28). Die Verfasserin stellte autaptische Kulturen zur Verfügung, die von Dr. Albrecht Sigler untersucht und ausgewertet wurden.

Die Vermutung, dass in der TKO-Gruppe Neuronen mehr Synapsen ausbilden, bestätigte sich. In APP-TKO-Neuronen wurden signifikant mehr Synapsen als im SKO gefunden (SKO: $307 \pm 47$ Synapsen, $\mathrm{n}=13$; TKO: $698 \pm 81, \mathrm{n}=20 ; \mathrm{p}<0,01$; siehe Abb. 27). Auch die Synapsendichte war signifikant erhöht (SKO: 0,51 $\pm 0,1 \mu \mathrm{m}^{-2}, \mathrm{n}=9$; TKO: 1,18 \pm $0,12 \mu \mathrm{m}^{-2}, \mathrm{n}=13 ; \mathrm{p}<0,001$; siehe Abb. 27), während die Dendritenfläche in beiden annähernd gleich war (Daten nicht gezeigt).

Dagegen zeigen unveröffentlichte Daten aus unserem Labor, dass Neuronen der Tage 20-21 in vitro keinen morphologischen Phänotyp mehr aufweisen. Sowohl die Synapsenzahl als auch die Synapsendichte sind in der SKO- und TKO-Stichprobe annähernd gleich (Synapsenzahl - SKO: $1580 \pm 305$, n=6; TKO:1732 \pm 312 , n=8; Synapsendichte - SKO: 2,0 $\pm 0,5 \mu \mathrm{m}^{-2}, \mathrm{n}=8$; TKO: $2,2 \pm 0,4 \mu \mathrm{m}^{-2}, \mathrm{n}=8$ ).

Der hier fehlende Phänotyp in späten Tagen in vitro ist konsistent mit den Ergebnissen aus den vorangegangenen elektrophysiologischen Experimenten.

Nach Betrachtung der Daten aus elektrophysiologischen und optischen Untersuchungen ergibt sich ein genaueres Bild der möglichen Funktion von APP und APLP an zentralen Synapsen.

\footnotetext{
${ }^{1}$ Autaptische Kulturen wurden wie in Kapitel 2 beschrieben von hippokampalen exzitatorischen Neuronen beider Stichproben angefertigt. Nach 7-9 Tagen in vitro wurden die Zellen mit 5 $\%$ Formaldehyd fixiert und mit einem primären Antikörper gegen Synaptophysin und Microtubule-Associated Protein 2 (MAP2) (Synaptic Systems und Chemicon) gefärbt. Danach erfolgte die Behandlung mit einem zweiten Antikörper (Alexa Fluor, Molecular Probes). Fluoreszenzmessungen, durchgeführt von Dr. Albrecht Sigler, erfolgten mit einem Zeiss LSM 410 konfokalem Mikroskop mit einem Zeiss 40x/1.4 NA Öl-Immersionsobjektiv. Unter Verwendung der Zeiss LSM 3.98 Software wurden Bilder im Abstand von $1 \mu \mathrm{m}$ aufgenommen. Danach wurden die Bilder Laplace-gefiltert. Im Anschluss erfolgte ein weiterer Schritt mit einem Gauss-Filter. Verwendete Software war TILLvisION 4.0 (TILL Photonics, Planegg, München). Die Bilder wurden nach einem optimierten Algorithmus [VAROQUEAUX et al. 2002] ausgewertet und ausgedruckt. Die Synapsenzählung erfolgte nach Sicht durch Dr. Albrecht Sigler. Die MAP2-gefärbte Fläche entsprach Soma- und Dendritenfläche. Die Synapsen-Dichte wurde als Synapsenzahl per Dendritenfläche bestimmt.
} 
Tage 7-9 in vitro

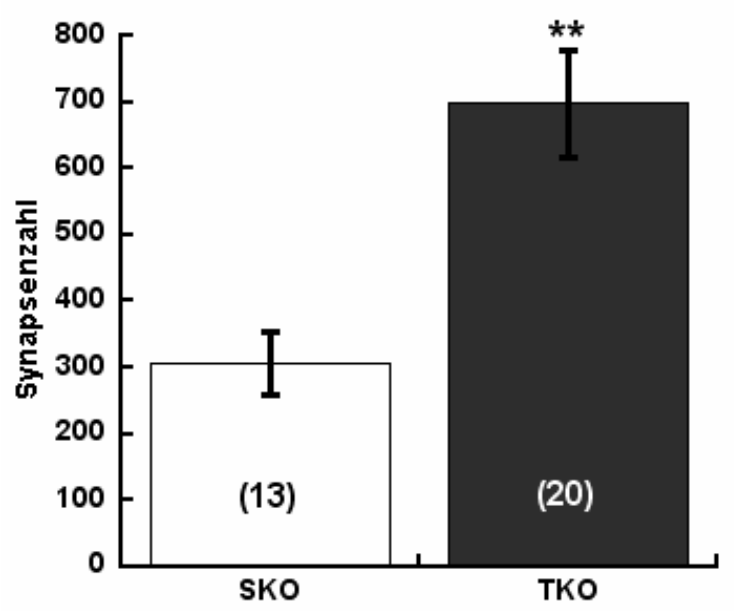

Tage 7-9 in vitro

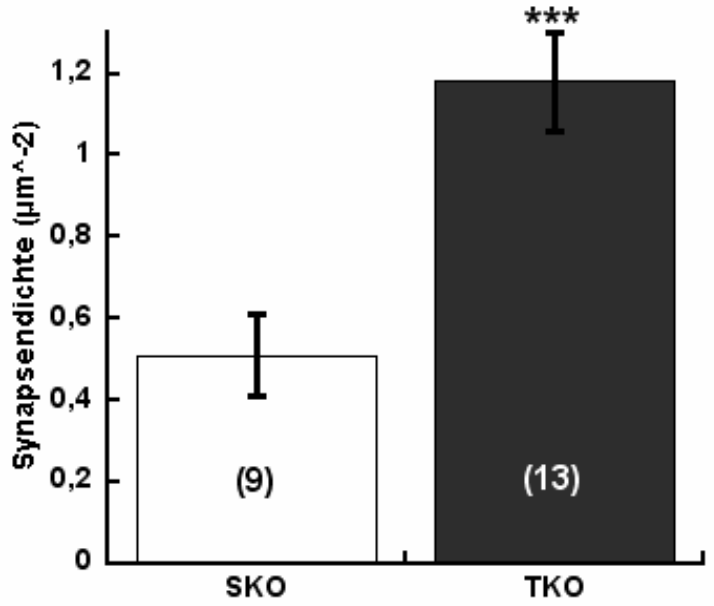

Abb. 27: Synapsenzahl und Synapsendichte

Sowohl Synapsenzahl als auch die Synapsendichte sind signifikant in der TKO-Stichprobe erhöht. (Die Daten wurden freundlicherweise von Dr. Albrecht Sigler zur Verfügung gestellt.)


Abb. 28: Originalaufnahmen von mit Antikörpern behandelter Neuronen Links: TKO-Neuron, rechts: SKO-Neuron.

(Die Bilder wurden freundlicherweise von Dr. Albrecht Sigler zur Verfügung gestellt.) 


\section{Diskussion}

\subsection{Die Funktion von APP und APLP an zentralen}

\section{Synapsen}

Ziel dieser Arbeit war zum einen herauszufinden, ob alle drei Proteine der APP/APLPFamilie einen Einfluss auf die synaptische Transmission haben, sowie zum anderen, basale Charakteristika der synaptischen Transmission zu erstellen.

Dazu wurden Tiere verwendet, die entweder nur für das Protein APP oder für die Proteine APP, APLP1 und APLP2 defizient waren.

Die hier beschriebene APP/APLP-Proteinfamilie besteht aus drei Proteinen, dem Amyloid-Precursor-Protein (APP) und den Amyloid-Precursor-Like-Proteinen (APLP) 1 und 2. Zur physiologischen Funktion dieser Proteine ist bisher wenig bekannt. Sie sollen u. a. eine Rolle beim Neuritenwachstum, bei der Bildung der VorderhirnKommissuren, dem postnatalen Wachstum und der lokomotorischen Aktivität oder Synaptogenese spielen [MOYA et al. 1994; ZHENG et al. 1995; LI et al. 1996; MORIMOTO et al. 1998]. Diese Arbeit konnte einen Einfluss der Proteinfamilie auf die synaptische Funktion bekräftigen. Einzelne Aspekte sollen hier diskutiert werden.

Als erstes stellt sich die Frage:

\section{Haben APP und APLP redundante Funktionen?}

Während APP und APLP2 ubiquitär exprimiert werden, wird APLP1 nur im Nervensystem gefunden. Wenn APP und APLP2 oder APLP1 und APLP2 gemeinsam genetisch modifiziert waren, führte diese Modifikation zu erhöhter perinataler Sterblichkeit. Dagegen waren APP/APLP1-Doppelmutanten lebensfähig und hatten keine morphologischen Besonderheiten [VON KOCH et al. 1997; HEBER et al. 2000]. Diese Beobachtungen unterstützen die These, dass APLP2 eine Schlüsselrolle innerhalb der Proteinfamilie einnimmt und teilweise identische Funktionen im Vergleich mit den beiden anderen Familienmitgliedern hat. Die Lebensfähigkeit der APP/APLP1-Doppelmutante kann nicht mit einer Hochregulation von APLP2 erklärt werden, da die APLP2Expression in dieser Doppelmutante nicht verändert war [HEBER et al. 2000]. Trotzdem scheint APLP2 eine Kompensation zu ermöglichen. Bisher wurde immer angenommen, dass APP und APLP2 weitgehend überlappende Funktionen haben [VON KOCH et al. 1997; STEINBACH et al. 1998; WHITE et al. 1998]. Dies wurde begründet durch Homologie, ähnliche Prozessierung durch Sekretasen, überlappende Expressionsmuster und perinatale Sterblichkeit der Doppelmutante. Doch die Lebensfähigkeit der APP/APLP1-Doppelmutante gegenüber der APLP1/APLP2-Doppelmutante, die nicht lebensfähig ist, lässt darauf schließen, dass APP und APLP2 neben identischen auch non-redundante Funktionen in vivo haben müssen [HEBER et al. 2000]. 
Untersuchungen zur Morphologie in Mäusen die für eines, zwei oder alle Proteine der APP/APLP-Familie homozygot defizient sind, liegen bereits vor [VON KOCH et al. 1997; MAGARA et al. 1999; HEBER et al. 2000; HERMS et al. 2004]. Wie im Kapitel 3 bereits beschrieben, traten insbesondere neuronale Besonderheiten auf. APP-SingleKnockouts zeigen neben einem reduzierten Hirngewicht Anomalien in den Vorderhirn-Kommissuren und im Balken. Die Veränderungen im Corpus callosum werden aber vermutlich auf den genetischen Hintergrund $129 / \mathrm{SvEv}^{2}$ zurückgeführt [MAGARA et al. 1999]. APLP1-Knockout-Tiere zeigen keine nennenswerten morpholgischen Anomalien bzw. Verhaltensauffälligkeiten. Hinsichtlich der APP/APLP1-DoppelKnockouts ergab sich der gleiche Befund wie im APLP1-Einzel-Knockout [HEBER et al. 2000]. Auch APLP2-defiziente Tiere weisen keine Besonderheiten auf. Hingegen sind APP/APLP2-Doppel-Knockouts stark beeinträchtigt. 80\% aller Tiere versterben innerhalb einer Woche nach Geburt. Auch neurologische Auffälligkeiten (z. B. Ataxien) prägen wiederum das Bild [VON KOCH et al. 1997]. Mäuse, die für alle drei Proteine defizient sind, sterben kurz nach der Geburt und zeigen gehäuft Anomalien des Schädels [HERMS et al. 2004].

Alle aufgeführten Untersuchungen lassen für APP und APLP eine wichtige Rolle in der Hirnentwicklung vermuten. Daher lag es nahe, ebenfalls einen Einfluss von APP und APLP auf die synaptische Transmission anzunehmen. Bereits veröffentlichte Arbeiten bestätigen die Lokalisation von APP in Synapsen [SCHUBERT et al. 1991] und einen Einfluss der Protein-Familie auf die synaptische Funktion hinsichtlich der Synaptogenese oder synaptischer Transmission [SEABROOK et al. 1999; SELKOE 2002; KAMENETZ et al. 2003; PRILLER et al. 2006].

Es wurde deshalb in dieser Arbeit erstmals auf Zellebene die synaptische Transmission in Triple-Knockout-Tieren untersucht. Dazu wurden autaptische Kulturen exzitatorischer Neuronen des Hippocampus elektrophysiologisch charakterisiert. Unterstützende optische Methoden wurden ebenfalls eingesetzt. Mit den vorliegenden Zuchttieren war es im Rahmen dieser Arbeit nicht möglich, einen Vergleich von Wildtypen, SingleKnockouts und Triple-Knockouts innerhalb einer Kultur zu erreichen. Aufgrund von Voruntersuchungen (kein Unterschied zwischen Neuronen von APLP2-Einzel-, APP/APLP2-Doppel- oder APLP1/APLP2-Doppel-Knockouts in Bezug auf die synaptische Stärke; unveröffentlichte Daten aus der Arbeitsgruppe) und ausschließlicher Verwendung von Geschwistertieren beschränkten wir uns darauf, nur den Single- und Triple-Knockout zu untersuchen.

Elektrophysiologische Untersuchungen an Tieren, die für eines oder mehrere Proteine der APP/APLP-Familie defizient sind, wurden bisher kaum beschrieben. PRILLER et al. konnten zeigen, dass eine APP-Defizienz in exzitatorischen Neuronen des Hippocampus zur Erhöhung der synaptischen Stärke an exzitatorischen Synapsen führt [PRILLER et al. 2006], während WANG et al. an der neuromuskulären Endplatte

\footnotetext{
2 siehe auch MULLER 1999. Es sind mehrere Mauslinien zur Generierung von Knockout-Tieren etabliert. Insbesondere die 129-Linie ist für eine nennenswerte genetische Variabilität bekannt.
} 
APP/APLP2-defizienter Mäuse ein gegenteiliges Ergebnis beobachteten. Dort kam es zu einer veränderten Anordnung präsynaptischer Proteine und postsynaptischer Acetylcholin-Rezeptoren. Ebenfalls bewirkte das Fehlen beider Proteine eine Reduktion der Gesamtzahl synaptischer Vesikel im präsynaptischen Terminal sowie ein verstärktes Aussprossen der Neuriten. WANG et al. schlussfolgerten, dass die beobachte Malformation der Synapsen auch zur verminderten synaptischen Transmission führen könne. Sie zeigten aber in ihren elektrophysiologischen Experimenten, dass zwischen APP/APLP2-defizienten Mäusen und Wildtypen kein Unterschied festzustellen war. Eine mögliche Erklärung für diese Beobachtung war die gleiche Anzahl "gedockter" Vesikel an den Aktiven Zonen trotz vorher gemessener Reduktion der Gesamtzahl synaptischer Vesikel [WANG P et al. 2005]. SEABROOK et al. zeigten in APP-SingleKnockout-Tieren, dass sowohl prä- als auch postsynaptische Funktionen in hippocampalen Neuronen verändert sind. Sie beobachteten in APP-defizienten Tieren eine Verringerung der Dendritenlänge sowie subtile Veränderung bei der LTP [SEABROOK et al. 1999]. SEABROOK und Kollegen verwendeten jedoch Tiere mit einer anderen APPMutation als die in unserer Arbeit oder in PRILLER et al. beschriebenen APP-SingleKnockouts; somit wird ein Vergleich der einzelnen Ergebnisse erschwert.

Sicherlich wäre eine vergleichende Analyse autaptischer Kulturen aller Tiere mit verschiedenen APP-Null-Mutationen hilfreich, um den Einfluss des genetischen Hintergrunds näher zu beleuchten. Dieser Ansatz ist durch unterschiedliche Lokalisation der Knockout-Tiere jedoch kompliziert und nur schwer durchführbar.

Elektrophysiologische Untersuchungen an Tieren, die APP oder beteiligte Sekretasen (siehe Kapitel 1) überexprimieren, liegen hingegen zahlreich vor. Auch hier sind kontroverse Beobachtungen aufgetreten. Veränderungen in der basalen synaptischen Transmission wurden in APP-transgenen Tieren beobachtet, die mit einer Verringerung der präsynaptischen Nervenendigungen verbunden war [HSIA et al. 1999], aber es wurde ebenso unveränderte basale synaptische Transmission beschrieben [CHAPMAN PF et al. 1999]. Trotz der Variabilität in den elektrophysiologischen Untersuchungen zeigen alle Arbeiten, dass eine Überexpression von APP zu synaptischer Dysfunktion führt. Widersprüchliche Aussagen in den elektrophysiologischen Experimenten bis hierher lassen vermuten, dass die Variabilität auch in den unterschiedlichen Mauslinien begründet sein kann. Viele verschiedene Mutationen führen zur Überexpression von APP oder zur Akkumulation des Plaque-bildenden A $\beta$ [zur Übersicht SELKOE 2002].

Eine Übersicht der Mauslinien ist in mehreren Arbeiten $\mathrm{zu}$ finden [SEABROOK und ROSAHL 1999; SPIRES und HYMAN 2005; MCGOWAN et al. 2006].

In der vorliegenden Arbeit wurden Knockout-Tiere verwendet, da ein Studium der Funktion so gezielter möglich ist.

Exzitatorische Neuronen des Hippocampus, die für alle drei Mitglieder der APP/APLP-Familie defizient waren, zeigten im Vergleich zum APP-Single-Knockout eine Erhöhung der synaptischen Stärke ohne Veränderungen der Freisetzungswahr- 
scheinlichkeit oder der Kurzzeitplastizität. Bemerkenswert ist hierbei die zeitliche Auflösung nach Kulturtagen in vitro. In einem sehr frühen Zeitfenster, 7 bis 8 Tage in vitro, gibt es einen deutlichen Unterschied in Amplitude und Ladung des EPSC. Im Verlauf verliert sich dieser Phänotyp, was auf eine Angleichung der synaptischen Stärke in beiden untersuchten Stichproben hindeutet. Um eine Veränderung der synaptischen Stärke beobachten zu können, scheint eine Defizienz für alle drei Proteine der APP/APLP-Familie vorliegen zu müssen (s.o.).

Ein anderes Ergebnis erbrachte hingegen die Untersuchung von APP-Single-Knockouts im Vergleich zu Wildtyp-Mäusen einer anderen Arbeitsgruppe. Es wurde eine Erhöhung der EPSC-Amplitude, ein vergrößerter RRP sowie eine Erhöhung der mEPSCFrequenz im APP-Single-Knockout gefunden. Auch eine signifikante Erhöhung der Synapsenzahl wurde aufgeführt [PRILLER et al. 2006]. Eine Unterscheidung in frühe und späte Tage in vitro erfolgte jedoch nicht, es wurden hauptsächlich die Tage 18 bis 20 in vitro für die elektrophysiologischen Messungen benutzt. Außerdem erfolgte eine P0-Präparation, weshalb die Kulturen im Vergleich zu denen dieser Arbeit nochmals als ein bis zwei Tage älter anzusehen sind. Die Ergebnisse stehen trotzdem nicht im Widerspruch zu denen unserer Arbeit, in der aber zusätzlich gezeigt und argumentiert wird, dass nicht APP allein für die Erhöhung der synaptischen Stärke verantwortlich sein kann, da erst eine Defizienz von APP, APLP1 und APLP2 zur signifikanten Erhöhung der synaptischen Stärke führt.

Wir beobachteten ebenfalls eine Veränderung in der mEPSC-Frequenz. Aber auch hier gilt wiederum die Unterscheidung nach Tagen in vitro. In späten Kulturtagen gleicht sich die mEPSC-Frequenz der beiden Stichproben an. Die Erhöhung der mEPSCFrequenz sollte ebenfalls mit einer Erhöhung der Vesikel-Gesamtzahl im RRP korrelieren. Dieser fehlende Befund lässt sich jedoch mit der hohen Variabilität der mEPSCFrequenzen einerseits sowie einer Erhöhung der Synapsenzahl andererseits erklären.

Zusammenfassend ist anzunehmen, dass synaptische Transmission nicht nur weiterhin in Triple-Knockout-Tieren möglich ist, sondern die synaptische Stärke sogar zunimmt.

Welche Gründe kommen hierfür in Frage? Da kein Unterschied in der vesikulären Freisetzungswahrscheinlichkeit zu verzeichnen war, nahmen wir an, dass insgesamt mehr Synapsen für die Glutamat-Freisetzung zur Verfügung standen, was durch optische Methoden auch bestätigt wurde.

\section{Aber welche Funktionen übernehmen APP und APLP an zentralen Synapsen?}

Zwar führt ein Ausschalten aller drei Proteine zum frühen Tod der Tiere, aber autaptisch kultivierte exzitatorische Neuronen zeigten keine Beeinträchtigung der synaptischen Transmission im negativen Sinne, im Gegenteil, synaptische Transmission war ausgeprägter in Dreifachmutanten. Wenn also das Fehlen der Proteine APP, APLP1 und APLP2 zu einer Steigerung der synaptischen Transmission führt, kann der Umkehrschluss lauten, dass diese Proteine eine regulatorische Rolle in der synaptischen 
Funktion spielen. Die Regulation ist sowohl prä- als auch postsynaptisch möglich. Ein möglicher Einfluss auf die Synaptogenese wurde bereits erwähnt [MOYA et al. 1994; MORIMOTO et al. 1998]. In dieser Arbeit wurde gezeigt, dass Erhöhungen in der Synapsenzahl und Synapsendichte durchaus die veränderte synaptische Stärke erklären können. Im Gegensatz zu PRILLER et al. (2006) setzt die Beschleunigung der Synaptogenese aber viel früher ein, und das Plateau wird ebenfalls früher erreicht. Die Synapsenanzahl und -dichte in späten Tagen in vitro begibt sich wieder auf ein gemeinsames Niveau (siehe 4.1.) Auffällig ist im Vergleich die Synapsenzahl. In PRILLER et al. wird nach $~ 20$ Tagen in vitro die gleiche Zahl an Synapsen in APP-defizienten Neuronen gefunden, die in unserer Untersuchung bereits nach 7 bis 9 Tagen in vitro als Befund vorlag. Hingegen war in unserer Untersuchung nach 20 Tagen in vitro die Synapsenzahl auf über 2000 gestiegen und in beiden Stichproben vergleichbar (siehe 4.1.). Auch die Befunde in der Dendritenfläche in PRILLER et al. sind nicht konsistent mit unseren Ergebnissen, da in unserer Arbeitsgruppe kein Unterschied in diesem Parameter gezeigt werden konnte (Daten nicht gezeigt). In PRILLER et al. wurden autaptische Kulturen erst Ende der 3. Woche in vitro gemessen, zu diesem Zeitpunkt konnten in dieser Arbeit keine Messungen mehr erhoben werden, da in beiden Stichproben die Amplituden der EPSC auf ein Niveau stiegen, das nicht mehr vom Verstärker kontrollierbar war. Gründe für diese Variabilität können in der autaptischen Kultur selbst begründet sein. In unserer Arbeitsgruppe wurde das Protokoll der autaptischen Kultur seit 1993 modifiziert und verbessert (siehe 2.2.2.). Bei zu starker mechanischer Lösung des Zellverbandes kann ein Entwicklungsdefizit der Neuronen in Kultur auftreten, da die Zellen eine längere Zeit benötigen, um ihren Axon- und Dendritenbaum neu auszubilden. Durch erwähnte Verbesserungen konnte in unserem Labor die Variabilität zwischen den Kulturen auf ein Minimum reduziert werden. Selbst bei Berücksichtigung der Variabilität ist in unseren Experimenten bei Tieren des gleichen Genotyps (APP-Single-Knockout) eine deutlich höhere Synapsenzahl nach 20 Tagen in vitro zu verzeichnen. Auch eine Variabilität zwischen Experimentatoren kann nicht ausgeschlossen werden. In der vorliegenden Arbeit wurden deshalb die Synapsenzählungen von Dr. Albrecht Sigler vorgenommen, der auch in anderen Arbeiten nach einem etablierten Algorithmus ähnliche Experimente durchführte, um so eine Konstanz in den Ergebnissen zu gewährleisten [ROSENMUND et al. 2002; VAROQUEAUX et al. 2002; ALTROCK et al. 2003]. Die zusätzliche Anwendung der optischen Methoden bestätigt und untermauert die in unserer Arbeit erhobenen elektrophysiologischen Befunde.

Arbeiten anderer Gruppen haben für adulte APP-Single-Knockout-Tiere bereits gezeigt, dass keine Veränderung in der synaptischen Stärke $\mathrm{zu}$ verzeichnen war [DAWSON et al. 1999; PHINNEY et al. 1999]. Zwei Erklärungsmöglichkeiten für diesen Mechanismus wurden diskutiert. Entweder beschleunigt das Fehlen von APP die Synaptogenese, oder die Beschleunigung der Synaptogenese wird in adulten Tieren durch eine erhöhte Eliminierung der Synapsen kompensiert [PRILLER et al. 2006]. Unsere Schlussfolgerung lautet, dass Neuronen der Triple-Knockouts bei gleicher Dendritenfläche in frühen Kulturtagen mehr Synapsen bilden, aber sich mit Maturation wie- 
der auf ein gemeinsames Niveau begeben, was auf eine Beschleunigung, nicht auf eine Eliminierung hinweist.

Des Weiteren wird APP vorwiegend präsynaptisch lokalisiert vermutet [SCHUBERT et al. 1991]. Das relevante Spaltprodukt von APP, A $\beta$, scheint aber besonders auf die postsynaptische Seite Einfluss zu nehmen. Neuronen transgener Tiere, die A $\beta$ akkumulieren, zeigen eine Reduktion von PSD-95 und Oberflächenexpression von GluR1 [ALMEIDA et al. 2005]. PSD-95 ist als postsynaptisches Markerprotein für sich entwickelnde Synapsen bekannt. Es vermittelt die Rekrutierung und Verankerung von Glutamatrezeptor-Untereinheiten in der Postsynaptischen Dichte. Wenn A $\beta$ Akkumulierung zur Reduktion von PSD-95 und GluR1 führen, könnte ein vollständiges Fehlen von $\mathrm{A} \beta$ eventuell zur Überexpression der Parameter und damit Erhöhung der synaptischen Stärke führen. Auch APLP1 wurde in Postsynaptischen Dichten des Cortex und des Hippocampus, aber nicht in denen des Kleinhirns gefunden [KIM et al. 1995]. So kann auch erklärt werden, dass Doppelmutanten (APP/APLP2) keinen Unterschied in der synaptischen Stärke gegenüber dem APP-Single-Knockout aufweisen, da immer noch ein weiteres Protein der Familie exprimiert wird und somit regulatorische Funktionen übernehmen kann.

Ebenfalls wurde schon früh gezeigt, dass APP eine wichtige Rolle in der Hirnentwicklung einnimmt. Die Expression der Isoform des Nervensystems, $\beta$ APP695, nimmt stetig während der in vitro-Differenzierung von primären embryonal gewonnenen hippocampalen Neuronen zu [HUNG et al. 1992].

Einen weiteren Hinweis auf Regulatorfunktionen des APP zeigt der Befund von $\beta$ APPdefizienten Mäusen. Sie sind gegenüber Kainat-induzierter Epilepsie vulnerabler als Wildtyp-Mäuse. Krämpfe treten in diesen Mutanten früher und in verstärkter Form auf [STEINBACH et al. 1998]. Epilepsien können als neuronale Hyperaktivität betrachtet werden. Neuronale Hyperaktivität hingegen scheint die Sekretion von A $\beta$ in Form einer Hochregulation $\mathrm{zu}$ modulieren. $\mathrm{A} \beta$ wird eine Depression der synaptischen Transmission in Form eines negativen Feedback-Mechanismus zugeschrieben. Dieser Mechanismus ist abhängig von der NMDA-Rezeptor-Aktivität und ist reversibel, sobald neuronale Hyperaktivität blockiert wird [KAMENETZ et al. 2003]. Wenn APP, und demzufolge auch die A $\beta$-Produktion, vollständig fehlt, ist anzunehmen, dass auch die synaptische Transmission in einer stärkeren Ausprägung zu erwarten ist.

Es gibt Hinweise auf weitere Interaktionspartner in der synaptischen Transmission. Mint-Proteine sollen ebenfalls mit APP interagieren [HO CS et al. 2002; LEE et al. 2003].

Mint und APP beeinflussen sich gegenseitig, wobei dieser Mechanismus durch Munc18 wahrscheinlich verstärkt wird [zur Übersicht DE STROOPER und ANNAERT 2000]. Munc-18 gilt als negativer Regulator der synaptischen Vesikelfusion [zur Übersicht GARNER et al. 2000]. Betrachtet man den APP-Mint-Munc-18-Kreislauf, ist möglich, dass bei APP-Deletion ein Interaktionspartner für Munc-18 fehlt, aber auch die Zusammenarbeit von Mint und Munc-18 dadurch verändert sein kann, was zu einer po- 
tenziell geringeren Hemmung auf Syntaxin führen könnte. Somit wäre ein Einfluss auf die synaptische Transmission gegeben (siehe Abb. 29).

Des Weiteren sollen Mint und APP gemeinsam im Golgi-Apparat lokalisiert sein und vermutlich den Aufbau von Synapsen beeinflussen [HO A et al. 2003]. Bei Annahme einer negativ regulatorischen Funktion von APP auf Mint-Proteine und Wegfall dieser in Knockout-Tieren kann es somit zu einer vermehrten Bildung von Synapsen kommen.

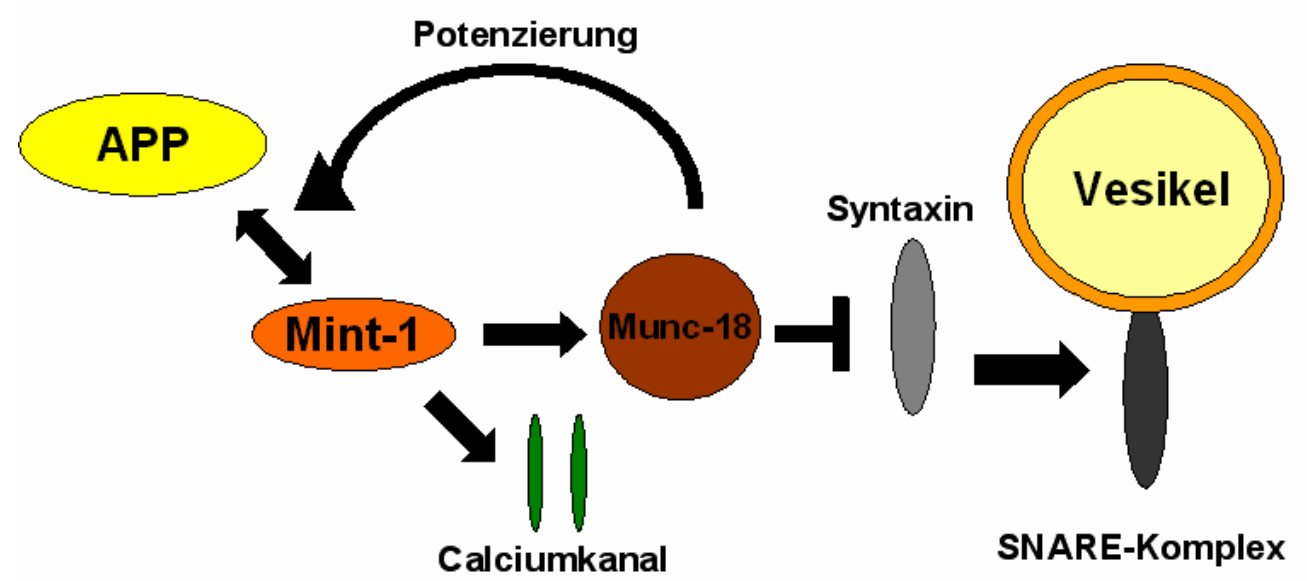

Abb. 29: APP und mögliche Interaktionen mit synaptischen Proteinen

APP und Mint beeinflussen sich gegenseitig, wobei dieser Mechanismus durch Munc-18 verstärkt wird. Mint wiederum hat Einfluss auf präsynaptische Calciumkanäle und Munc-18. Munc-18 wird eine negativ regulierende Rolle auf Syntaxin zugeschrieben.

Doch auch Mint scheint die Prozessierung von APP zu modulieren, indem nach Bindung von Mint die Prozessierung von APP zu A $\beta$ abnimmt. Der Mechanismus bleibt unklar [LEE et al. 2003].

APP ist als einziges Protein der Familie für die Produktion von A $\beta$ verantwortlich, deshalb scheinen APLP1 und APLP2 eine zusätzliche regulatorische Funktion zu übernehmen, die noch nicht geklärt ist. Vermutet wird ein Einfluss der APP-intrazellularDomäne (AICD). APP und APLP werden durch Sekretasen ähnlich gespalten. Als Produkte entstehen dabei A $\beta$ (nur aus APP) und AICD (sowohl aus APP und APLP). Wird diese $\gamma$-Sekretase geblockt, kann auch in Wildtypen gegenüber APP-defizienten Tieren der gleiche Phänotyp mit Erhöhung der synaptischen Stärke erzeugt werden [PRILLER et al. 2006]. Die dort in Verbindung mit anderen Arbeiten gezogene Schlussfolgerung, dass aber nur A $\beta$ statt aller AICD in Frage kommt, kann in dieser Arbeit nicht bestätigt werden. Das Ausschalten aller Proteine der APP/APLP-Familie führt nachweislich zur Erhöhung der synaptischen Stärke. Somit kann nicht $A \beta$ allein für diesen Phänotyp verantwortlich sein.

Ein weiterer Hinweis auf wichtige Funktionen der APLP ist die Lokalisation der Proteine. Insbesondere APLP1 wird selektiv in den Postsynaptischen Dichten exprimiert. Des Weiteren wurde beobachtet, dass die APLP1-Expression während der postnatalen 
Cortex-Entwicklung in den Postsynaptischen Dichten zunimmt, sodass eine Rolle in der Synaptogenese und synaptischer Maturation vermutet wurde [KIM et al. 1995]. Bei fehlender APLP1-Expression in Mutanten kann die vermutete regulatorische Funktion nicht mehr ausgeübt werden. Die synaptische Entwicklung kann dadurch entweder beschleunigt oder gehemmt werden. Die vorliegende Arbeit lässt eine Beschleunigung vermuten.

Um die angenommene Angleichung in adulten Tieren zu bestätigen, wären elektrophysiologische Experimente an adulten Knockout-Mäusen von großem Interesse. Da aber die Triple-Knockout-Tiere eine erhöhte postnatale Letalität aufweisen [HERMS et al. 2004], ist dieses Ziel schwer zu verfolgen.

\subsection{Morbus Alzheimer - eine „Synapsenkrankheit“?}

Morbus Alzheimer ist eine neurodegenerative Erkrankung und die häufigste Form der Demenz im Alter. Klinische Auffälligkeiten sind insbesondere Vergesslichkeit, Aphasie, Apraxie, Raumsinn- und Raumverarbeitungsstörungen, Unmöglichkeit des abstrakten Denkens, Desorientiertheit und andere kognitive Defizite bis hin zur Handlungsunfähigkeit. Neuropathologische Auffälligkeiten des Gehirns von Alzheimer-Patienten sind u.a. Verlust von Synapsen, reaktive Gliose, dystrophische Neuriten, neuronale Atrophie bzw. Neuronenuntergang, intraneuronale Fibrillenbildung und extrazelluläre Plaquebildung (s. Kapitel 1). Der Schweregrad der Krankheit ist stark mit kognitiven Defiziten verbunden, die wiederum besser mit der Schwere der synaptischen Beeinträchtigung korrelieren als mit dem Grad der Akkumulierung von A $\beta$, Neurofibrillen oder Neuronenverlust [MUCKE et al. 2000; ODDO et al. 2003]. Frühe Alzheimer-Symptome sind durch Schädigungen an cholinergen und glutamatergen Synapsen gekennzeichnet. Dieser Synapsenverlust, der früh auftritt, wiegt dabei schwerer als der spätere Neuronenverlust [zur Übersicht SELKOE 2002]. Verschiedene Studien konnten zeigen, dass synaptische Proteine im Hippocampus und Assoziations-Cortex verringert in Alzheimer-Patienten exprimiert werden [SZE et al. 2000; MASLIAH et al. 2001]. Insbesondere Proteine, die in der synaptischen Vesikelmembran lokalisiert sind (Synaptobrevin, Synaptotagmin, Rab 3a) sind reduziert, während Proteine mit vorrangiger Lokalisation in der präsynaptischen Membran (Syntaxin, SNAP 25) unverändert exprimiert wurden. Die frühen Schäden sind so auf den synaptischen Vesikelzyklus zurückzuführen [SZE et al. 2000]. SZE et al. schlossen aus ihren Arbeiten, dass a) Synapsen in Alzheimer-Patienten intakt sind; b) präsynaptische Vesikelproteine eher betroffen sind, als dass ein Komplettverlust von Synapsen auftritt; c) der Verlust synaptischer Marker im Hippocampus mit einer funktionalen Beeinträchtigung in kognitiven Tests korreliert sowie d) Exozytose-Defekte auftreten können [SZE et al. 2000]. Diesem Verlust auf Proteinebene widerspricht die Untersuchung von MASLIAH et al., in deren Experimenten es auch im frühen Stadium zu einem Komplettverlust von Synapsen kommt [MASLIAH et al. 2001]. Beide Untersuchungen bestätigten aber, dass die ver- 
mutete Beeinträchtigung der synaptischen Funktion bereits vor der Bildung der A $\beta$ Plaques auftrat.

Auch elektrophysiologische Untersuchungen weisen darauf hin, dass die basale synaptische Transmission vor Bildung der Plaques bereits in transgenen Tieren, die APP überexprimieren, beeinträchtigt war [HSIA et al. 1999].

Trotzdem muss die synaptische Dysfunktion auch durch $A \beta$ hervorgerufen werden, denn Immunisierung mit einem Antikörper gegen $A \beta$ führte zu einer Besserung der Gedächtnisdefizite in APPV717F-transgenen Mäusen. Diese Mäuse entwickeln neuropathologische Auffälligkeiten, die dem Morbus Alzheimer des Menschen entsprechen. Objekterkennung, Gedächtnis und Lernen waren in Verhaltenstests nach Injektion des Antikörpers signifikant verbessert [DODART et al. 2002]. Eine andere Arbeit konnte zeigen, dass synaptische Degeneration durch $A \beta$ in transgenen Mäusen aufgehalten werden kann, indem passiv oder aktiv gegen $A \beta$ immunisiert wurde [BUTTINI et al. 2005].

Lernen und Gedächtnis sind auf Modulierungen der synaptischen Stärke zurückzuführen, also auf die Anzahl und die Funktion von Synapsen. Der Verlust synaptischer Integrität besonders im Hippocampus beeinträchtigt insbesondere Lernen und Gedächtnis [NICOLL et al. 1988]. Die synaptische Funktion im Hippocampus bestimmt also die Möglichkeit, zu lernen und sich zu erinnern. Die synaptische Funktion ist abhängig von der Exozytose Neurotransmitter-gefüllter Vesikel. Studien haben zuvor gezeigt, dass der Verlust präsynaptischer Proteine nicht letal sein muss, aber die synaptische Transmission beeinflussen kann [REIM et al. 2001; ALTROCK et al. 2003]. Wenn demzufolge die synaptische Transmission in dieser Hirnregion beeinträchtigt ist, sind ebenfalls Lern- und Erinnerungsmechanismen betroffen.

\section{Welche Einflüsse haben APP und APLP auf die Entstehung des Morbus Alzheimer?}

Ein wichtiges neuropathologisches Charakteristikum des Morbus Alzheimer ist die Akkumulation von $A \beta$, die schließlich zur extrazellulären Plaque-Bildung führt. Doch bereits die gesteigerte Produktion von $A \beta$ bei Überexpression von APP ohne nachfolgende Plaquebildung führt zur Depression der synaptischen Transmission [KAMENETZ et al. 2003].

In dieser Arbeit konnte gezeigt werden, dass bei Verlust der APP und APLP-Proteine die synaptische Stärke, die Synapsenzahl und Synapsendichte zunimmt und die Proteinfamilie eine wichtige Rolle bei der Regulation der synaptischen Funktion zu haben scheint. Wie der genaue Mechanismus der vermuteten Regulatorfunktion von APP und APLP aussieht, ist nicht klar.

Auch APLP1 und APLP2 sind an molekularpathologischen Auffälligkeiten des Morbus Alzheimer beteiligt [WASCO et al. 1992; BAYER et al. 1997; MCNAMARA et al. 1998; BAYER et al. 1999]. Die genaue Funktion von APLP1 und APLP2 bleibt aber weiterhin unklar. Derzeit fehlen noch transgene Tiere, die nicht nur APP, sondern auch APLP 
überexprimieren. Eine vergleichende Studie könnte genauer zeigen, ob APLP in der Lage sind, eine Progression der Alzheimer-Krankheit hervorzurufen bzw. mitverantwortlich für deren Pathogenese sind.

Die APP-Familie kann einen wichtigen Einfluss auf die Synapsenbildung und Synapsenerhaltung haben und damit zelluläre Mechanismen des Lernens und des Gedächtnisses beeinflussen [KIM et al. 1995; BAYER et al. 1999], wobei im Gehirn von Alzheimer-Patienten die Missregulation der Proteinfamilie und letztendlich das Fehlen funktionaler APP und APLP zu chronisch kognitiven Defiziten durch Verlust der strukturellen Integrität von Synapsen und fehlenden Einfluss auf die Synapsenerhaltung führen kann. 


\section{$5 \quad$ Zusammenfassung}

APP und APLP sind homologe Proteine, deren physiologische Funktion nur sehr unvollständig geklärt ist. Die Proteinfamilie ist synaptisch lokalisiert und wird durch Sekretasen in ähnlicher Weise prozessiert. Einem Spaltprodukt, dem A $\beta$, wird eine Schlüsselrolle in der Entstehung der Alzheimer-Krankheit zugeordnet.

In der vorliegenden Arbeit konnten wir erstmals zeigen, dass nicht nur APP, sondern auch APLP einen Einfluss auf die synaptische Transmission hat. Wir untersuchten APP/APLP1/APLP2-Triple-Knockout-Mäuse mittels der patch-clamp-Technik auf Veränderungen der synaptischen Transmission, indem wir hippocampale exzitatorische Neuronen autaptisch kultivierten. Überraschenderweise führte die dreifache Mutation zu einer Erhöhung der synaptischen Stärke, die sich insbesondere in einer Vergrößerung der Amplitude und Ladung der evozierten exzitatorischen postsynaptischen Ströme sowie einer Veränderung der Synapsenzahl äußerte.

Unsere Experimente stützen die Hypothese, dass APP und APLP die synaptische Funktion durch Regulation der Synapsenzahl entwicklungsabhängig modulieren können. In einem frühen Stadium der Hirnentwicklung wirkt sich das Fehlen von APP und APLP auf die Synapsenzahl aus, indem Synapsen wahrscheinlich schneller gebildet werden, während mit Maturation des Hirns der Einfluss der Proteine auf die Synapsenbildung abnimmt und wahrscheinlich in der Synapsenerhaltung eine größere Rolle spielt. 


\section{Literatur}

ALMEIDA CG, TAMPELLINI D, TAKAHASHI RH, GREENGARD P, LIN MT, SNYDER EM, GOURAS GK (2005): Beta-amyloid accumulation in APP mutant neurons reduces PSD-95 and GluR1 in synapses. Neurobiol Dis 20, 187-198.

ALTROCK WD, TOM DIECK S, SOKOLOV M, MEYER AC, SIGLER A, BRAKEBUSCH C, FASSLER R, RICHTER K, BOECKERS TM, POTSCHKA H (2003): Functional inactivation of a fraction of excitatory synapses in mice deficient for the active zone protein bassoon. Neuron $\underline{37}$ 787-800.

ARAVAMUDAN B, FERGESTAD T, DAVIS WS, RODESCH CK, BROADIE K (1999): Drosophila UNC-13 is essential for synaptic transmission. Nat Neurosci $2,965-$ 971.

AUGUSTIN I, ROSENMUND C, SUDHOF TC, BROSE N (1999): Munc13-1 is essential for fusion competence of glutamatergic synaptic vesicles. Nature $\underline{400}, 457-461$.

BAYER TA, PALIGA K, WEGGEN S, WIESTLER OD, BEYREUTHER K, MULTHAUP G (1997): Amyloid precursor-like protein 1 accumulates in neuritic plaques in Alzheimer's disease. Acta Neuropathol (Berl) 94, 519-524.

BAYER TA, CAPPAI R, MASTERS CL, BEYREUTHER K, MULTHAUP G (1999): It all sticks together--the APP-related family of proteins and Alzheimer's disease. Mol Psychiatry $\underline{4}$, 524-528.

BEKKERS JM, STEVENS CF (1991): Excitatory and inhibitory autaptic currents in isolated hippocampal neurons maintained in cell culture. Proc Natl Acad Sci U S A 88, 7834-7838. 
BETZ A, ASHERY U, RICKMANN M, AUGUSTIN I, NEHER E, SUDHOF TC, RETTIG J, BROSE N (1998): Munc13-1 is a presynaptic phorbol ester receptor that enhances neurotransmitter release. Neuron 21, 123-136.

BLENNOW K, DE LEON MJ, ZETTERBERG H (2006): Alzheimer's disease. Lancet $\underline{368}$ 387-403.

BUTTINI M, MASLIAH E, BARBOUR R, GRAJEDA H, MOTTER R, JOHNSONWOOD K, KHAN K, SEUBERT P, FREEDMAN S, SCHENK D (2005): Betaamyloid immunotherapy prevents synaptic degeneration in a mouse model of Alzheimer's disease. J Neurosci 25, 9096-9101.

CASTILLO PE, SCHOCH S, SCHMITZ F, SUDHOF TC, MALENKA RC (2002): RIM1alpha is required for presynaptic long-term potentiation. Nature $\underline{415}, 327-$ 330.

CHAPMAN ER (2002): Synaptotagmin: a $\mathrm{Ca}(2+)$ sensor that triggers exocytosis? Nat Rev Mol Cell Biol $\underline{3}$ 498-508.

CHAPMAN PF, WHITE GL, JONES MW, COOPER-BLACKETER D, MARSHALL VJ, IRIZARRY M, YOUNKIN L, GOOD MA, BLISS TV, HYMAN BT (1999): Impaired synaptic plasticity and learning in aged amyloid precursor protein transgenic mice. Nat Neurosci 2, 271-276.

CHEN YA, SCHELLER RH (2001): SNARE-mediated membrane fusion. Nat Rev Mol Cell Biol 2, 98-106.

CLEMENTS JD, BEKKERS JM (1997): Detection of spontaneous synaptic events with an optimally scaled template. Biophys J $\underline{73}$, 220-229.

DAWSON GR, SEABROOK GR, ZHENG H, SMITH DW, GRAHAM S, O'DOWD G, BOWERY BJ, BOYCE S, TRUMBAUER ME, CHEN HY (1999): Age-related cog- 
nitive deficits, impaired long-term potentiation and reduction in synaptic marker density in mice lacking the beta-amyloid precursor protein. Neuroscience $90,1-13$.

DE STROOPER B, ANNAERT W (2000): Proteolytic processing and cell biological functions of the amyloid precursor protein. J Cell Sci 113 (Pt 11), 1857-1870.

DICK O, TOM DIECK S, ALTROCK WD, AMMERMULLER J, WEILER R, GARNER CC, GUNDELFINGER ED, BRANDSTATTER JH (2003): The presynaptic active zone protein bassoon is essential for photoreceptor ribbon synapse formation in the retina. Neuron $\underline{37}$,775-786.

DODART JC, BALES KR, GANNON KS, GREENE SJ, DEMATTOS RB, MATHIS C, DELONG CA, WU S, WU X, HOLTZMAN DM (2002): Immunization reverses memory deficits without reducing brain Abeta burden in Alzheimer's disease model. Nat Neurosci $\underline{5}, 452-457$.

DRESBACH T, QUALMANN B, KESSELS MM, GARNER CC, GUNDELFINGER ED (2001): The presynaptic cytomatrix of brain synapses. Cell Mol Life Sci $\underline{58}$, 94116.

EGGERT S, PALIGA K, SOBA P, EVIN G, MASTERS CL, WEIDEMANN A, BEYREUTHER K (2004): The proteolytic processing of the amyloid precursor protein gene family members APLP-1 and APLP-2 involves alpha-, beta-, gamma-, and epsilon-like cleavages: modulation of APLP-1 processing by nglycosylation. J Biol Chem $\underline{279}, 18146-18156$.

FENSTER SD, CHUNG WJ, ZHAI R, CASES-LANGHOFF C, VOSS B, GARNER AM, KAEMPF U, KINDLER S, GUNDELFINGER ED, GARNER CC (2000): Piccolo, a presynaptic zinc finger protein structurally related to bassoon. Neuron $\underline{25}$, 203214. 
FERNANDEZ-CHACON R, KONIGSTORFER A, GERBER SH, GARCIA J, MATOS MF, STEVENS CF, BROSE N, RIZO J, ROSENMUND C, SUDHOF TC (2001): Synaptotagmin I functions as a calcium regulator of release probability. Nature $\underline{410}$, 41-49.

FESCE R, GROHOVAZ F, VALTORTA F, MELDOLESI J (1994): Neurotransmitter release: fusion or 'kiss-and-run'? Trends Cell Biol $\underline{4}, 1-4$.

GARNER CC, KINDLER S, GUNDELFINGER ED (2000): Molecular determinants of presynaptic active zones. Curr Opin Neurobiol 10, 321-327.

GEPPERT M, GODA Y, HAMMER RE, LI C, ROSAHL TW, STEVENS CF, SUDHOF TC (1994): Synaptotagmin I: a major Ca2+ sensor for transmitter release at a central synapse. Cell 79, 717-727.

GUNDELFINGER ED, KESSELS MM, QUALMANN B (2003): Temporal and spatial coordination of exocytosis and endocytosis. Nat Rev Mol Cell Biol $\underline{4}$, 127-139.

HAMILL OP, MARTY A, NEHER E, SAKMANN B, SIGWORTH FJ (1981): Improved patch-clamp techniques for high-resolution current recording from cells and cell-free membrane patches. Pflugers Arch 391, 85-100.

HEBER S, HERMS J, GAJIC V, HAINFELLNER J, AGUZZI A, RULICKE T, VON KRETZSCHMAR H, VON KOCH C, SISODIA S, TREMML P (2000): Mice with combined gene knock-outs reveal essential and partially redundant functions of amyloid precursor protein family members. J Neurosci 20, 7951-7963.

HERMS J, ANLIKER B, HEBER S, RING S, FUHRMANN M, KRETZSCHMAR H, SISODIA S, MULLER U (2004): Cortical dysplasia resembling human type 2 lissencephaly in mice lacking all three APP family members. Embo J 23, 4106-4115. 
HEUSER JE, REESE TS (1973): Evidence for recycling of synaptic vesicle membrane during transmitter release at the frog neuromuscular junction. J Cell Biol $\underline{57}$ 315-344.

HO A, MORISHITA W, HAMMER RE, MALENKA RC, SUDHOF TC (2003): A role for Mints in transmitter release: Mint 1 knockout mice exhibit impaired GABAergic synaptic transmission. Proc Natl Acad Sci U S A 100 , 1409-1414.

HO CS, MARINESCU V, STEINHILB ML, GAUT JR, TURNER RS, STUENKEL EL (2002): Synergistic effects of Munc18a and X11 proteins on amyloid precursor protein metabolism. J Biol Chem 277, 27021-27028.

HSIA AY, MASLIAH E, MCCONLOGUE L, YU GQ, TATSUNO G, HU K, KHOLODENKO D, MALENKA RC, NICOLL RA, MUCKE L (1999): Plaqueindependent disruption of neural circuits in Alzheimer's disease mouse models. Proc Natl Acad Sci U S A 96, 3228-3233.

HUNG AY, KOO EH, HAASS C, SELKOE DJ (1992): Increased expression of betaamyloid precursor protein during neuronal differentiation is not accompanied by secretory cleavage. Proc Natl Acad Sci U S A $\underline{89}$ 9439-9443.

JAHN R, SUDHOF TC (1999): Membrane fusion and exocytosis. Annu Rev Biochem 68 , 863-911.

KAMENETZ F, TOMITA T, HSIEH H, SEABROOK G, BORCHELT D, IWATSUBO T, SISODIA S, MALINOW R (2003): APP processing and synaptic function. Neuron $\underline{37}$, 925-937.

KANG J, LEMAIRE HG, UNTERBECK A, SALBAUM JM, MASTERS CL, GRZESCHIK KH, MULTHAUP G, BEYREUTHER K, MULLER-HILL B (1987): The precursor of Alzheimer's disease amyloid A4 protein resembles a cell-surface receptor. Nature $\underline{325}$, 733-736. 
KIM TW, WU K, XU JL, MCAULIFFE G, TANZI RE, WASCO W, BLACK IB (1995): Selective localization of amyloid precursor-like protein 1 in the cerebral cortex postsynaptic density. Brain Res Mol Brain Res $\underline{32}$, 36-44.

LEE JH, LAU KF, PERKINTON MS, STANDEN CL, SHEMILT SJ, MERCKEN L, COOPER JD, MCLOUGHLIN DM, MILLER CC (2003): The neuronal adaptor protein X11alpha reduces Abeta levels in the brains of Alzheimer's APPswe Tg2576 transgenic mice. J Biol Chem $\underline{278}$, 47025-47029.

LI ZW, STARK G, GOTZ J, RULICKE T, GSCHWIND M, HUBER G, MULLER U, WEISSMANN C (1996): Generation of mice with a 200-kb amyloid precursor protein gene deletion by Cre recombinase-mediated site-specific recombination in embryonic stem cells. Proc Natl Acad Sci U S A $\underline{93}$, 6158-6162.

LING Y, MORGAN K, KALSHEKER N (2003): Amyloid precursor protein (APP) and the biology of proteolytic processing: relevance to Alzheimer's disease. Int J Biochem Cell Biol 35, 1505-1535.

MAGARA F, MULLER U, LI ZW, LIPP HP, WEISSMANN C, STAGLJAR M, WOLFER DP (1999): Genetic background changes the pattern of forebrain commissure defects in transgenic mice underexpressing the beta-amyloid-precursor protein. Proc Natl Acad Sci U S A $\underline{96}$, 4656-4661.

MAKOWSKI L, CASPAR DL, PHILLIPS WC, GOODENOUGH DA (1984): Gap junction structures. V. Structural chemistry inferred from X-ray diffraction measurements on sucrose accessibility and trypsin susceptibility. J Mol Biol 174, 449481.

MASLIAH E, MALLORY M, ALFORD M, DETERESA R, HANSEN LA, MCKEEL DW, JR., MORRIS JC (2001): Altered expression of synaptic proteins occurs early during progression of Alzheimer's disease. Neurology $\underline{56}$, 127-129. 
MCGOWAN E, ERIKSEN J, HUTTON M (2006): A decade of modeling Alzheimer's disease in transgenic mice. Trends Genet 22, 281-289.

MCNAMARA MJ, RUFF CT, WASCO W, TANZI RE, THINAKARAN G, HYMAN BT (1998): Immunohistochemical and in situ analysis of amyloid precursor-like protein-1 and amyloid precursor-like protein-2 expression in Alzheimer disease and aged control brains. Brain Res $\underline{804}$ 45-51.

MELDOLESI J, CECCARELLI B (1981): Exocytosis and membrane recycling. Philos Trans R Soc Lond B Biol Sci 296, 55-65.

MORIMOTO T, OHSAWA I, TAKAMURA C, ISHIGURO M, KOHSAKA S (1998): Involvement of amyloid precursor protein in functional synapse formation in cultured hippocampal neurons. J Neurosci Res 51, 185-195.

MOYA KL, BENOWITZ LI, SCHNEIDER GE, ALLINQUANT B (1994): The amyloid precursor protein is developmentally regulated and correlated with synaptogenesis. Dev Biol 161, 597-603.

MUCKE L, MASLIAH E, YU GQ, MALLORY M, ROCKENSTEIN EM, TATSUNO G, HU K, KHOLODENKO D, JOHNSON-WOOD K, MCCONLOGUE L (2000): High-level neuronal expression of abeta 1-42 in wild-type human amyloid protein precursor transgenic mice: synaptotoxicity without plaque formation. J Neurosci 20, 4050-4058.

MULLER U (1999): Ten years of gene targeting: targeted mouse mutants, from vector design to phenotype analysis. Mech Dev 82, 3-21.

MULLER U: Family of APP-related proteins, Website http://www.dkfz.de/tbi/uni/mueller/projects_german.html 2005 
MULLER U, CRISTINA N, LI ZW, WOLFER DP, LIPP HP, RULICKE T, BRANDNER S, AGUZZI A, WEISSMANN C (1994): Behavioral and anatomical deficits in mice homozygous for a modified beta-amyloid precursor protein gene. Cell $\underline{79}, 755-$ 765.

MURTHY VN, STEVENS CF (1999): Reversal of synaptic vesicle docking at central synapses. Nat Neurosci $\underline{2}, 503-507$.

NICOLL RA, KAUER JA, MALENKA RC (1988): The current excitement in long-term potentiation. Neuron $1,97-103$.

NUMBERGER M, DRAGUHN A: Patch-Clamp-Technik, Spektrum Akademischer Verlag, Heidelberg 1996

ODDO S, CACCAMO A, SHEPHERD JD, MURPHY MP, GOLDE TE, KAYED R, METHERATE R, MATTSON MP, AKBARI Y, LAFERLA FM (2003): Tripletransgenic model of Alzheimer's disease with plaques and tangles: intracellular Abeta and synaptic dysfunction. Neuron $\underline{39}$, 409-421.

OHTSUKA T, TAKAO-RIKITSU E, INOUE E, INOUE M, TAKEUCHI M, MATSUBARA K, DEGUCHI-TAWARADA M, SATOH K, MORIMOTO K, NAKANISHI H (2002): Cast: a novel protein of the cytomatrix at the active zone of synapses that forms a ternary complex with RIM1 and munc13-1. J Cell Biol $\underline{158}, 577-590$.

PALIGA K, PERAUS G, KREGER S, DURRWANG U, HESSE L, MULTHAUP G, MASTERS CL, BEYREUTHER K, WEIDEMANN A (1997): Human amyloid precursor-like protein 1--cDNA cloning, ectopic expression in COS-7 cells and identification of soluble forms in the cerebrospinal fluid. Eur J Biochem $\underline{250}$, 354-363. 
PHINNEY AL, CALHOUN ME, WOLFER DP, LIPP HP, ZHENG H, JUCKER M (1999): No hippocampal neuron or synaptic bouton loss in learning-impaired aged beta-amyloid precursor protein-null mice. Neuroscience 90, 1207-1216.

PRILLER C, BAUER T, MITTEREGGER G, KREBS B, KRETZSCHMAR HA, HERMS J (2006): Synapse formation and function is modulated by the amyloid precursor protein. J Neurosci 26, 7212-7221.

REIM K, MANSOUR M, VAROQUEAUX F, MCMAHON HT, SUDHOF TC, BROSE N, ROSENMUND C (2001): Complexins regulate a late step in Ca2+-dependent neurotransmitter release. Cell $\underline{104}$, 71-81.

ROSENMUND C, STEVENS CF (1996): Definition of the readily releasable pool of vesicles at hippocampal synapses. Neuron $\underline{16}$, 1197-1207.

ROSENMUND C, SIGLER A, AUGUSTIN I, REIM K, BROSE N, RHEE JS (2002): Differential control of vesicle priming and short-term plasticity by Munc13 isoforms. Neuron $\underline{33}, 411-424$.

ROSENMUND C, RETTIG J, BROSE N (2003): Molecular mechanisms of active zone function. Curr Opin Neurobiol 13, 509-519.

SAKMANN B, NEHER E: Single-channel recording, Plenum Press, New York 1995

SCHÄFER E: Textbook of Physiology, Young J Pentland, Edinburgh und London 1900

SCHIKORSKI T, STEVENS CF (1997): Quantitative ultrastructural analysis of hippocampal excitatory synapses. J Neurosci $\underline{17}$ 5858-5867.

SCHOCH S, CASTILLO PE, JO T, MUKHERJEE K, GEPPERT M, WANG Y, SCHMITZ F, MALENKA RC, SUDHOF TC (2002): RIM1alpha forms a protein scaffold for regulating neurotransmitter release at the active zone. Nature $\underline{415}$, 321-326. 
SCHUBERT W, PRIOR R, WEIDEMANN A, DIRCKSEN H, MULTHAUP G, MASTERS CL, BEYREUTHER K (1991): Localization of Alzheimer beta A4 amyloid precursor protein at central and peripheral synaptic sites. Brain Res $\underline{563}$, 184-194.

SEABROOK GR, ROSAHL TW (1999): Transgenic animals relevant to Alzheimer's disease. Neuropharmacology $\underline{38}, 1-17$.

SEABROOK GR, SMITH DW, BOWERY BJ, EASTER A, REYNOLDS T, FITZJOHN SM, MORTON RA, ZHENG H, DAWSON GR, SIRINATHSINGHJI DJ (1999): Mechanisms contributing to the deficits in hippocampal synaptic plasticity in mice lacking amyloid precursor protein. Neuropharmacology $\underline{38}$, 349-359.

SELKOE DJ (2002): Alzheimer's disease is a synaptic failure. Science 298, 789-791.

SHENG M (2001): Molecular organization of the postsynaptic specialization. Proc Natl Acad Sci U S A $\underline{98}$ 7058-7061.

SHENG M, KIM MJ (2002): Postsynaptic signaling and plasticity mechanisms. Science $\underline{298}, 776-780$.

SPIRES TL, HYMAN BT (2005): Transgenic models of Alzheimer's disease: learning from animals. NeuroRx 2, $423-437$.

STEINBACH JP, MULLER U, LEIST M, LI ZW, NICOTERA P, AGUZZI A (1998): Hypersensitivity to seizures in beta-amyloid precursor protein deficient mice. Cell Death Differ $\underline{5}, 858-866$.

SUDHOF TC (1995): The synaptic vesicle cycle: a cascade of protein-protein interactions. Nature $\underline{375}, 645-653$. 
SZE CI, BI H, KLEINSCHMIDT-DEMASTERS BK, FILLEY CM, MARTIN LJ (2000):

Selective regional loss of exocytotic presynaptic vesicle proteins in Alzheimer's disease brains. J Neurol Sci $175,81-90$.

TOM DIECK S, SANMARTI-VILA L, LANGNAESE K, RICHTER K, KINDLER S, SOYKE A, WEX H, SMALLA KH, KAMPF U, FRANZER JT (1998): Bassoon, a novel zinc-finger CAG/glutamine-repeat protein selectively localized at the active zone of presynaptic nerve terminals. J Cell Biol 142, 499-509.

TURNER PR, O'CONNOR K, TATE WP, ABRAHAM WC (2003): Roles of amyloid precursor protein and its fragments in regulating neural activity, plasticity and memory. Prog Neurobiol 70, 1-32.

VAROQUEAUX F, SIGLER A, RHEE JS, BROSE N, ENK C, REIM K, ROSENMUND C (2002): Total arrest of spontaneous and evoked synaptic transmission but normal synaptogenesis in the absence of Munc13-mediated vesicle priming. Proc Natl Acad Sci U S A 99 , 9037-9042.

VON KOCH CS, ZHENG H, CHEN H, TRUMBAUER M, THINAKARAN G, VAN DER PLOEG LH, PRICE DL, SISODIA SS (1997): Generation of APLP2 KO mice and early postnatal lethality in APLP2/APP double KO mice. Neurobiol Aging 18, 661-669.

WALSH DM, KLYUBIN I, FADEEVA JV, CULLEN WK, ANWYL R, WOLFE MS, ROWAN MJ, SELKOE DJ (2002): Naturally secreted oligomers of amyloid beta protein potently inhibit hippocampal long-term potentiation in vivo. Nature $\underline{416}, 535-539$.

WANG P, YANG G, MOSIER DR, CHANG P, ZAIDI T, GONG YD, ZHAO NM, DOMINGUEZ B, LEE KF, GAN WB (2005): Defective neuromuscular synapses in mice lacking amyloid precursor protein (APP) and APP-Like protein 2. J Neurosci $\underline{25}$, 1219-1225. 
WANG X, KIBSCHULL M, LAUE MM, LICHTE B, PETRASCH-PARWEZ E, KILIMANN MW (1999): Aczonin, a 550-kD putative scaffolding protein of presynaptic active zones, shares homology regions with Rim and Bassoon and binds profilin. J Cell Biol 147, 151-162.

WASCO W, BUPP K, MAGENDANTZ M, GUSELLA JF, TANZI RE, SOLOMON F (1992): Identification of a mouse brain cDNA that encodes a protein related to the Alzheimer disease-associated amyloid beta protein precursor. Proc Natl Acad Sci U S A $\underline{89}$ 10758-10762.

WASCO W, GURUBHAGAVATULA S, PARADIS MD, ROMANO DM, SISODIA SS, HYMAN BT, NEVE RL, TANZI RE (1993): Isolation and characterization of APLP2 encoding a homologue of the Alzheimer's associated amyloid beta protein precursor. Nat Genet $\underline{5}, 95-100$.

WHITE AR, ZHENG H, GALATIS D, MAHER F, HESSE L, MULTHAUP G, BEYREUTHER K, MASTERS CL, CAPPAI R (1998): Survival of cultured neurons from amyloid precursor protein knock-out mice against Alzheimer's amyloid-beta toxicity and oxidative stress. J Neurosci $\underline{18}$, 6207-6217.

YAMADA T, SASAKI H, FURUYA H, MIYATA T, GOTO I, SAKAKI Y (1987): Complementary DNA for the mouse homolog of the human amyloid beta protein precursor. Biochem Biophys Res Commun $\underline{149}$, 665-671.

ZHANG W, EFANOV A, YANG SN, FRIED G, KOLARE S, BROWN H, ZAITSEV S, BERGGREN PO, MEISTER B (2000): Munc-18 associates with syntaxin and serves as a negative regulator of exocytosis in the pancreatic beta -cell. J Biol Chem $\underline{275}, 41521-41527$.

ZHENG H, JIANG M, TRUMBAUER ME, SIRINATHSINGHJI DJ, HOPKINS R, SMITH DW, HEAVENS RP, DAWSON GR, BOYCE S, CONNER MW (1995): beta-Amyloid precursor protein-deficient mice show reactive gliosis and decreased locomotor activity. Cell $\underline{81}$ 525-531. 


\section{Danksagung}

Ich danke allen, die mich bei der Verwirklichung dieser Arbeit unterstützt haben.

Ich möchte mich an erster Stelle außerordentlich bei PD Dr. Christian Rosenmund bedanken, der mir dieses interessante Thema zur Verfügung stellte, meine Arbeit betreute und jederzeit für Diskussionen und konstruktive Kritik zur Verfügung stand.

Weiterhin möchte ich mich bei Prof. Dr. Erwin Neher bedanken, in dessen Abteilung ich die Arbeit durchführen konnte.

Allen Mitarbeitern der Abteilung Membranbiophysik, besonders Ina Herfort, Irmgard Barteczko, Frank Köhne und Frank Würriehausen danke ich für ihre Unterstützung. Weiterhin gilt mein Dank den Mitarbeitern des Tierstalls von Turm 6.

Des Weiteren danke ich Dr. Jong-Cheol Rah und Dr. Veronika Müller für viele schöne Stunden in der Abteilung und Zuspruch, wenn mein Mut sank.

Besonders möchte ich mich bei Dr. Alexander Meyer für seine geduldige Einarbeitung und Unterstützung (vor allem an den vielen Sonntagen, wenn der Tierstall früh anrief) sowie viele gewinnbringende Diskussionen bedanken. Dr. Albrecht Sigler und Dr. Jeong-Seop Rhee danke ich für ihre Kooperation und die vielen Diskussionen im Rahmen dieser Arbeit.

Dr. Axenia Schäfer und Dr. Maruschka Weber danke ich für viele Anregungen bei der Durchsicht des Manuskripts. Ich danke Wiebke Pekrull und Dr. Andreas Schäfer für ihre Unterstützung in den schweren Stunden. Prof. Dr. Wischmeyer und PD Dr. Sebastian Maier danke ich für ihre Unterstützung während der Finalphase der Manuskripterstellung.

Mein besonderer Dank gilt meinen Eltern und Großeltern, die mir mein Studium der Medizin ermöglicht haben. Sie haben mich ebenfalls in allen Phasen dieser Arbeit begleitet und unterstützt.

Ich danke ganz besonders Christian Unzicker, der geduldig und sehr hilfsbereit alle Phasen meiner Arbeit begleitete, mich unterstützte und immer ein offenes Ohr für alle Details und Schwierigkeiten hatte.

Und nicht zuletzt gilt mein besonderer Dank der Studienstiftung des deutschen Volkes, die mich ideell und finanziell während meines Studiums unterstützte.

Diese Arbeit wurde finanziell durch die German Israeli Foundation unterstützt. 


\section{Lebenslauf}

Am 1. April 1977 wurde ich in Parchim als Tochter der DiplomVerwaltungs/Betriebswirtin Gabriele Kaufmann, geb. Göwe, und des DiplomLandwirts Reimer Freude geboren. Ich habe noch zwei jüngere Geschwister.

1983 wurde ich an der Polytechnischen Oberschule Fritz Reuter eingeschult. Von 1991 bis 1995 besuchte ich das Sprachgymnasium Juri Gagarin, an dem ich 1995 auch mein Abitur ablegte.

Im Jahr 1995 begann ich eine Ausbildung zur Kinderkrankenschwester, die ich 1998 mit dem Staatsexamen beendete.

Von 1999 bis 2005 studierte ich an der Georg-August-Universität Göttingen Medizin.

2001 legte ich das Physikum ab. Im Jahr 2002 absolvierte ich erfolgreich den 1. Teil der Ärztlichen Prüfung. Im April 2002 begann ich den experimentellen Teil meiner Dissertation am Max-Planck-Institut für biophysikalische Chemie Göttingen in der Abteilung Membranbiophysik (Prof. Dr. Erwin Neher), Arbeitsgruppe Molekulare Mechanismen der Signalübertragung (PD Dr. Christian Rosenmund). Im September 2004 waren meine Experimente abgeschlossen. 2004 legte ich ebenfalls erfolgreich den 2. Teil der Ärztlichen Prüfung ab.

2003 wurde ich in die Studienstiftung des deutschen Volkes aufgenommen.

2004 leitete ich einen Kurs im Rahmen einer Schülerakademie mit dem Titel: „Psychische Krankheiten, Psychiatrie und Gesellschaft.“

Von Oktober 2004 bis November 2004 absolvierte ich acht Wochen meines 1. Tertials des Praktischen Jahres in Innerer Medizin am Princess Margaret Hospital in Toronto, Kanada. Im Anschluss verbrachte ich weitere acht Wochen am London Health Science Center in London, Kanada. Von Februar bis Mai 2005 leistete ich mein chirurgisches Tertial des Praktischen Jahres in Florenz, Italien. Von Juni 2005 bis September 2005 verbrachte ich mein Wahltertial Anästhesie in Palermo, Italien, am IsMeTT (Istituto Mediterraneo per i trapianti e terapie ad alta specializzazione).

Im November 2005 bestand ich den 3. Teil der Ärztlichen Prüfung und erhielt nachfolgend die Approbation als Ärztin.

Seit dem 1. Januar 2006 bin ich an der Universitätsklinik Würzburg in der Anästhesiologischen Klinik und Poliklinik Wissenschaftliche Mitarbeiterin. Im Februar 2006 erhielt ich eine IZKF-Förderung über BAT IIa/1 Jahr, die ich seit Mai 2006 zur Durchführung wissenschaftlicher Projekte nutze. 